Onawa. Canada

KIA ON4

The quality of this microform is heavily dependent upon the quality of the original thesis submitted for microfilming. Every effort has been made to ensure the highest quality of reproduction possible.

If pages are missing, contact the university which granted the degree.

Some pages may have indistinct print especially if the original pages were typed with a poor typewriter ribbon or if the university sent us an inferior photocopy.

Reproduction in full or in part of this microlorm is governed by the Canadian Copyright ACt. R.S.C. 1970, C. C-30, and subsequent amendments.

\begin{abstract}
AVIS
La qualité de cette microlorme dépend grandement de la qualité de la thèse soumise au microfilmage. Nous avons tout fait pour assurer une quatité supérieure de reproduc. tion.

Sil manque des pages, veuillez communiquer avec funiversité qui a contéré le grade.

La qualité d'impression de certaines pages peut laisser à désirer, surtout si les pages originales ont été dactylogra. phiées à raide d'un nuban usé ou si l'université nous a teit parvenir une photocopie de qualité inférieure.
\end{abstract}

La reproduction, mẽme partielle, de celte microlorne esi soumise a la Loi canadienne sur le droit daauteur. SFC 1970, c. C-30, et ses amendements subséquents. 


\title{
MECHANICAL PROPERTIES OF CONCRETE \\ AT EARLY AGES
}

by Jianwei Zhao

\begin{abstract}
A thesis
submitted in conformity with the requirements

for the degree of

Master of Applied Science

in Civil Engineering
\end{abstract}

University of Ottawa

Ottawa, Canada

March, 1990

(C) Jlanwel zhao, Ottawa, Canada, I99I 
Canadian Theses Service Service des thèses canadiennes

The author has granted an irrevocable nonexclusive licence allowing the National Library of Canada to reproduce, loan, distribute or sell copies of his/her thesis by any means and in any form or format, making this thesis available to interested persons.

The author retains ownership of the copyright in his/her thesis. Neither the thesis nor substantial extracts from it may be printed or otherwise reproduced without his/her permission.
L'auteur a accordé une licence irrévocable et non exclusive permettant à la Bibliothéque nationale du Canada de reproduire, prêter. distribuer ou vendre des copies de sa thèse de quelque manière et sous quelque forme que ce soit pour mettre des exemplaires de cette thèse à la disposition des personnes intéressèes.

L'auteur conserve la proprièté du droit d'auteur qui protège sa thèse. Ni la thèse ni des extraits substantiels de celle-ci ne doivent être imprimés ou autrement reproduits sans son autorisation.

ISBN $0-315-68000-8$

\section{Canadä}




\section{UNIVERSITÉ D'OTTAWA \\ UNIVERSITY OF OTTAWA}


To My Wife Jinghua 


\section{Abstract}

Modern construction techniques enable reinforced concrete structures to be constructed in a very short time. The loads occurring due to the construction process on the partially completed structure can be larger than the design service load. The available strength of the immature partially completed structure is dependent upon the available concrete strength which may be less than the specified strength. Failure would occur if the available strength is less than that required to support the construction loads.

The construction loads can also cause significant immediate deflection due to concrete cracking and its low early age modulus of elasticity. Because of the high applied stress/developed strength ratio and shrinkage, the time dependent deflection may be unacceptably large.

This thesis examines the early age behaviors of concrete tensile strength, modulus of elasticity, concrete shrinkage and creep, and develops prediction equations which are demonstrated to be more appropriate than the current code equations. 


\section{Acknowledgements}

The author would like to express his sincere appreciation to Dr. N. J. Gardner for his supervision, constructive suggestions, valuable discussions and continuous assistance throughout this research program.

The author gratefully appreciates the financial support provided by the National Sciences and Engineering Research Council of Canada under grant A5645.

The author is greatly indebted to his wife and parents for their understanding and support. 


\section{Contents}

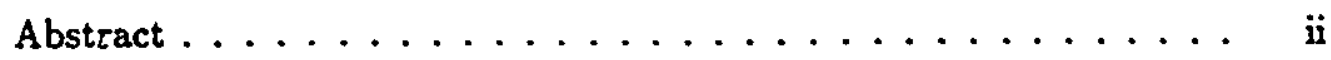

Acknowledgements ................. iii

1 Introduction 1

1.1 Early-Age Loads . . . . . . . . . . . . . . 1

1.2 Early-Age Strength . . . . . . . . . . . . 3

1.3 Tensile Strength $\ldots \ldots \ldots \ldots \ldots \ldots \ldots \ldots$

1.4 Modulus of Elasticity . . . . . . . . . . . . 6

1.5 Shrinkage and Creep $\ldots \ldots \ldots \ldots \ldots \ldots \ldots$

2 Maturity of Concrete $\quad 8$

2.1 Introduction . . . . . . . . . . . . . 8

2.2 Historical Review . . . . . . . . . . . . 9

2.3 Basis of the Maturity Concept . . . . . . . . . 12

2.4 Modified Maturity Method . . . . . . . . . . 15

2.5 Comparison with Experiments $\ldots \ldots \ldots \ldots \ldots \ldots$

2.6 Discussion . . . . . . . . . . . . . . . 22

2.7 Summary . . . . . . . . . . . . . . . 24

3 Mechanical Properties 39

3.1 Modulus of Elasticity . . . . . . . . . . . . . 39

3.1 .1 Introduction $\ldots \ldots \ldots \ldots \ldots \ldots \ldots \ldots \ldots$

3.1 .2 Test Data . . . . . . . . . . . . . 43

3.1.3 Analysis of Data . . . . . . . . . . . 45 
3.1.4 Summary . . . . . . . . . . . . . . . 4i

3.2 Tensile Strength $\ldots \ldots \ldots \ldots \ldots \ldots \ldots \ldots$. . . . . .

3.2 .1 Introduction $\ldots \ldots \ldots \ldots \ldots \ldots \ldots \ldots \ldots$

3.2 .2 Test Data . . . . . . . . . . . . . . 50

3.2.3 Analysis of Data . . . . . . . . . . . 52

3.2 .4 Summary . . . . . . . . . . . . . . 53

3.3 Discussion on Punching Shear . . . . . . . . . . . 53

4 Time Dependent Deformation $\quad 60$

4.1 Shrinkage . . . . . . . . . . . . . . 61

4.1 .1 Introduction $\ldots \ldots \ldots \ldots \ldots \ldots \ldots$

4.2 Factors Influencing Shrinkage $\ldots \ldots \ldots \ldots \ldots \ldots$

4.2 .1 Curing Conditions . . . . . . . . . 68

4.2 .2 Relative Humidity . . . . . . . . . . . . 69

4.2.3 Concrete Composition . . . . . . . . . . i1

4.2.4 Geometry of Concrete Member . . . . . . . . 72

4.2 .5 Time . . . . . . . . . . . . . 72

4.3 Shrinkage Prediction $\ldots \ldots \ldots \ldots \ldots \ldots \ldots \ldots$

4.3.1 Fin'Shrinkage . . . . . . . . . . 73

4.3.2 Time Function $\ldots \ldots \ldots \ldots \ldots \ldots \ldots$

4.3.3 Proposed Method . . . . . . . . . . . 77

4.4 Creep $\ldots \ldots \ldots \ldots \ldots \ldots \ldots \ldots \ldots \ldots$

4.4.1 Introduction $\ldots \ldots \ldots \ldots \ldots \ldots \ldots \ldots$

4.4.2 Creep Coefficients $\ldots \ldots \ldots \ldots \ldots \ldots$

4.4 .3 Creep Prediction . . . . . . . . . . . . 90

4.4 .4 Proposed Formula $\ldots \ldots \ldots \ldots \ldots$

4.4 .5 Discussion . . . . . . . . . . . . . . 93

4.5 Summary $\ldots \ldots \ldots \ldots \ldots \ldots$

5 Conclusions and Recommendations $\quad 110$

5.1 Conclusions . . . . . . . . . . . . . . 110 
5.2 Recommendations ................. 113 


\section{List of Figures}

2.1 Comparison of different maturity functions $\ldots \ldots \ldots \ldots 26$

2.2 Strength vs. equivalent age in $20^{\circ} \mathrm{C}$ days $\ldots \ldots \ldots \ldots$

2.3 Strength vs. equivalert age in $20^{\circ} \mathrm{C}$ days $\ldots \ldots \ldots \ldots 27$

2.4 Strength vs. equivalent age in $20^{\circ} \mathrm{C}$ days $\ldots \ldots \ldots \ldots . \ldots 27$

2.5 Strength vs. equivalent age in $20^{\circ} \mathrm{C}$ days $\ldots \ldots \ldots \ldots 28$

2.6. Strength vs. equivalent age in $20^{\circ} \mathrm{C}$ days . . . . . . . 28

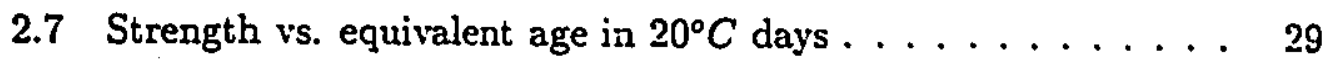

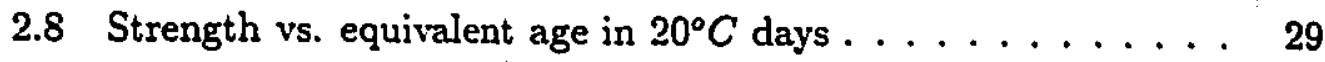

2.9 Strength vs. equivalent age in $20^{\circ} \mathrm{C}$ days $\ldots \ldots \ldots \ldots . . .30$

2.10 Strength vs. equivalent age in $20^{\circ} \mathrm{C}$ days . . . . . . 30

2.11 Strength vs. equivaient age in $20^{\circ} \mathrm{C}$ days . . . . . . . 31

2.12 Strength vs. equivalent age in $20^{\circ} \mathrm{C}$ days . . . . . . . 31

2.13 Strength vs. equivalent age in $20^{\circ} \mathrm{C}$ days $\ldots \ldots \ldots \ldots 32$

2.14 Strength vs. equivalent age in $20^{\circ} \mathrm{C}$ days . . . . . . . 32

2.15 Strength vs. equivalent age in $20^{\circ} \mathrm{C}$ days $\ldots \ldots \ldots \ldots \ldots$

2.16 Strength vs. equivalent age in $20^{\circ} \mathrm{C}$ days $\ldots \ldots \ldots \ldots 33$

2.17 Strength vs. equivalent age in $20^{\circ} \mathrm{C}$ days . . . . . . . 34

2.18 Strength vs. equivalent age in $20^{\circ} \mathrm{C}$ days $\ldots \ldots \ldots \ldots 34$

2.19 Strength vs. equivalent age in $20^{\circ} \mathrm{C}$ days $\ldots \ldots \ldots \ldots$

2.20 Strength gain for CSA Type 10 cement . . . . . . . . . 35

2.21 Strength gain for CSA Type 20 cement . . . . . . . 36

2.22 Strength gain for CSA Type 30 cement . . . . . . . . . 36

2.23 Arrhenius function with $\mathrm{E}=41 \mathrm{KJ} / \mathrm{mol} \ldots \ldots \ldots \ldots . \ldots 37$ 
2.24 Arrhenius function with $E=18 \mathrm{KJ} / \mathrm{mol} \ldots \ldots \ldots \ldots 3 T$

2.25 Comparison with ACI expression for Type 10 cement . . . . . 38

2.26 Comparison with ACI expression for Type 30 cement . . . . 38

3.1 Stress-strain relation curve for concrete $\ldots \ldots \ldots \ldots \ldots 6$

3.2 The best-fit empirical curve for $E_{\mathrm{c}}$ vs. $f_{c}^{\prime}$ relation . . . . . 56

3.3 The proposed formula for modulus of elasticity . . . . . 57

3.4 Test data classified by the age at testing . . . . . . . 57

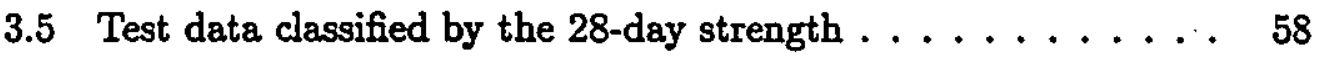

3.6 Relationship between relative strength and relative modulus . . 58

3.7 Relationship between tensile and compressive strengths . . . 59

3.8 Test data classified by the age at testing . . . . . . . . 59

4.1 Time development function for shrinkage proposed by ACI . . 96

4.2 Time development function for shrinkage proposed by CEB-90 96

4.3 Proposed time development function for shrinkage . . . . . . 97

4.4 Comparison of the proposed shrinkage prediction model with the published experimental data $\ldots \ldots \ldots \ldots \ldots \ldots$

4.5 Comparison of the proposed shrinkage prediction model with the published experimental data $\ldots \ldots \ldots \ldots \ldots$

4.6 Comparison of the proposed shrinkage prediction model with the published experimental data $\ldots \ldots \ldots \ldots \ldots \ldots$

4.7 Comparison of the proposed shrinkage prediction model with the published experimental data $\ldots \ldots \ldots \ldots \ldots \ldots$

4.8 Comparison of the proposed shrinkage frediction model with the published experimental data . . . . . . . . 100

4.9 Comparison of the proposed shrinkage prediction model with the published experimental data . . . . . . . . . 100

4.10 Effect of relative strength when loaded on long-term creep . . 101

4.11 Effect of concrete age when loaded on long-term creep, from Reference 4.28. . . . . . . . . . . . . . . ' 101 
4.12 Effect of relative humidity on long-term drying creep . . . . . 102

4.13 Comparison of the proposed creep prediction model with the

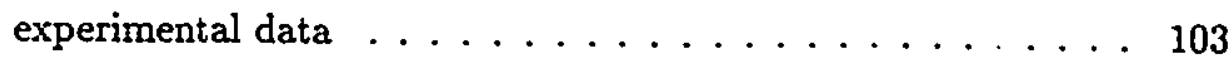

4.14 Comparison of the proposed creep prediction model with the experimental data ........................ 103

4.15 Comparison of the proposed creep prediction model with the experimental data .................. . . 104

4.16 Comparison of the proposed creep prediction model with the experimental data . . . . . . . . . . . . . . . 104

4.17 Comparison of the proposed creep prediction model with the experimental data .................... 105

4.18 Comparison of the creep prediction model proposed by ACI with the experimental data . . . . . . . . . . . . 106

4.19 Comparison of the creep prediction model proposed by ACI with the experimental data . . . . . . . . . . . . . 106

4.20 Comparison of the creep prediction model proposed by ACI with the experimental data . . . . . . . . . . . . . 107

4.21 Comparison of the creep prediction model proposed by CEB-90 with the experimental data ................ 107

4.22 Comparison of the creep prediction model proposed by CEB-90 with the experimental data ............... . . . 108

4.23 Comparison of the creep prediction model proposed by CEB-90 with the experimental data .............. . . 108

4.24 Comparison of the creep prediction model proposed by BazantPanula with the experimental data . . . . . . . . . 109 


\section{List of Tables}

2.1 Calculated $S_{7} / S_{28}$ values using modified maturity method . . 25

$2.2 S_{7} / S_{28}$ values used in different countries .......... 25

4.1 Relative effect of $\mathrm{RH}$ on long-term shrinkage ........ 70

4.2 Calculated final shrinkage by different models. $\left(\times 10^{-6}\right) . \ldots 76$

4.3 Coefficient for basic creep from tests ............. 91

4.4 Coefficient for drying creep from tests . . . . . . . . 92 


\section{Chapter 1}

\section{Introduction}

\section{$1.1 \quad$ Early-Age Loads}

Traditionally engineering education and design practice have concentrated upon the detailed design of the finished structure to resist specified loads due to self-weight, occupancy, wind, earthquake, etc. The choice of the construction method and temporary members to resist loads occurring during construction has been left to the constructor. This is illogical as the majority of building and bridge failures occur during construction rather than after the structure has been completed.

Secondly, all the long term quality of a structure is significantly determined during the construction process; any cracks or deflection which occur during construction, with few exceptions, remain in the structure.

Most reinforced concrete high rise buildings are constructed by casting onto forms which are, in turn, supported by one or more previously cast floors. The loads applied during the construction process to the supporting floors are great, and can significantly exceed the supporting structure's capacity developed at that time. The loads applied to the slabs and forms are dependent on the number of forms, number of reshores, and the sequence of stripping the 
forms and reshores. The imposition of load on young concrete can lead to an undesirable level of stress and deformation in the slabs. A short-term overload at an early age may cause extensive cracking that will be detrimental to the subsequent performance of the structures. Consequently, it is important that the performance of a concrete member be considered with reference to not only the service or design load, but also the load history during construction of the building.

As concrete has attained only low strength when the transient construction luad is applied, the ratio of the stress applied to the available strength is high, resulting in large immediate deflection because of the low modulus of elasticity of the concrete. This temporary overload can also result in cracks, which in turn, reduce the stiffness of the slab. Furthermore, the early age load can increase the long-term creep of concrete. The deflection caused by these early age loads are essentially irrecoverable, and thus, the long-term deflection of slabs can be excessive due to the early age construction loads.

The problems implied in the construction process have become more pronounced as the rate of construction has been increased. It is now not unusual to build a multi-floor flat slab building at rates of 2 or 3 floors a week. When structures are constructed at this rate, significant forces occur on the structural system, in which the concrete has not developed its full strength.

Currently a structure is designed so that the factored resistance of the structural elements shall exceed the total factored load effect; and for serviceability, the deflections and crack widths should not exceed certain limits. The design of reinforced concrete floor slabs must take into consideration both the design or service loads and the construction loads. The design loads are specified, but the construction loads are usually not well defined; they are dependent upon the number of forms, number of reshores, and the sequence of stripping the forms and reshores. A method for calculating the loads imposed during construction of flat slabs was proposed by Gardner ${ }^{1.2}$. Gardner found that if the design live load to dead load ratio of the building slabs was 0.5 , the loads 
carried by the floor slabs for a typical construction cycle of one level of shores and one two levels of reshores placed at one floor per week was 1.4 times of the slab self weight. According to the ACI (American Concrete Institute) or CSA (Canadian Standard Association) design criteria, the available strength of the concrete slab at 7 days should not less 0.87 of the 28-day strength to support the dead loads. Therefore, the problem arises to determine the early-age load capacity of a structure for safety during construction and how the early-age loads affect the long-term performance of a structure.

\subsection{Early-Age Strength}

The strength capacity of reinforced concrete slabs or structures is dependent upon the structural detail of the structure, the rate of construction, and rate of gain of concrete strength. Therefore, it is dependent upon the 28-day design strength, age of the concrete, temperature, type of cement, possible admixtures used, etc.

The typical equation determining the moment capacity $M_{u}$ of a reinforced concrete beam in flexure can be written as

$$
M_{u}=A_{s} f_{y} d\left(1-0.59 \rho \frac{f_{y}}{f_{c}^{\prime}}\right)
$$

where $A_{z}$ is the area of steel, $f_{y}$ is the steel yielding strength, $f_{c}^{\prime}$ is the concrete strength, $\rho$ is steel ratio, and $d$ is the distance from the steel to the top of the concrete section.

This equation has been verified by many researchers using values of $f_{y}$ and $f_{c}^{\prime}$ measured at the day of test.

However, does the equation apply at early ages? If the equation is time independent, all that is required to calculate early age flexural strength is to use the early age concrete strength with the realization that the beam may become over-reinforced because of the low concrete strength. 
For beams or slabs withnut shear reinforcement, shear is potentially more disastrous than flexure as the failure load is directly dependent ipon concrete strength. Two prediction equations from ACI/CSA and BS (British Standards), neither of which can be defended on the basis of statics, are available.

ACI 318-89 / CSA A23.3M-84:

$$
V_{u} \propto b d\left(f_{c}^{\prime}\right)^{1 / 2}
$$

BS 8110-85:

$$
V_{u} \propto b d\left(\rho f_{c}^{\prime}\right)^{1 / 3}
$$

The BS $8110-85$ relationship is less sensitive to concrete strength than the ACI-CSA equation. By appropriate choice of constant either equation can hold at 28 days, but what happens at early ages?

If the shear strength equation is time-independent, the shear capacity can be easily determined when the compressive strength at the time of loading is known.

It is generally accepied that for mature concrete, all the mechanical properties, such as modulus of elasticity and tensile strength, are related to the compressive strength. Are those relationships time-independent? If the answer is yes, they can be predicted from the early-age compressive strength.

Because the primary purpose of concrete, when used as a structural material, is to resist compression, and because it is easy to determine and provides a good picture of general capacity of the concrete, the compressive strength of concrete is usually considered as the indication of concrete quality.

It is well-known that the growth of strength of concrete is linked to the quantity of cement gel formed by hydration. During the past decades, many methods have been proposed for predicting the early age strength of concrete.

One method ${ }^{1.4}$ to predict strength assumes that the compressive strength of concrete is a unique function of gel/space ratio, which in turn, is a function of water/cement ratio and the degree of hydration. Whereas in hardened ce- 
ment paste or mortar the porosity can be related to strength, with concrete the situation is not simple. The presence of microcracks in the transition zone between the coarse aggregate and the cement paste make concrete too complex a material for prediction of strength by precise strength-porosity relations. With concrete containing conventional low-porosity or high-strength aggregates, the strength of the material will be governed by both the strength of cement paste and the strength of the transition zone. At early ages, the transition zone is weaker than the matrix, and will govern the concrete strength.

Another method, which is commonly used to predict the early-age strength of concrete, is the maturity concept based on the Saul-Nurse function or the Arrhenius function. The Saul-Nurse function is recommended by ACI Committee 306 as an alternative to using laboratory or field-cured tests, whereas the Arrhenius function has been accepted by the CEB (Comite EuroInternational Du Beton) code. While both can be shown to work well for isothermally cured concrete, the Saul-Nurse function gives a relatively poor representation for concrete cured at low temperatures.

Some researchers have reported good correlations between maturity and compressive strength of concrete, but others have questioned the validity of the maturity concept. For instance, it is pointed out that the maturity concept does not take into consideration of the influence the casting temperature or the humidity of curing. Ther efore, it is necessary that the concept be reinvestigated.

\subsection{Tensile Strength}

The properties of concrete in tension have not been studied to the same extent as those of concrete under compression, because the capacity of the concrete for carrying compressive loads is far greater than its capacity for carrying tensile loads. Information on the tensile properties of the concrete 
is, however, required to be able to assess the risk of cracking. In conjunction with plastic shrinkage, temperature stresses due to heat of hydration, or early age loading stresses, or to calculate the structural stifness affected by cracks requires a knowledge of the tensile properties of the concrete at early ages. With the increasing use of finite element methods for structural analysis, a full understanding of the available tensile strength at early ages has become more important.

Since determining the uniaxial tensile strength of corcrete is complicated from the testing point of view, the split cylinder tension test is widely accepted.

It is known that the growth of tensile strength is mainly influenced by the same factors as those which influence the compressive strength. For mature concrete, tensile strength is related to its compressive strength. Although different formulae are used in North American and Furope, the concept is the same. Do these equations apply to early-age concrete? If the answer is yes, the problem becomes simple, all that needs to be known is the early-age compressive strength and the appropriate relationships.

\subsection{Modulus of Elasticity}

Early investigators found that the modulus of elasticity increases more rapidly than the compressive strength at early ages. The modulus of elasticity of concrete has been treated as 2 unique function of compressive strength using formula derived from tests of mature concrete.

Recently, Byfors ${ }^{1.1}$ found that the relationship between the modulus of elasticity of concrete at early ages and its compressive strength is influenced not only by the water-cement ratios, but also by the age at test. The recently proposed British Code BS8110-85 states that the modulus of elasticity of concrete at an early age is a function of its compressive strength as well as the age 
at loading. Therefore, the question arises as to if the moduius of elasticity can be related to its compressive strength regardless of its age?

In addition, for mature concrete, the relationship between modulus of elasticity and compressive strength used in North America is quite different from that used in Europe, hence it is necessary to verify which relation gives a better representation.

For those reasons, modulus of elasticity of concrete at a wide range of ages was investigated.

\subsection{Shrinkage and Creep}

Recent work by Gardner and $F u^{1.3}$ indicated that the contribution of the effects of construction loads to the long term deflection could not be ignored. The long term deflection of a concrete member will include a deflection due to shrinkage of the concrete and the elastic deflection caused by the various dead and live loads plus creep deflections calculated for each of the loads taking account of the age at loading.

In addition to serviceability considerations, time-dependent deformations may affect structural integrity. For example, prestressed beams are sub-

jected to losses in prestressing force caused by creep and shrinkage, which may, in some cases, reduce loading capacity.

For prediction of shrinkage and creep of concrete, different procedures are proposed by the ACI and CEB codes. Since different procedures present quite different values of creep and shrinkage, comparison of the code calculated results with reported experimental data, and also, an attempt to modify the existing formulae, has been made in this study. 


\section{Chapter 2}

\section{Maturity of Concrete}

\subsection{Introduction}

Concrete gains sizength as a result of chemical reactions (hydration) between the cement and water; and for a given concrete mixture strength at any age and in normal conditions is related to the degree of hydration. The rate of hydration and, therefore, strength development of a given concrete will be a function of its temperature. Thus, assuming that sufficient moisture is always present for hydration, the strength of concrete depends on its time-temperature history.

- Around 1950, a series of articles appeared that proposed a method for accounting the combined effects of time and temperature on strength development by using a "maturity rule", which states simply that the strength of a given concrete is a single-valued function of the maturity. The maturity $M$ is calculated from the temperature history of the concrete according to the traditional relation proposed by $\mathrm{Saul}^{2.36}$ and $\mathrm{Nurse} \mathrm{e}^{2.29}$.

$$
M=\int\left(T-T_{0}\right) d t
$$

Where $\mathrm{T}$ is the temperature of the concrete, $T_{0}$ is the temperature below which hardening concrete ceases to gain strength with time t. 
Various values have been suggested for the datum temperature $T_{0}$. Plowman ${ }^{2.31}$ determined that the value was $-11.7^{0} \mathrm{C}$. Others 2.34 .2 .30 .2 .12 .2 .11 .2 .10 have suggested different values for $T_{0}$ (from $-15^{\circ} \mathrm{C}$ to $10^{\circ} \mathrm{C}$ ) depending on the expected range of curing temperature. The recommended value in American practice is $-10^{\circ} \mathrm{C}^{2.2}$.

In the mid 50's, there were serious doubts on the ability of the NurseSaul function to accurately account for temperature-time effects ${ }^{2.24,2.32 .2 .26}$. It was shown that when initial curing temperatures differed, there was not a unique strength versus maturity relation for a given concrete ${ }^{2.33}$.

Investigations by Kasai ${ }^{2.23}$, Bresson $^{2.7}$ and Carino ${ }^{2.9}$ indicated that the maturity function is influenced by curing conditions, water/cement ratio, cement type and admixture used, but no quantitative conclusions were given.

Recently, tests performed by Byfors $s^{2.8}$ indicated that the Nurse-Saul function gave very poor representation of the maturity of concrete at low curing temperatures; while the Arrhenius function gave a much better maturitystrength relationship than the Nurse-Saul function over a wide range of concrete curing temperature variations.

The main reason that the maturity method is not widely used in North America may be the lack of familiarity with the method and questions about its reliability. Since the strength-maturity relation is influenced by so many factors, it should be verified if this method is useful in practice and to what extent the method is accurate. The major objective of this chapter is to examine the strength-maturity relation and its validity.

\subsection{Historical Review}

In the late 1940's and early 1950's a series of papers were published dealing with accelerated curing methods for concrete. The ideas presented were the roots of the maturity concept. In $1949, M c I n t o s h^{2.25}$ reported experiments 
to develop procedures for electric curing of concrete. In devising a method to account for the temperature-time history on strength development, McIntosh proposed that th's product of time and temperature be used to summarize the effects of curing history. McIntosh reasoned as follows:

"The rate of hardening of concrete decreases with fall of temperature; the hydration of cement virtually ceases at a temperature referred to as the 'no-hardening temperature' and taken to be $30^{\circ} \mathrm{F}$ for convenience. . It is assumed that the rate of hariening at any moment is directly proportional to the amourt by which the curing temperature exceeds the no-hardening temperature; the amount of hydration which has taken place in a specimen with therefore is proportional to the area of under the temperature-time curve, with $30^{\circ} \mathrm{F}$ as a datum."

The area under the temperature-time curve was called "basic age" and expressed in units of ${ }^{\circ} \mathrm{F}$-hours.

A similar approach was suggested by $N u r s e^{2.29}$ in a paper dealing with low-pressure steam curing of concrete. He suggested a datum temperature of $0^{\circ} \mathrm{C}$, corresponding to the freezing temperature of water. He demonstrated that when relative strength development was plotted as a function of product of temperature and age, the data for different mixtures and curing conditions fell close to a single non-linear curve.

In 1951, Saul ${ }^{2.36}$ summarized the research on steam curing of concrete, and for the first time used the term "maturity" to describe the product of age and temperature above a datum. Saul recognized that hardening concrete can continue to develop strength at temperature below the freezing point of water and suggested that $-10.5^{\circ} \mathrm{C}$ be used as the datum for ordinary temperature curing. Saul also presented his "law of gain of strength with maturity":

"concrete of the same mix at the same maturity has approximately the same strength whatever combination of temperature and time 
goes to make up that maturity."

Mathematically, maturity is defined as Equation2.1, which is generally referred to as the Nurse-Saul maturity function.

In 1953, Bergstrom $^{2.5}$ demonstrated the applicability of the maturity concept by analyzing experimental data which dealt with temperature effects on strength development of concrete. He found that when relative strength was expressed in terms of maturity, there was little deviation of the data from a common curve. But unfortunately, he did not explain how to determine the ultimate strength for a given concrete mix and curing conditions.

In 1956, Plowman ${ }^{2.31}$ reported on research aimed at experimental determination of the datum temperature, which was defined as "the curing temperature at which the strength of concrete remains constant irrespective of age". He found this temperature to be $-11.7^{\circ} \mathrm{C}$. He proposed that the strength (S) is a linear function of the logarithm of maturity:

$$
S=a+b(\ln M)
$$

where $a$ and $b$ are constants for a particular concrete mixture.

In Plowman's experiments, all specimens were cured between $16^{\circ} \mathrm{C}$ and $19^{\circ} \mathrm{C}$ during the first 24 hours before being subjected to the different curing temperatures. On the other hand, McIntosh ${ }^{2.26}$ and Klieger ${ }^{2.24}$ subjected their specimens to different initial temperatures, and concluded that there was no unique strength-maturity relation for a given concrete mix. The strengthmaturity relations were affected by the curing temperature. Thus, series doubts arose concerning the general applicability of the maturity concept, and little additional research was reported until the late 1960's.

In 1967, Swenson ${ }^{2.37}$ reported on the use of maturity to estimate the concrete strength in a failure investigation. In 1971, Chin ${ }^{2.15}$ investigated Plowman's maturity-strength relation with his own data, and proposed the following hyperbolic strength-maturity relationship:

$$
S=\frac{M}{a M+b}
$$


where $S$ is strength of concrete, $M$ is maturity, and $a$ and $b$ are constants. Again, he found that for a given concrete, different initial temperatures gave different maturity-strength curves.

In the late 1970's, Carino ${ }^{2.12}$ concluded that it was the early age temperature that influences the strength-maturity relationship, which confirmed the previous observations. In 1985, experimental results performed at the University of Sherbrooke $e^{2.3}$ indicated that the period of initial time is about ten hours after casting.

In 1977, Freiesleben Hansen ${ }^{2.21}$ proposed using a single rate Arrlienius type of chemical reaction relationship to model the cement hydration:

$$
k=A \exp \left(-\frac{E}{R T}\right)
$$

where $k$ is rate constant, $E$ is the activation energy, $R$ is gas constant, $T$ is absolute temperature, and $A$ is a constant.

Since cement hydration is not a simple chemical reaction, it is very difficult to predict the activation energy of a particular cement based upon its chemical composition. Various values of activation energy, from $4 \mathrm{KJ} / \mathrm{mol}$ to $65 \mathrm{KJ} / \mathrm{mol}$, have been reported by Freiesleben Hansen ${ }^{2.21}$, Bresson ${ }^{2.7}$, Gauthier ${ }^{2.13}$, and so on. Nevertheless, other researchers, including Carino ${ }^{2.9}$, $B_{\text {resson }}^{2.7}$, Cauthier ${ }^{2.13}$ and $N a i k^{2.27}$, reported that Arrhenius function gives a better S-M relationship than the Nurse-Saul function. Currently, the Arrhenius function is widely accepted in Europe.

In 1981, Carino ${ }^{2.9}$ investigated the basis of the maturity concept from the fundamental assumptions to quantify the differences between the NurseSaul function and the Arrhenius function.

\subsection{Basis of the Maturity Concept}

The fundamental assumption for the Nurse-Saul maturity function is that the rate of strength development is a linear function of temperature above 
the datum temperature. The datum temperature, in turn, is assumed to be a constant value under all conditions. However, it is known that when the temperature, especially the early age temperatures, are different, a unique strength-maturity relationship is not obtained.

To arrive at an understanding of the above problem, the subject of strength development under constant temperature was re-examined.

In 1956, Bernhardt ${ }^{2.6}$ suggested the following differential equation to describe the rate of relative strength development:

$$
\frac{d\left(S / S_{u}\right)}{d t}=k\left(1-S / S_{u}\right)^{2}
$$

where
$S:$ strength
$S_{u}:$ ultimate strength
$k$ : rate constant, and
$t$ : time

Soi ving the differential equation by using the boundary condition $S=0$ when $t=t_{0}$, the following equation is obtained:

$$
\frac{S}{S_{u}}=\frac{k\left(t-t_{0}\right)}{1+k\left(t-t_{0}\right)}
$$

The rate constant $k$ is a function of temperature. Let us assume that $k$ is a linear function of temperature:

$$
k=k_{m}\left(T-T_{0}\right)
$$

Substituting Eq. 2.7 into Eq. 2.6, we obtain:

$$
\frac{S}{S_{u}}=\frac{k_{m}\left(T-T_{0}\right)\left(t-t_{0}\right)}{1+k_{m}\left(T-T_{0}\right)\left(t-t_{0}\right)}
$$

Equation 2.8 can be simplified by introducing the Nurse-Saul maturity function as following:

$$
M=\left(T-T_{0}\right) t
$$




$$
M_{0}=\left(T-T_{0}\right) t_{0}
$$

where $M_{0}$ represents the maturity when strength development is assumed to begin. Thus, Equation 2.8 becomes:

$$
\frac{S}{S_{u}}=\frac{k_{m}\left(M-M_{0}\right)}{1+k_{m}\left(M-M_{0}\right)}
$$

Equation 2.11 indicates that the relative strength is a single value function of maturity beyond $M_{0}$. Equations 2.7 to 2.11 state that the rate constant of Nurse-Saul maturity function is a linear function of curing temperature.

How well does the above assumption fit the actual behavior? Figure2.1, given by Carino $^{2.9}$, shows experimental values of the rate constant $k$ for a mortar cube subjected to different, but constant, curing temperature ranging from $5^{\circ} \mathrm{C}$ to $43^{\circ} \mathrm{C}$. It can be observed that the rate constant is a non-linear function of temperature. Thus, Eq. 2.11 can not accurately model the relative strength development for all curing temperatures. The best approximation is obtained by choosing the best-fit straight line to present the actual k-temperature data. This means that different ranges of temperature give different datum temperatures $T_{0}$. This explains why various datum temperatures have been suggested by different researchers.

From Figure 2.1, one can also see that a straight line can not represent a large difference of temperature, so the Nurse-Saul function can only be used for a limited range of temperatures by choosing the best-fit value of $T_{0}$. This explains why some researchers found that the Nurse-Saul function gave very poor correlation at low temperatures using the a value of $T_{0}=-10^{\circ} \mathrm{C}$.

As an alternative to the Nurse-Saul function, the Arrhenius function, Eq. 2.4, presents an non-linear effect of curing temperature on the rate constant. Since $R$ is a constant, by choosing a proper value of $E$, one can get a 'best-fit curve to model $\mathrm{k}-\mathrm{T}$ relation. Therefore, the Arrhenius function gives relatively better correlation between strength and maturity, and can be used for a relatively wider range of curing temperatures.

The real difference between the Nurse-Saul function and the Arrhenius 
function is that they use different ways to model the $k-T$ relation. But what does the $\mathrm{k}-\mathrm{T}$ relation really imply?

From Eq. 2.6, it is clear that at a given time, the relative strength is a single function of the rate constant $k$, which, in turn, is a function of temperature. So, $k$ is used to justify the weight of the temperature in the combined influence of temperature-time on the hardening of concrete; or, in the other word, to justify the weight of temperature in calculating maturity. The only difference between the two functions is that they use different ways to justify the weight of temperature in the maturity functions. From this point of view, the maturity method can be further improved by choosing more appropriate k-T functions to fit the actual data. $G u o^{2.20}$ chose a parabolic expression for $\mathrm{k}-\mathrm{T}$ relation, and showed that the prediction results were closer to his experimental data than those calculated from the Nurse-Saul or the Arrhenius functions.

\subsection{Modified Maturity Method}

It is well-known that the hardening of concrete is the result of hydration of portland cement. The hydration of cement is found to occur in four stages:

(1) Early period - a initial stage of rapid hydration (in which up to $15 \%$ hydration takes place);

(2) Induction period - a very slow hydration stage (15\%-20\% hydration);

(3) Acceleratory period- a very fast hydration stage $(20 \%-30 \%$ hydration); and

(4) Post-Acceleratory period - a final slow hydration stage (30\% $100 \%$ hydration). 
The first two stages last less than three hours, and the final slow bydration stage begins after 24 hours.

Tenoutasse and DeDonder ${ }^{2.38}$ studied the kinetics of the hydration of $C_{3} S$ during the first 24 hours, and found that a nucleation based relationship derived by $A v r a m i^{2.4}$ gave a good fit with their experiments. The relationship is expressed by:

$$
\ln (1-\alpha)=-k t^{3}
$$

where $\alpha$ is the degree of cement hydration, $k$ is the rate constant, and $t$ is the hydration time.

The model assumes that the consumption of original crystallization nuclei occurs slowly and that plate-like, rather than linear, growth occurs on the surface. A model having the same mathematical form was derived by Erofeyer ${ }^{2.16}$ based on probabilistic arguments. The activation energy for nucleation was found to be $34 \mathrm{KJ} / \mathrm{mol}$.

Urzhenko and Usherov - Marshak ${ }^{2.39}$ studied the hydration kinetics of $C_{3} S$ between $20^{\circ} \mathrm{C}$ and $80^{\circ} \mathrm{C}$. The data was analyzed using a relationship similar to that of Avrami2.4:

$$
\ln (1-\alpha)=-k t^{n}
$$

From linearizing plots, the value of $n$ was found to average 2.5 for $3 \%<\alpha<13 \%$. The activation energy for the nucleation process was found to be $35 \mathrm{KJ} / \mathrm{mol}$, which was similar to the value found by Tenoutasse and DeDonder ${ }^{2.38}$. For $\alpha>15 \%$, hydration rates fell sharply and Equation 2.13 was only able to fit the data when n was near unity. This value corresponded to a diffusion-controlled model.

A diffusion-controlled reaction stage was hypothesized to occur after the surface of the $C_{3} S$ had become fully covered with hydrates. At this point, the overall reaction rate was considered to decrease because the nucleation crystallization growth reaction no longer spread across the surface but grew inwards into the particles. The activation energy for diffusion was found to be 
$18 \mathrm{KJ} / \mathrm{mol}$ to $20 \mathrm{KJ} / \mathrm{mol}^{2.38,2.14,2.39}$.

Although cement hydration is more complicated because of the reactions between $S_{3} A$ and gypsum, and interactions among the major constituents of portland cement, it is found that hydration and heat liberation curves for portland cement show the same general shape as those for $C_{3} S$. Therefore, the above model can be used to predict hardening of portland cement.

Assuming $n=1$ in Equation2.13 and substituting it into Equation2.11, we get:

$$
\frac{S}{S_{u}}=\frac{-\ln (1-\alpha)}{1-\ln (1-\alpha)}
$$

From Equation 2.14, it can be concluded that the Arrhenius maturity function, from the fundamental point of view, is based on the following two hypotheses:

1) For a given concrete mix, the relative strength at any time is a function of its degree of hydration only.

2) The whole procedure of cement hydration follows the function

$$
\ln (1-\alpha)=-k t
$$

and has a single value of rate constant $k$.

It should be mentioned that, from the knowledge of chemistry, it is known that in Equation2.4, neither A nor E is constant throughout the total process of the reaction; the values vary from one step to another, and even change with hydration rate and temperature. The activation energy is determined by plotting $k$ vs. $1 / T$ curve from experimental data. Different experiments will give different value of $E$ because of the differences in the range of age and temperature in the experiments. By using the following modified Arrhenius function, a satisfactory result was fitted to the previous test data.

Equation 2.12 can be rewritten as:

$$
\ln (1-\alpha)=-k t^{n}=-\exp \left(-\frac{E}{R T}\right) t^{n}
$$


Let us introduce equivalent age $t_{20}$ at $20^{\circ} \mathrm{C}$. In order to have the same hydration rate,

$$
-\exp \left(-\frac{E}{R T_{20}}\right) t_{30}^{n}=-\exp \left(-\frac{E}{R T}\right) t^{n}
$$

Therefore,

$$
t_{20}=t * \exp \left(\frac{E}{n R}\left(\frac{1}{T_{20}}-\frac{1}{T}\right)\right)
$$

The above expression shows that although for different hydration stages, there are different values of $n$, a constant value of activation energy can be used for each hydration stage in the maturity function, regardlessness of the value of $n$,

$$
t_{20}=t * \exp \left(\frac{E_{e}}{R}\left(\frac{1}{T_{20}}-\frac{1}{T}\right)\right)
$$

Where $E_{\mathrm{e}}=E / n$, is the equivalent activation energy for a certain hydration stage.

Therefore, the total equivalent time will be the summation of each stage. As a simplification, the process of cement hardening can be considered in two stages (within one day and after one day), according to the nucleation and diffusion control respectively.

From the experimental data, it is found that there is a linear relationship similar to Eq. 2.2 between strength $S$ and equivalent age $t_{20}$. By assuming Eq. 2.2 and using statistical analysis, the activation energies for each step was determined. These are $25 \mathrm{KJ} / \mathrm{mol}$ for first day and $16 \mathrm{KJ} / \mathrm{mol}$ after one day. These values are very close to those proposed by other researchers ${ }^{2.38,2.14,2.39}$. It must be mentioned that the activation energies obtained by this method as well as by plotting $k$ vs. $1 / T$, are called observed activation energies. Since the Arrhenius function itself is an experimental expression, it is obvious that using observed activation energy always gives more satisfactory results than a mathematically derived $\mathrm{E}$ value.

Concrete strength rather than relative strength, as proposed in $E q .2 .5$, is used because there is no simple way to predict the ultimate strength $S_{u} . S_{u}$ is 
dominated by water cement ratio, but is also significantly influenced by casting and initial curing temperature, as well as admixtures involved. The reason might be that these conditions influence the hydration speed, and therefore, influence the micro-structure of the hydration products. A high temperature, which gives a high rate of reaction, means that the newly formed products do not have enough time to diffuse sufficiently far out from the point of reaction which will prevent further reactions. In addition, the newly formed products are concentrated in a zone close up against the cement particle, i.e., the cement gel is less evenly distributed. That leads, in turn, to weaker zones with a reduction in the strength as a consequence. It seems unlikely that increases in the curing temperature after a certain period of time would prevent continued reactions. Careful investigations have been made by Gardner ${ }^{2.18}$ and Poon ${ }^{2.19}$. The conclusion was that it was casting and initial curing temperature that affects the long term strength. The same conclusion was made by $B y$ fors ${ }^{2.8}$.

\subsection{Comparison with Experiments}

Since the modified Arrhenius function is based on observed activation energy, various experimental data has been employed to determined the activation energy as well as to compare with the predicted strength values.

In order to derive relationships between cylinder strength and split cylinder tensile strength and dynamic modulus of concrete at early ages, Gardner ${ }^{\mathbf{2 . 1 7}}$ made a large scale experimental investigation using ready mixed concretes cured in water at different temperatures. Six different concretes were considered using respectively Type I cement, Type I cement with $25 \%$ replacement by flyash, and Type III cement, at water cementious product ratios of 0.35 and 0.55. The specimens were cured in water at $0^{\circ} \mathrm{C}, 10^{\circ} \mathrm{C}, 20^{\circ} \mathrm{C}$ and $30^{\circ} \mathrm{C}$. The mechanical properties measured were compressive strength, tensile strength and dynamic modulus at ages of $1,3,7,14,28,56$ and 112 days. Sufficient samples were tested to enable both mean values and small sample standard 
deviations to be calculated.

Gardner ${ }^{2.18}$ also reported an experimental investigation into the strength development and durability of CSA Type 30 cement concretes, 50\% CSA Type 30 cement $/ 50 \%$ slag coucretes, and $75 \%$ Type 30 cement $/ 25 \%$ flyash concretes, with nominal water/cement ratios of $0.35,0.45$ and 0.55 , cast at $0^{\circ} \mathrm{C}$ and cured in sea water at $0^{\circ} \mathrm{C}$, and cast at $22^{\circ} \mathrm{C}$ and cured in a moist chamber respectively. The mechanical properties measured were compressive strength and tensile strength at ages of 3, 7, 14, 28 days, 3 months, 6 months and 12 months.

Early experiments by $\mathrm{Sau}^{2.35}$ consisted of nine series of specimens, three cast at $45^{\circ} \mathrm{C}$, three cast at $16^{\circ} \mathrm{C}$, and the remaining three cast at $0^{\circ} \mathrm{C}$, using Type 10 cement. Each three series of specimens were cast with water cement ratios of $0.35,0.45$ and 0.55 , respectively. To examine the significance of casting and initial curing temperature on the concrete, some of the compression test specimens were later removed to the other curing environments. The tests on compressive strength, tensile strength, static and dynamic modulus of elasticity were made on specimens cured at the casting temperatures at ages of $3,7,14$, $28,90,180$ and 360 days after casting. For the cylindrical specimens cured at temperatures different from casting temperatures, only compressive strengths were measured at ages of $7,28,90$ and 360 days. A total of 666 concrete cylinders and 18 concrete prisms were cast.

In addition to the experimental data mentioned above, data from Carino ${ }^{2.10}$ and Price ${ }^{2.33}$ were also used to verify the modified Arrhenius method.

From Figure 2.2 to Figure 2.19 one can see that by using the modified Arrhenius function, there is an approximate unique and linear relationship between the compressive strength and equivalent age for a given concrete mix at various curing temperatures. It is also shown that at equivalent ages, the maximum variations of compressive strength at different temperatures are basically within $20 \%$.

Figures 2.11, 2.12, and 2.13 show that Type 30/slag cement concretes give very poor strength at low temperatures, especially when the water cement 
ratios are greater than 0.45 . It is recommended that these not be used at low temperature conditions.

In order to be practically useful, the maturity method has to be accurate, universal and simple. But because of the limitation of the available data, only CSA Type 10, Type 20 and Type 30 cement concretes were studied here.

From Eq. 2.2, one can see that when maturity $\mathrm{M}$ increases infinitely, there is no limit for strength S. On the other hand, although Eq. 2.11 gives a reasonable format, the ultimate strengths, as mentioned previously in this chapter, are influenced by so many factors that contractors can not simply predict them by design specification and construction conditions. What they do know is the standard 28-day compressive strength of the designed concrete cured at $20^{\circ} \mathrm{C}$. Therefore, the following formula can be used to present the early age strength of concrete at various temperatures:

$$
\frac{S}{S_{28 / 20}}=\frac{\left(t_{20}\right)^{n}}{a+b\left(t_{20}\right)^{n}}
$$

Where $S$ is concrete strength, $S_{28 / 20}$ is the design 28-day concrete strength when cured at $20^{\circ} \mathrm{C}, t_{20}$ is the equivalent age at $20^{\circ} \mathrm{C}$ in days, and $n, a$ and $b$ are constants.

By using regression analysis, $a$ and $b$ were determined to be 2.8 and 0.77 for Type 10 cement concrete, 3.5 and 0.71 for Type 20 cement concrete, and, 1.3 and 0.89 for Type 30 cement concrete, respectively; and $n$ was calculated to be $3 / 4$ for Type 10, Type 20 and Type 30 cement concrete.

From Figure 2.20 and Figure 2.22, one can roughly see that the water cement ratio does not affect the relation expressed by Eq. 2.20. To verify that, the method of Analysis of Variance was used. The test null hypothesis was that the mean values for different water cement ratios are equal, i.e., $\mu_{1}=\mu_{2}=\cdots=\mu_{k}$. The test results showed that on the significance level $\alpha=0.05$, there was no reason to reject the null hypothesis. Therefore, it is believed that Equation 2.20 is not significantly affected by water cement ratios.

By using the same method, it was also found that curing temperature 
had no significant influence on the Equation 2.20 on the significance level $\alpha=$ 0.05 .

To compare the results between the modified Arrhenius function and the normal Arrhenius function, the data from Reference 2.17 was chosen as an example. In Figure 2.23, Arrhenius function was used with $E=41 \mathrm{KJ} / \mathrm{mol}$ proposed by Carino ${ }^{2.10}$; while in Figure 2.24, the Arrhenius function was used with $E=18 \mathrm{KJ} / \mathrm{mol}$, which was obtained by using least square method, considering the activation energy was unique through the whole hydration process. It can be nbserved that for the same data, Figure 2.4 gives the best representation, and the Figure 2.24 looks much better than Figure 2.23.

\subsection{Discussion}

The rate of gain of strength of different cements is affected by temperature, water cement ratio, type of cement, and curing regime. ACI committee $209^{2.1}$ proposed the following equation to represent the rate of strength gain for concrete moist cured at $70^{\circ} \mathrm{F}$,

$$
f_{c(t)}^{\prime}=f_{c(28)}^{\prime}\left(\frac{t}{a+b t}\right)
$$

Where, $f_{c(t)}^{\prime}$ is the compressive strength at age $t$ days. $a$ and $b$ are coefficients, with 4 and 0.85 for Type I ( CSA Type 10 ) cement concrete, and 2.3 and 0.92 for Type III Cement ( CSA Type 30) cement concrete.

According to ASTM Standard C917-80, American Type I cements have such ratio of 28 -day to 7 -day strength that $57 \%$ of them have a ratio of at least 1.32 and only $2 \%$ higher than 1.50 .

In Britain, when no specific data on the materials used are available, the 28-day strength may be assumed to be 1.5 times the 7-day strength of test cubes, the British Code of Practice CP114 (1969) accepts a 7-day strength equal to not less than $2 / 3$ of the required 28 -day strength. It was mentioned that in a hot climate the early strength gain is high and the ratio of 28 -day to 
7-day strength tends to be lower than in cooler weather.

In Germany, the relation between the $2 S$-day strength $f_{i, 28}$ and the $i$-day strength $f_{c, i}$ is assumed to lie between

$$
f_{c, 28}=1.4 f_{c .7}+1.0
$$

and

$$
f_{c, 28}=1.7 f_{c .7}+5.9
$$

$f_{c}$ being expressed in $\mathrm{MPa}$.

Hummel.22 recommended the use of an approximately linear relation between the strength and the logarithm of age within the range of 3 days to 2 months. Thus, if the strength is determined at 3 and 7 days, it is possible to estimate the 28-day strength by extrapolation.

All the expressions mentioned apply only to concrete made with ordinary Portland cement at a limited range of temperature. F r many of the other types of cement, for example, ASTM Type III cement, or for changes of curing temperature, only experimental results can be used to predict the early age strength.

By introducing the modified Arrhenius function and Equation 2.20, the early age strength for different types of cement can be predicted in all kinds of conditions. Table 2.1 and Table 2.2 show the 7-day to 28 -day relative strength from proposed formula and codes.

Figure 2.25 shows the comparison of the modified maturity method with the ACI expression given by Equation 2.21 for Type 10 cement concrctc, and Figure 2.26 shows the same comparison for Type 30 cement concrete. It can be seen that the ACI expression gives satisfactory accuracy for the early age strength prediction at the temperature of $70^{\circ} \mathrm{F}$ for both Type 10 and Type 30 (ASTM Type I and Type III) cement concretes. But the shortcoming is that it can only be used for those particular conditions. 


\subsection{Summary}

1. Basically, maturity method gives a satisfactory representation of the strength gain under isothermal curing conditions for concrete cast at the same temperature.

2. The basis of the difference between Nurse-Saul maturity function and Arrhenius function is that different ways are used to model the $\mathrm{k}-\mathrm{T}$ relation.

3. The Nurse-Saul function uses a straight line with a best fit $T_{0}$.

4. The Arrhenius function represents a non-linear effect of curing ternperature on the rate constant $k$ by choosing an appropriate value of activation energy $E$ to get a best-fit curve to model the $k-T$ relationship. Therefore, it gives relatively better correlation between strength and maturity, and can be used for a wider range of curing temperatures.

5. The maturity method can be further improved by choosing appropriate $k-T$ functions to fit actual data.

6. The Arrhenius function can be modified by using different activation energies on each hydration stage to represent nucleation and diffusion controlled reactions. The values of $E$ can be found by using Multiple Regression Analysis method from experimental data.

7. The ultimate strength of concrete is affected by casting and initial curing temperature, especially when the water cement ratio is high, which indicates differences in the microstructure of the concrete.

8. For practical purpose, relation between early strength to 28-day strength ratio and equivalent age is given by Eq. 2.20. The relation varies with type of cement, but is independent of water cement ratio and curing temperature. 


\begin{tabular}{|l|lllll|}
\hline Temperature & $0^{\circ} \mathrm{C}$ & $10^{\circ} \mathrm{C}$ & $20^{\circ} \mathrm{C}$ & $30^{\circ} \mathrm{C}$ & $40^{\circ} \mathrm{C}$ \\
\hline Type 10 & 0.57 & 0.63 & 0.70 & 0.75 & 0.79 \\
Type 20 & 0.51 & 0.58 & 0.66 & 0.72 & 0.77 \\
Type 30 & 0.73 & 0.78 & 0.84 & 0.87 & 0.90 \\
\hline
\end{tabular}

Table 2.1: Calculated $S_{7} / S_{28}$ values using modified maturity method

\begin{tabular}{|lr|l|l|}
\hline ACI & ACI & British Code & German Code* \\
\hline Type I & Type III & Normal & Mean \\
\hline 0.70 & 0.80 & 0.67 & 0.59 \\
\hline \multicolumn{3}{|c|}{ Assuming $f_{c, 28}^{\prime}=35 \mathrm{MPa}}$.
\end{tabular}

Table 2.2: $S_{7} / S_{28}$ values used in different countries 


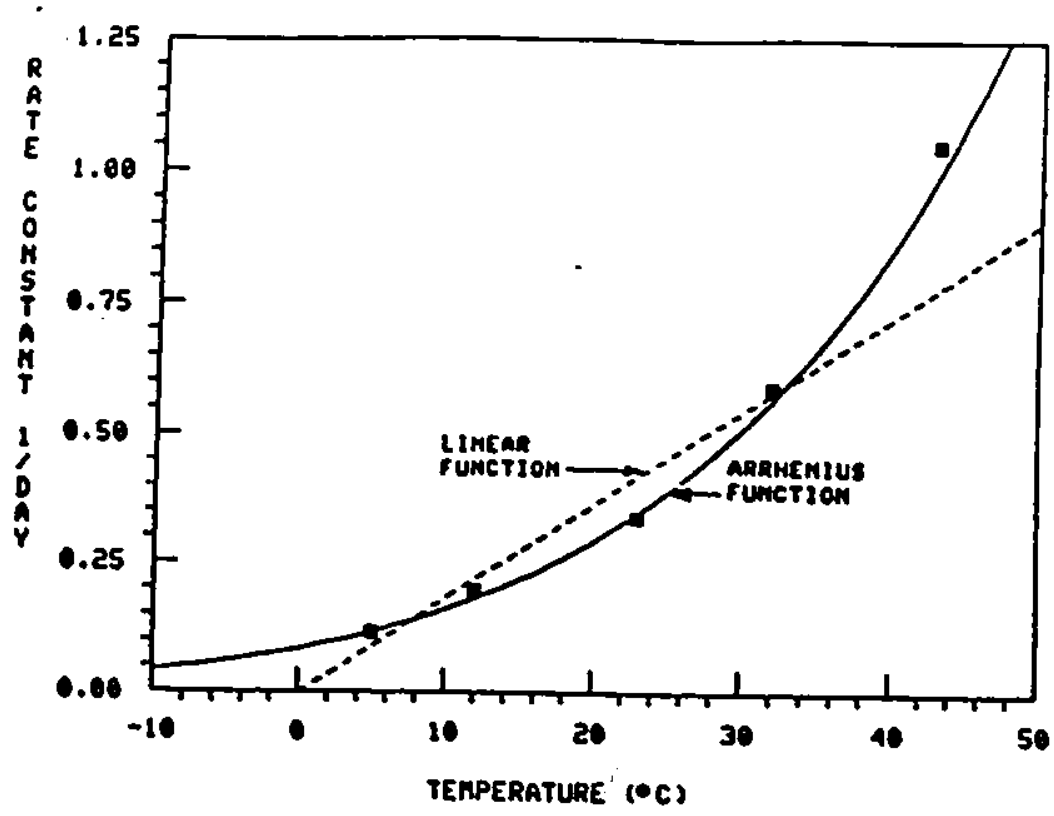

Figure 2.1: Comparison of different maturity functions

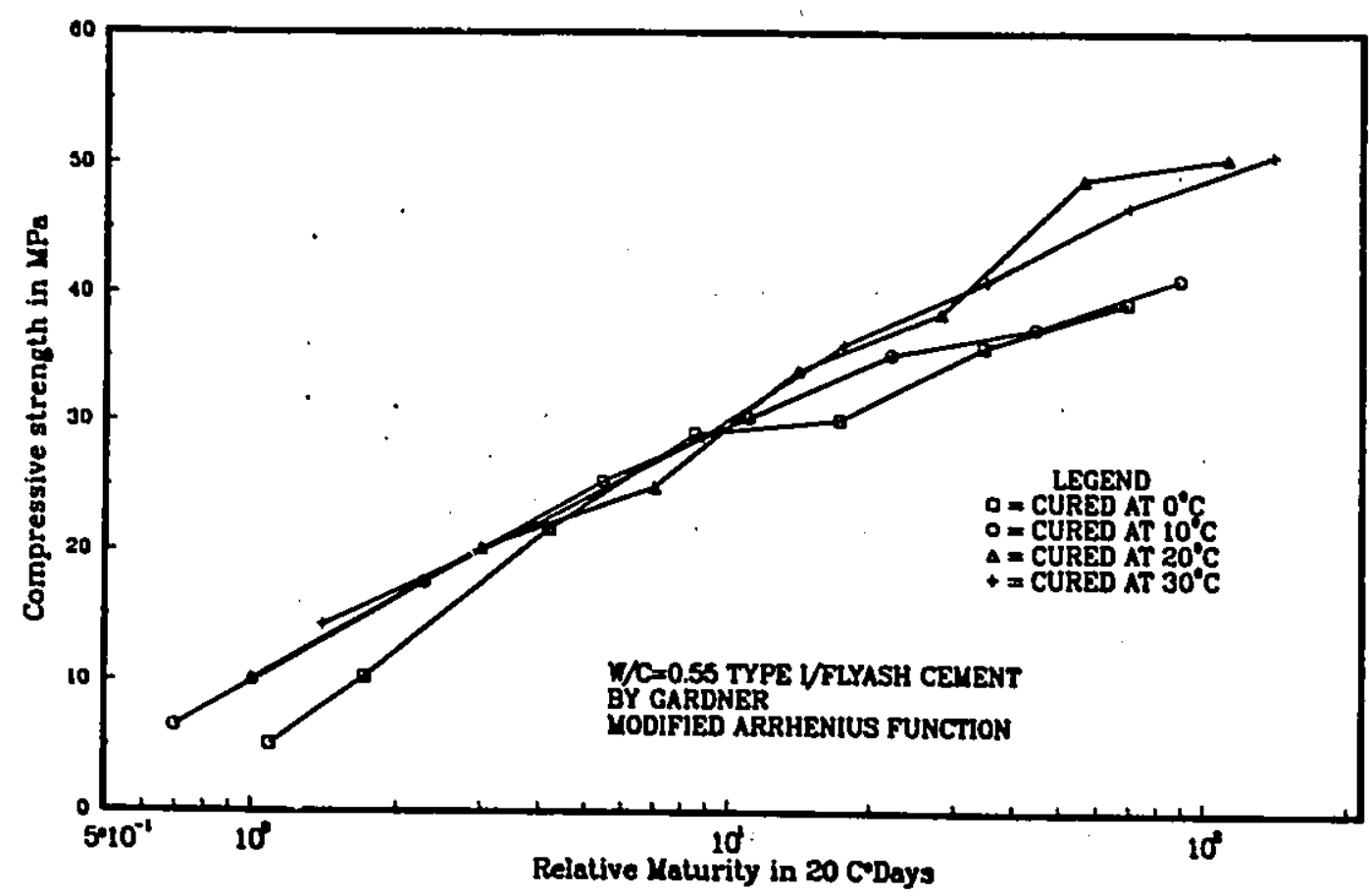

Figure 2.2: Strength vs. equivalent age in $20^{\circ} \mathrm{C}$ days 


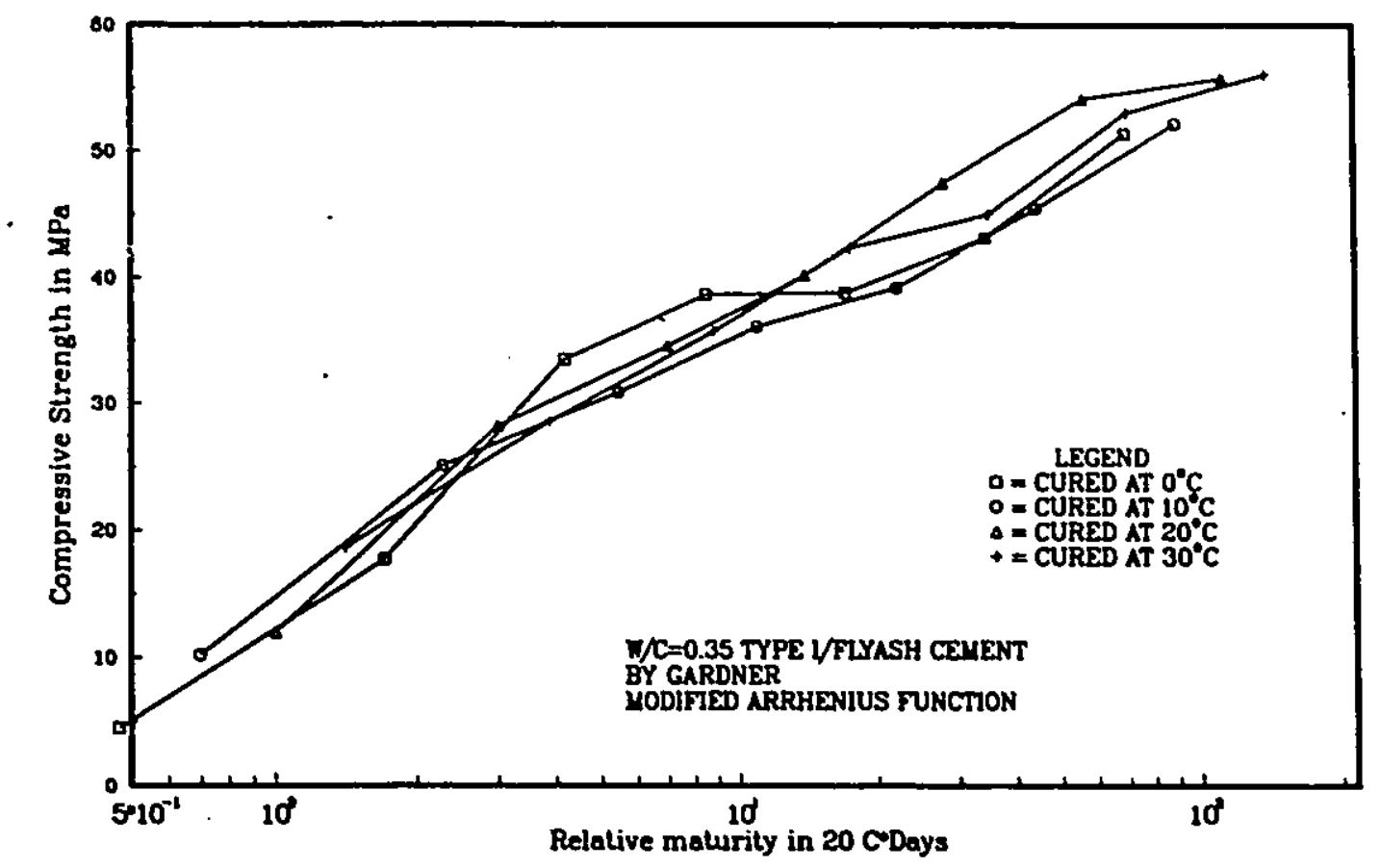

Figure 2.3: Strength vs. equivalent age in $20^{\circ} \mathrm{C}$ days

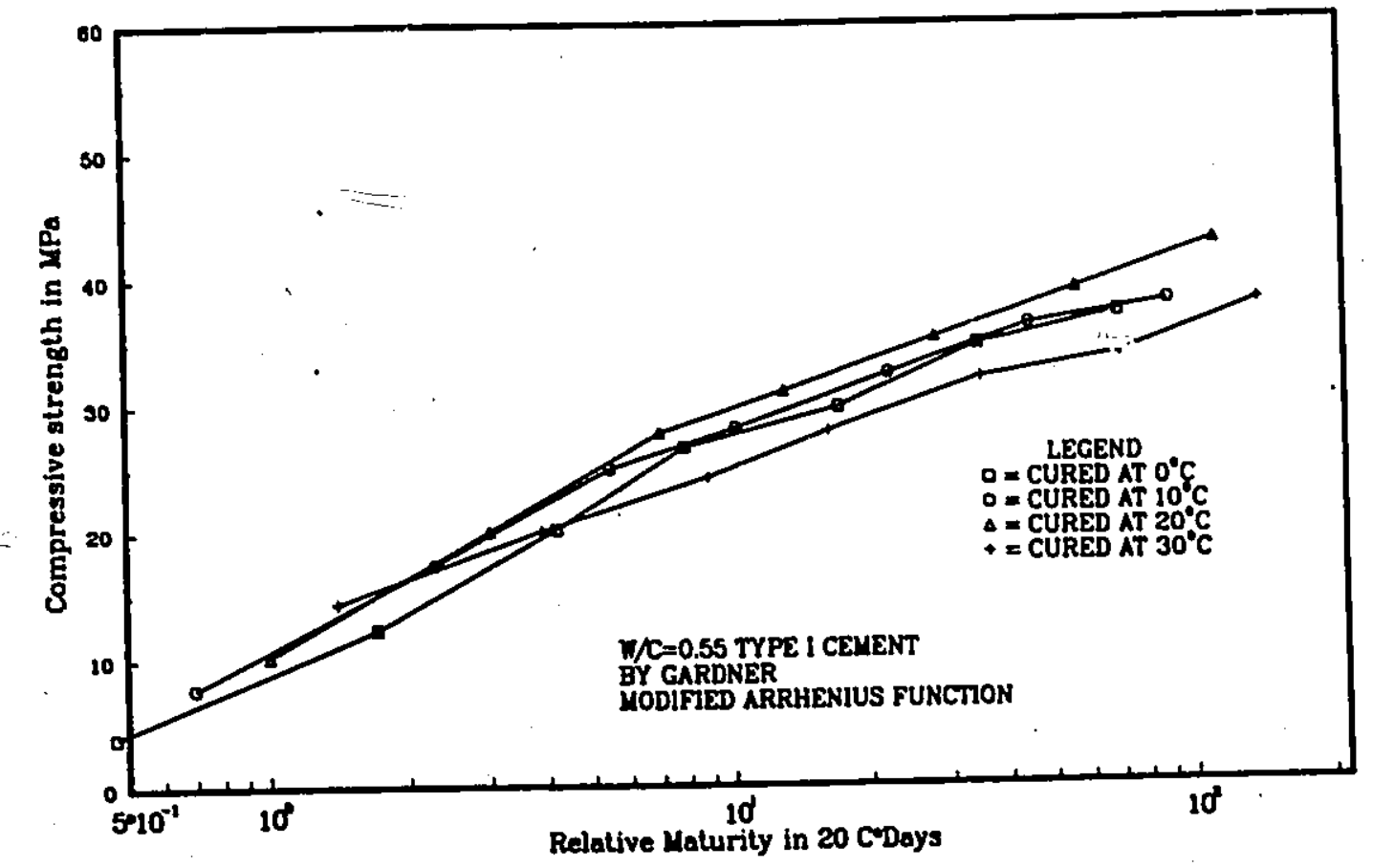

Figure 2.4: Strength vs. equivalent age in $20^{\circ} \mathrm{C}$ days 


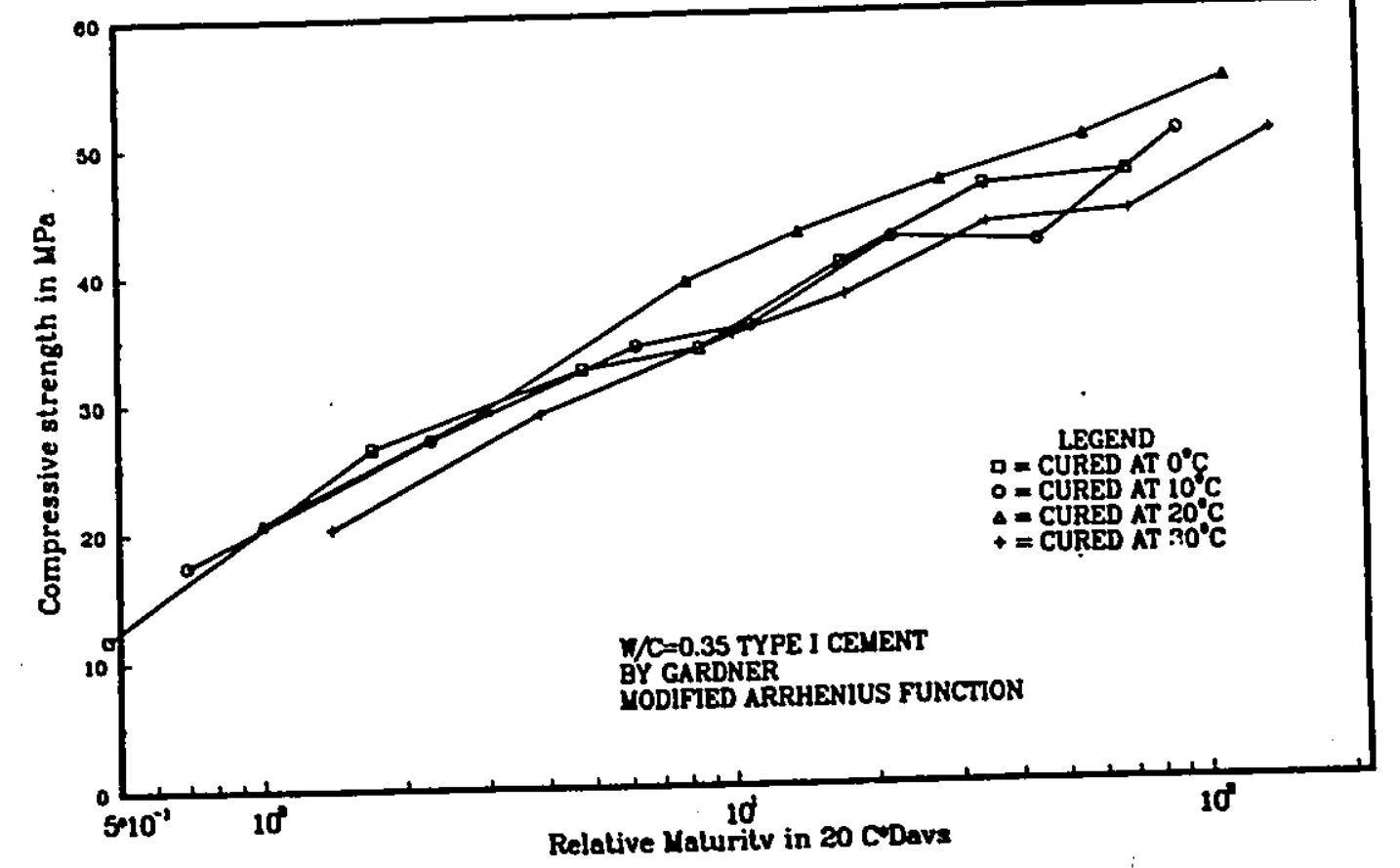

Figure 2.5: Strength vs. equivalent age in $20^{\circ} \mathrm{C}$ days

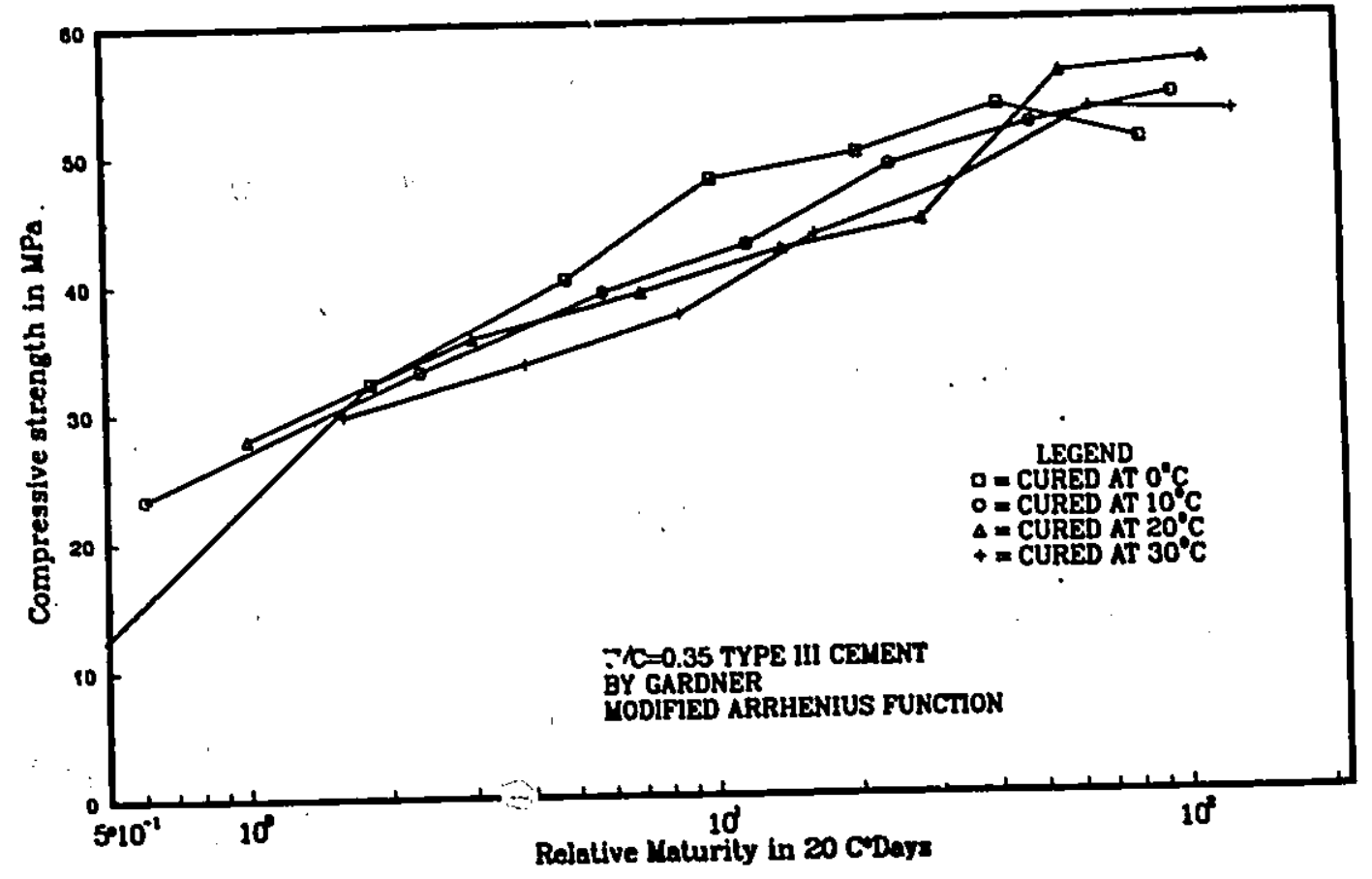

Figure 2.6: Strength vs. equivalent age in $20^{\circ} \mathrm{C}$ days 


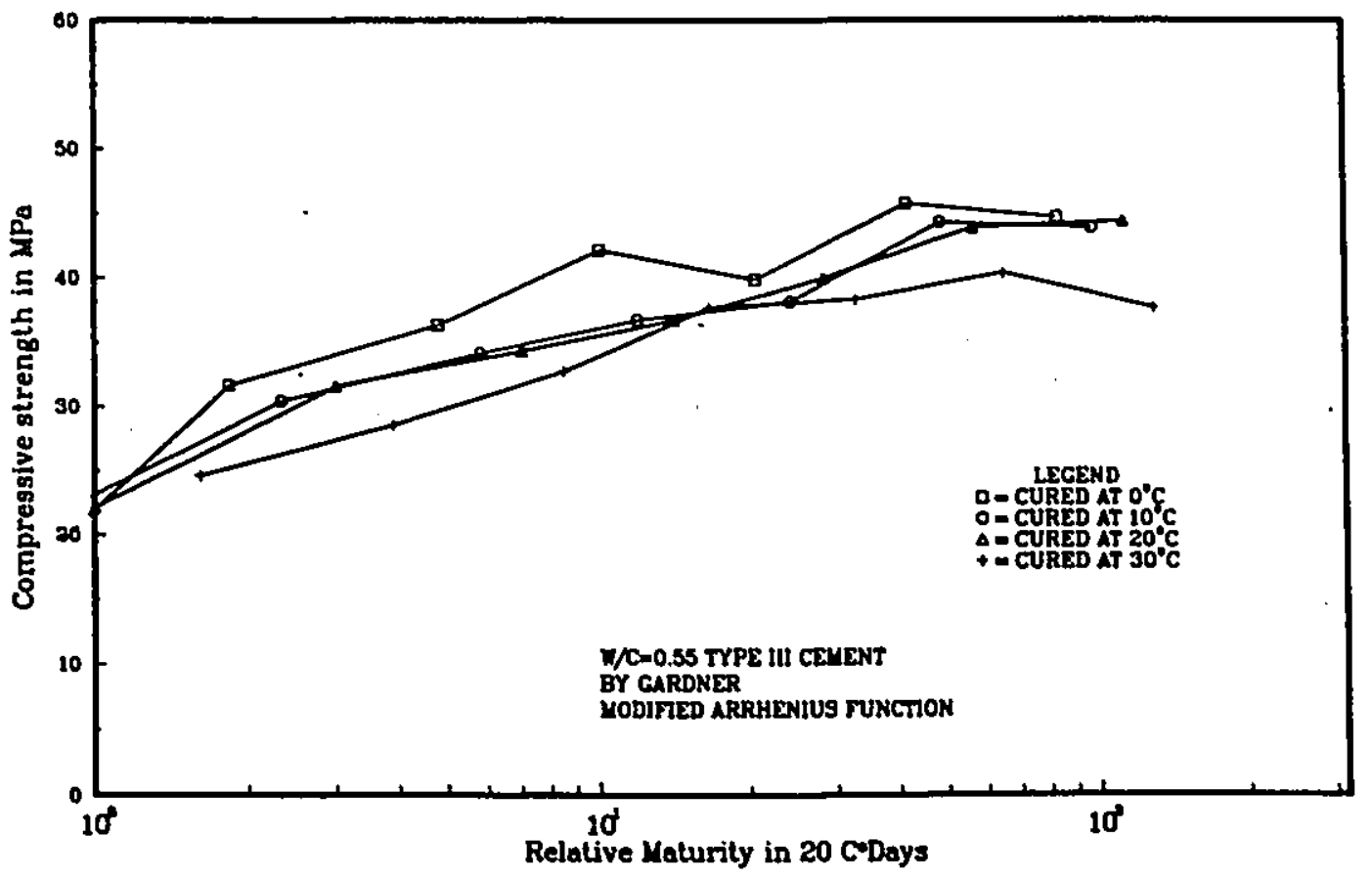

Figure 2.7: Strength vs. equivalent age in $20^{\circ} \mathrm{C}$ days

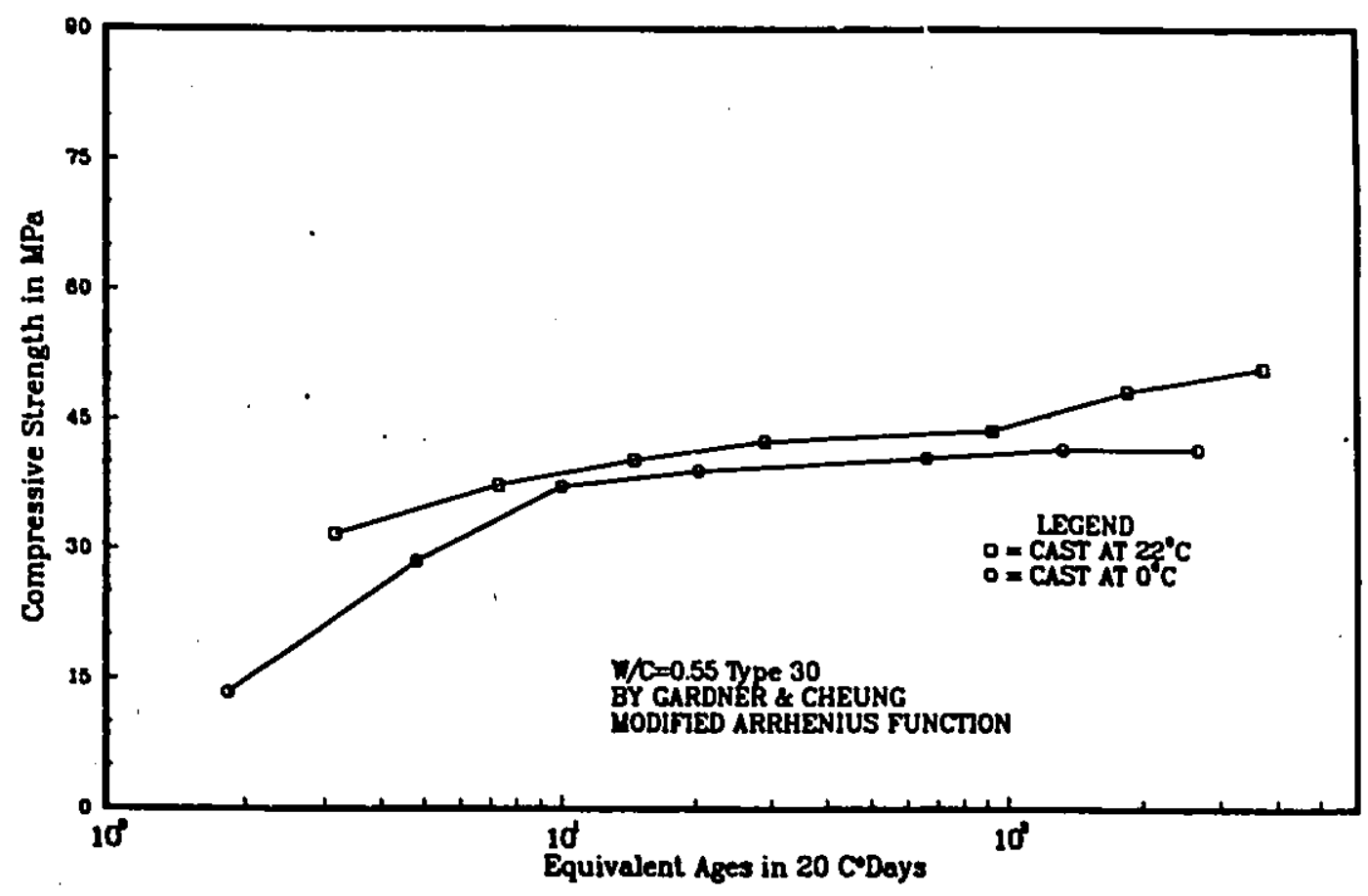

Figure 2.8: Strength vs. equivalent age in $20^{\circ} \mathrm{C}$ days 


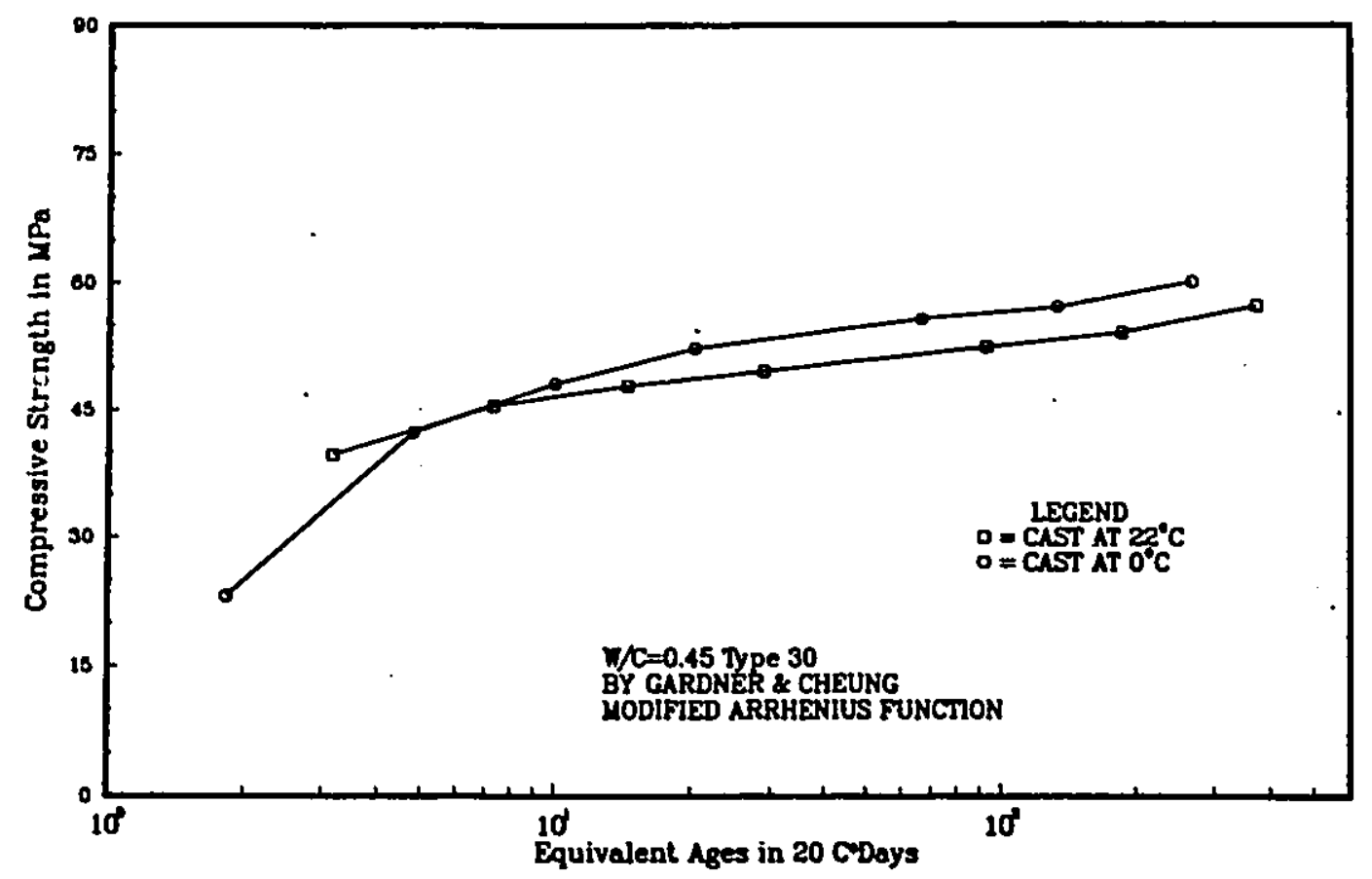

Figure 2.9: Strength vs. equivalent age in $20^{\circ} \mathrm{C}$ days

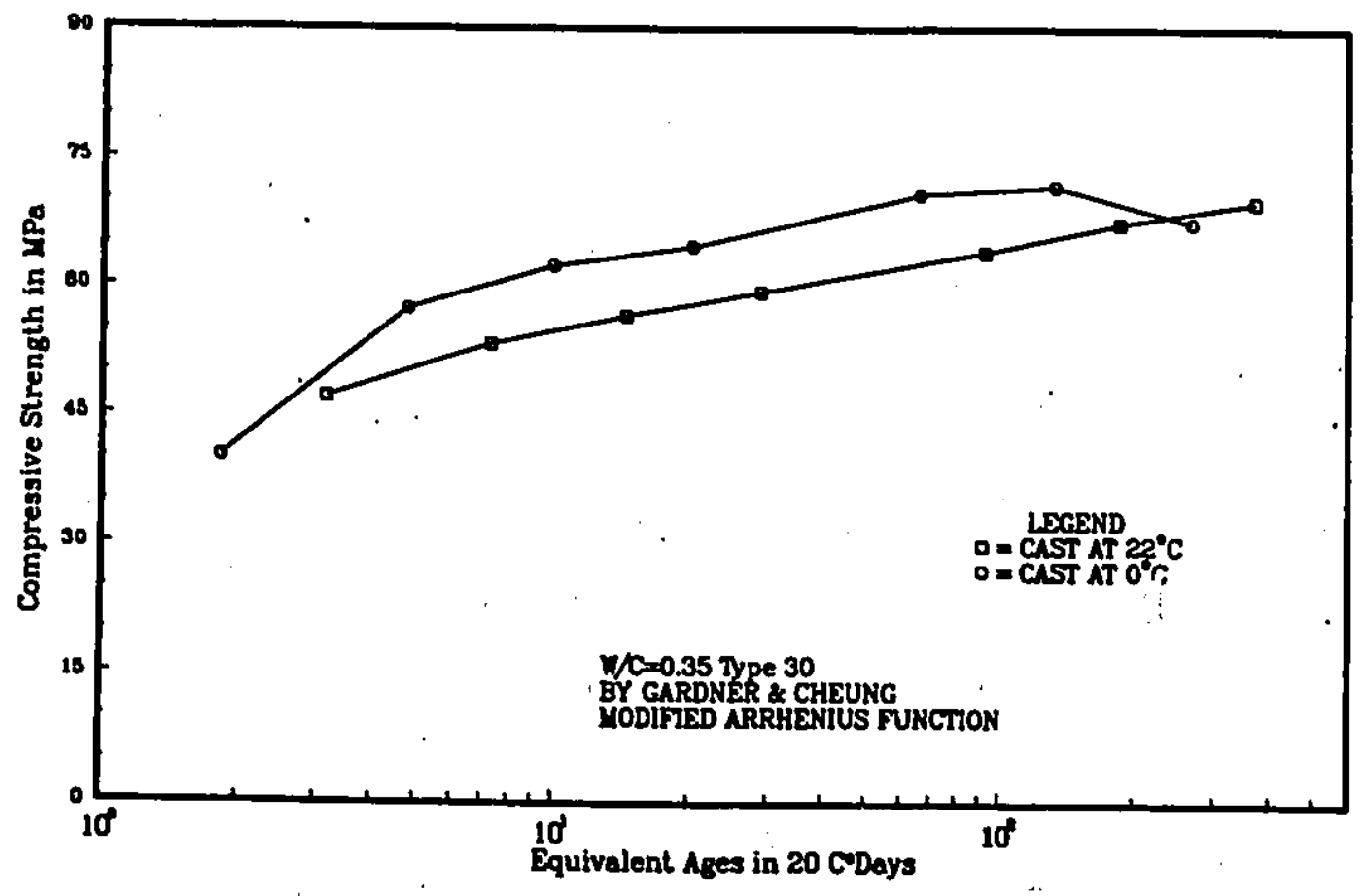

Figure 2.10: Strength vs. equivalent age in $20^{\circ} \mathrm{C}$ days 


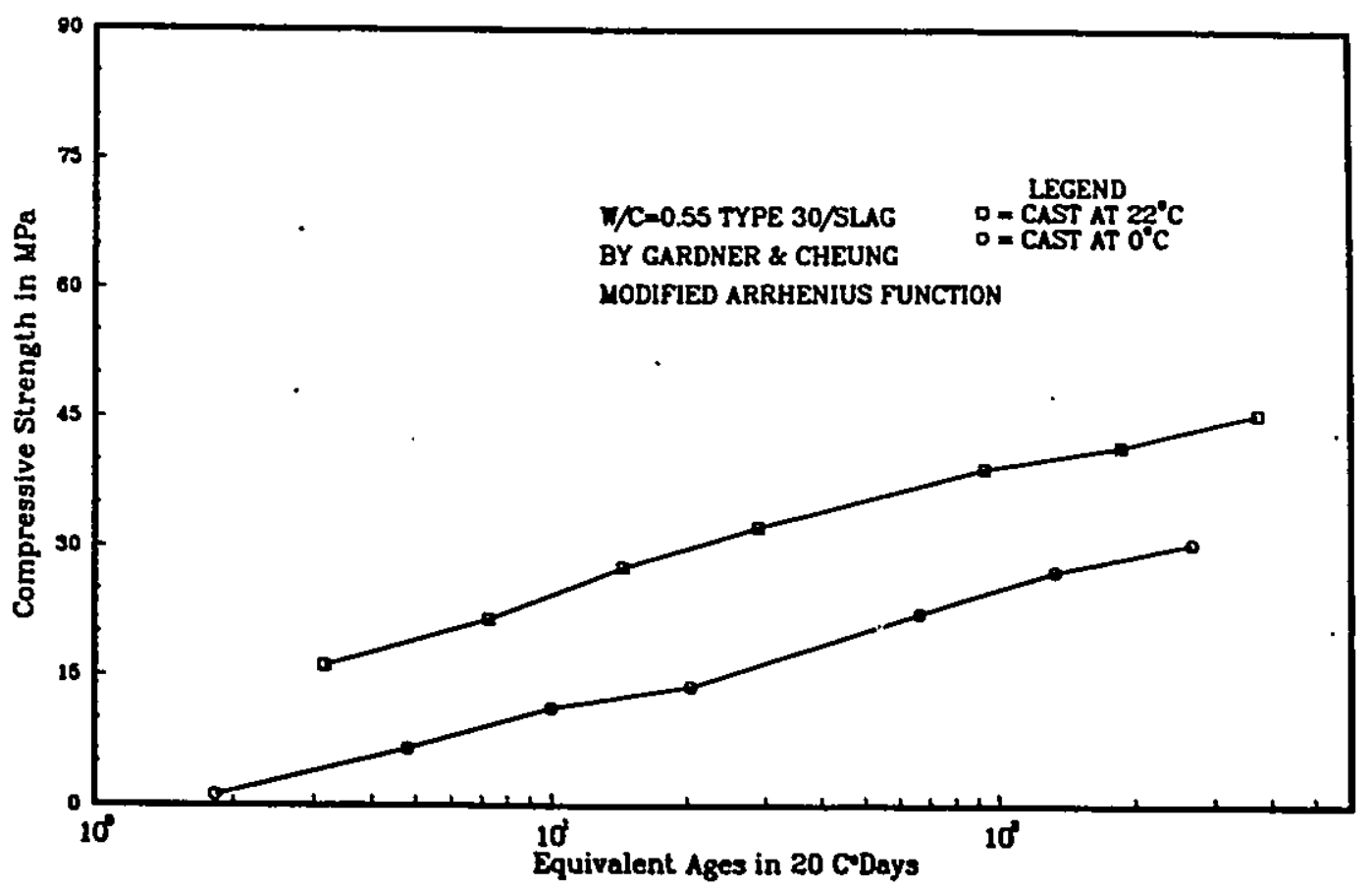

Figure 2.11: Strength vs. equivalent age in $20^{\circ} \mathrm{C}$ days

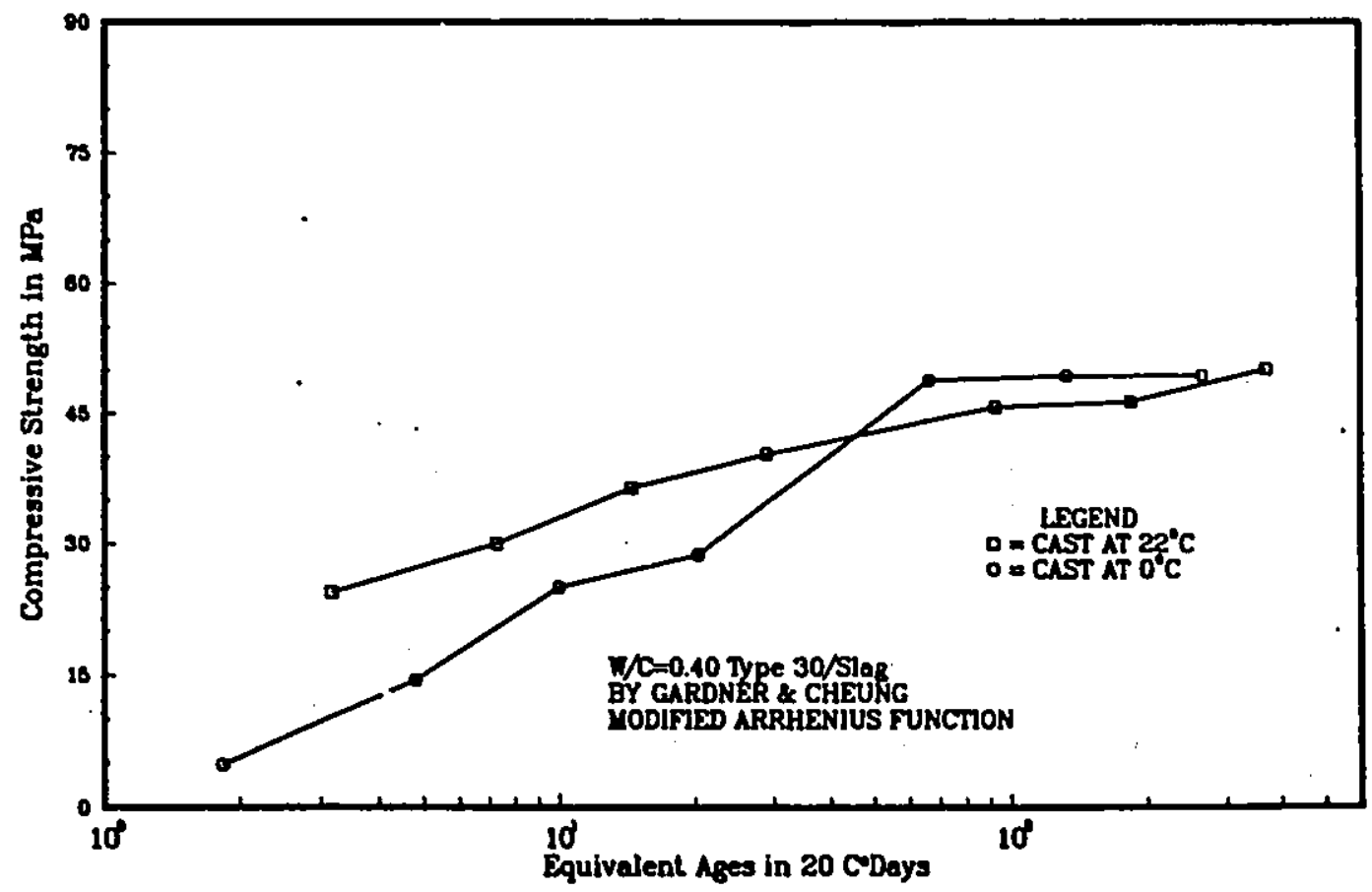

Figure 2.12: Strength vs equivalent age in $20^{\circ} \mathrm{C}$ days 


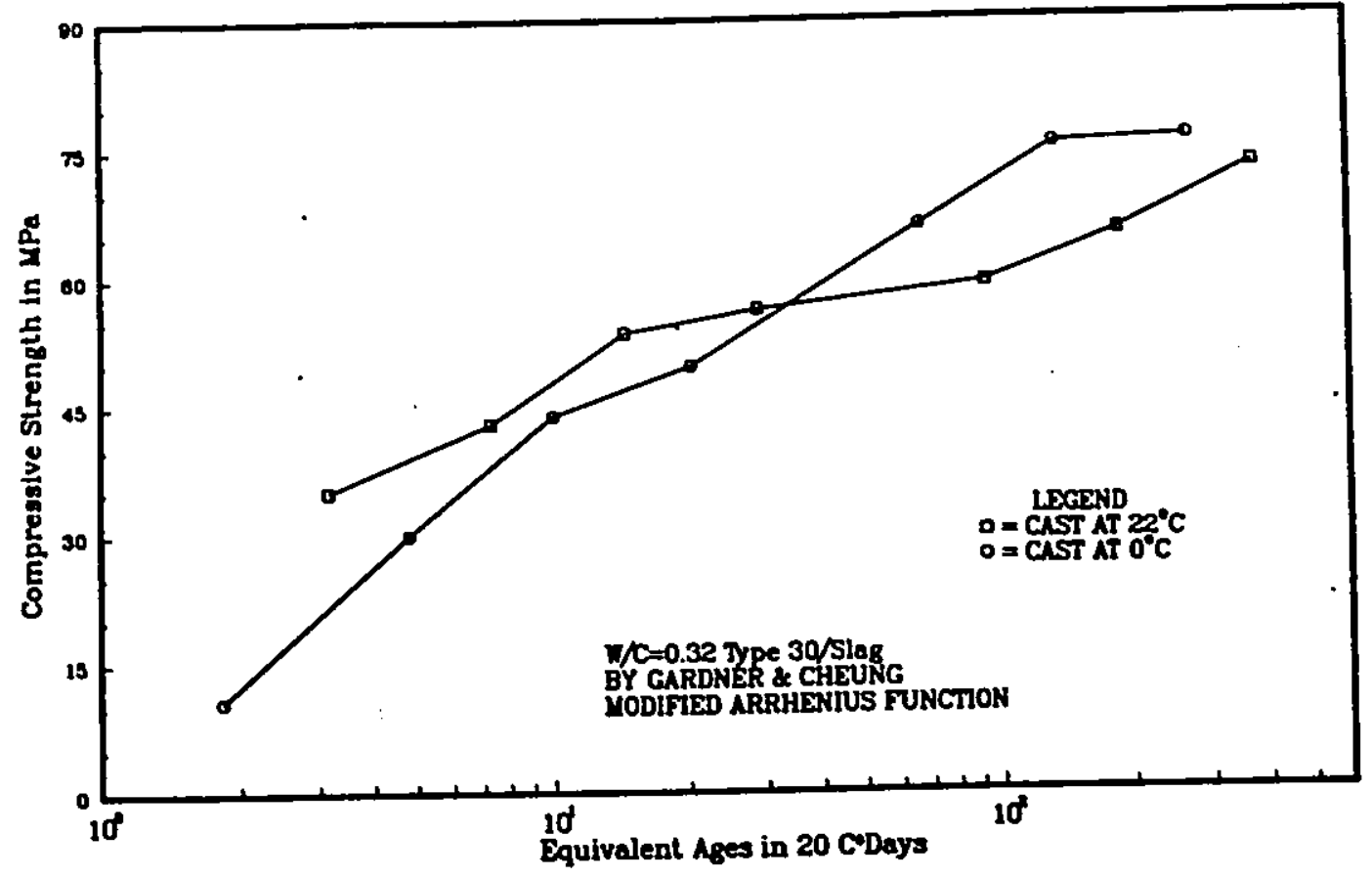

Figure 2.13: Strength vs. equivalent age in $20^{\circ} \mathrm{C}$ days

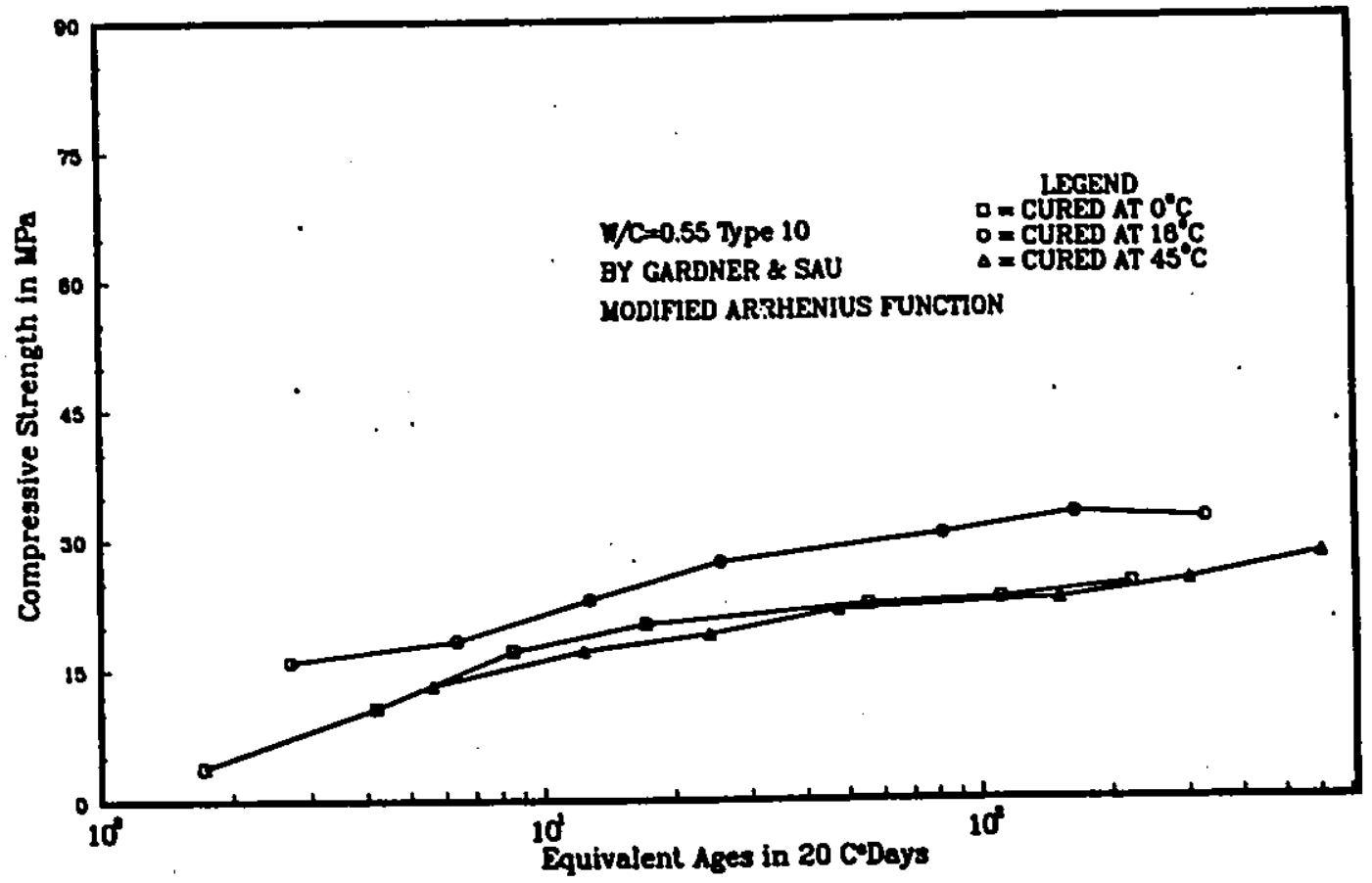

Figure 2.14: Strength vs. equivalent age in $20^{\circ} \mathrm{C}$ days 


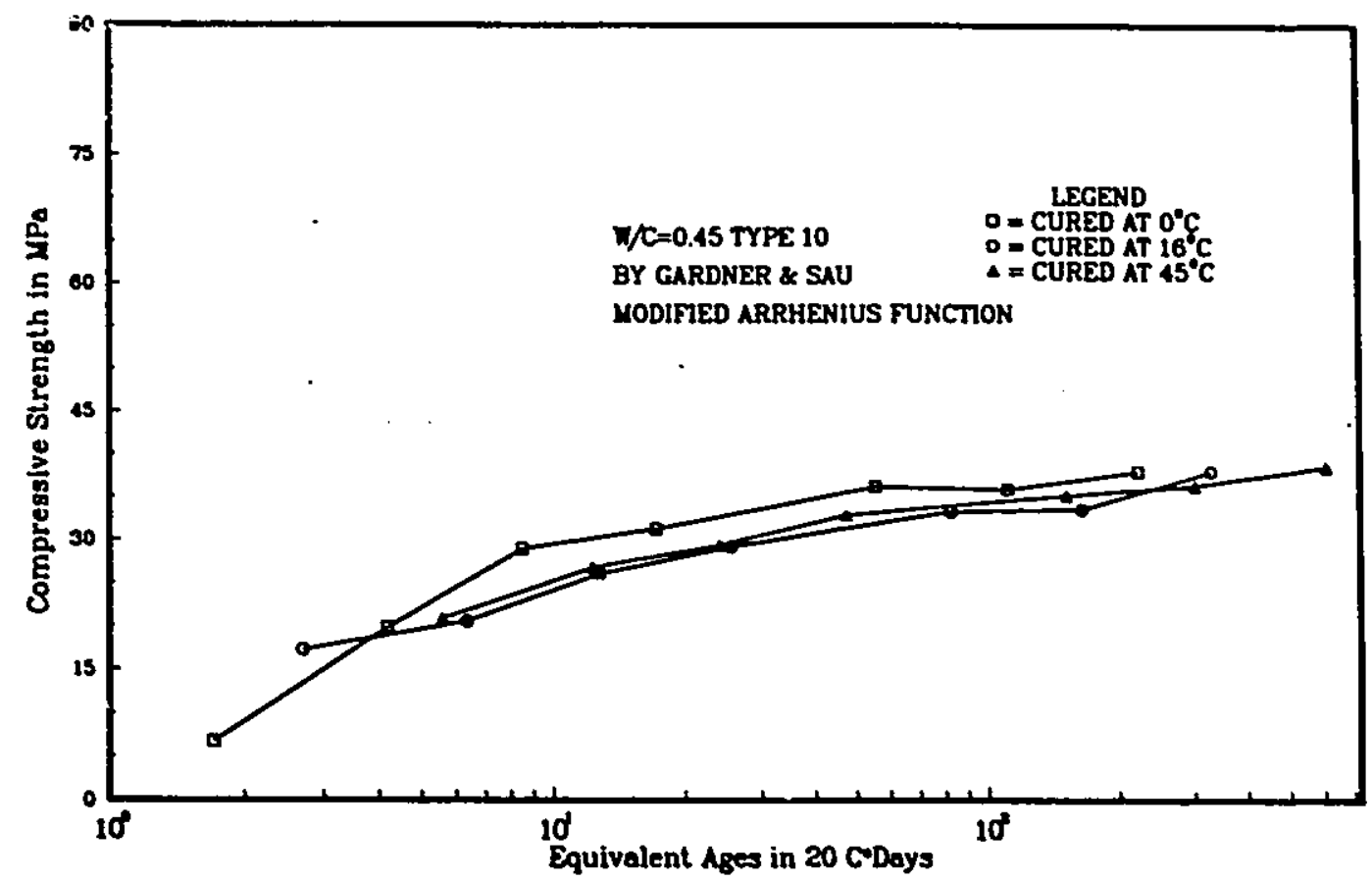

Figure 2.15: Strength vs. equivalent age in $20^{\circ} \mathrm{C}$ days

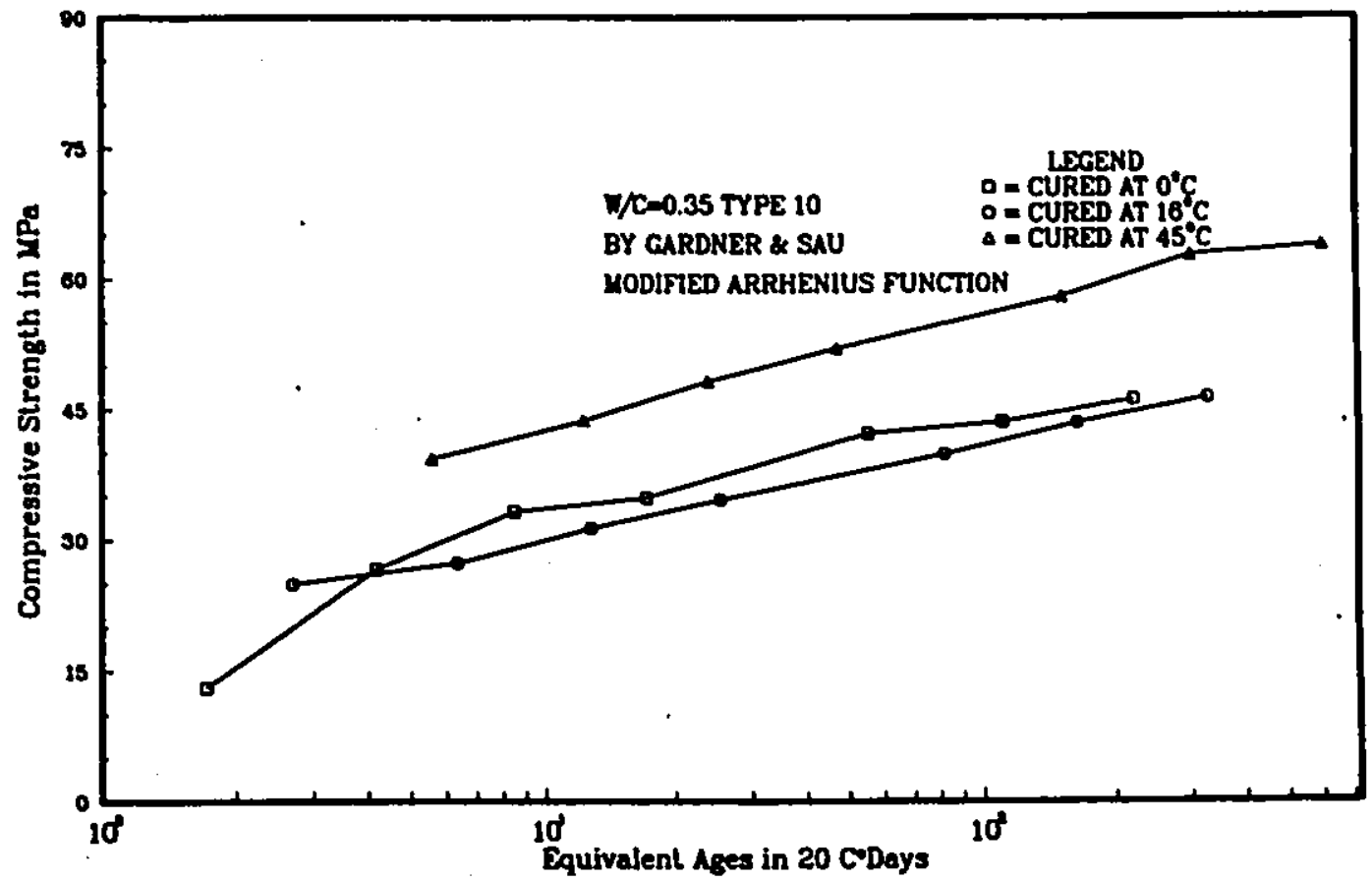

Figure 2.16: Strength vs. equivalent age in $20^{\circ} \mathrm{C}$ days 


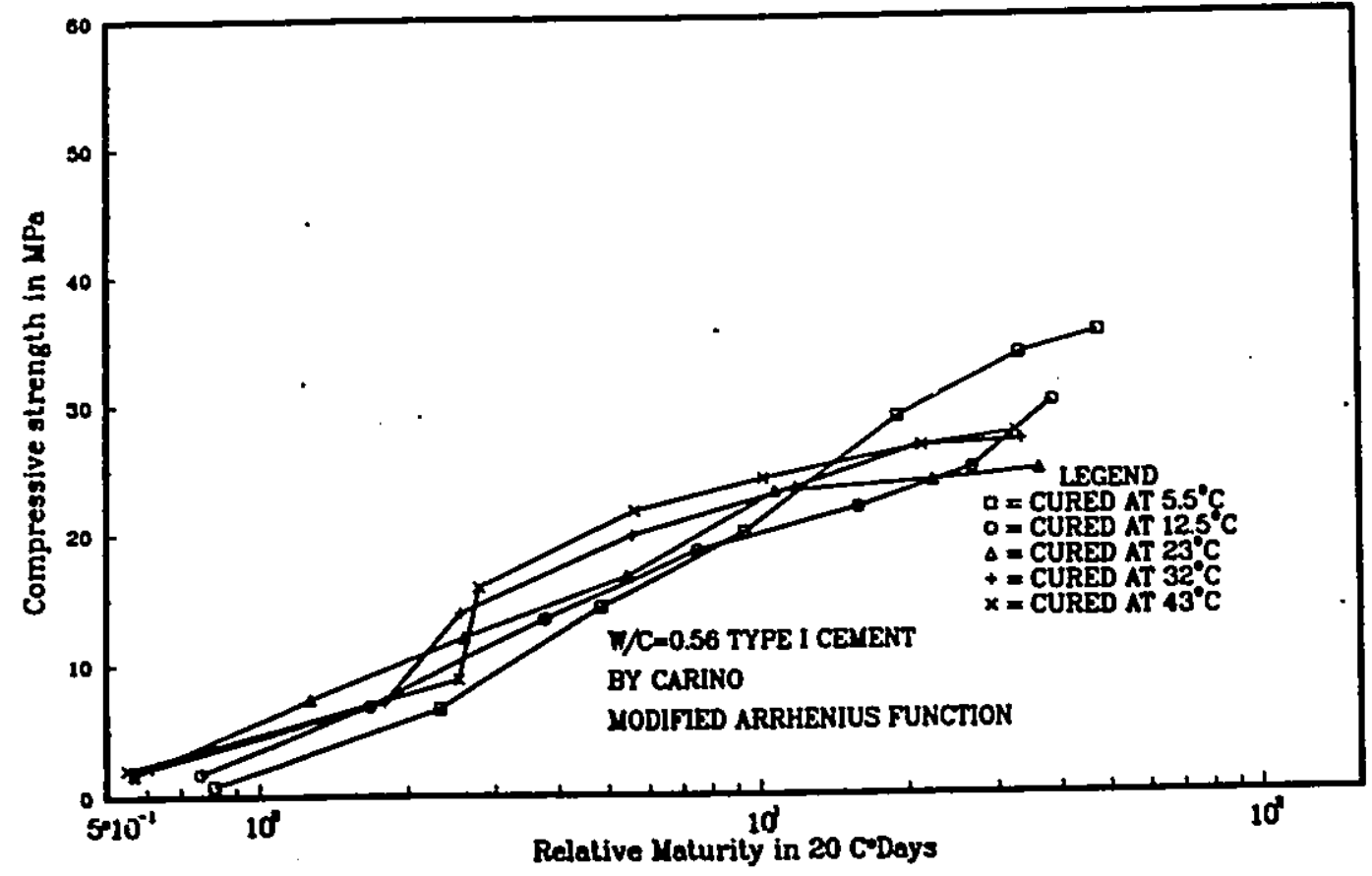

Figure 2.17: Strength vs. equivalent age in $20^{\circ} \mathrm{C}$ days

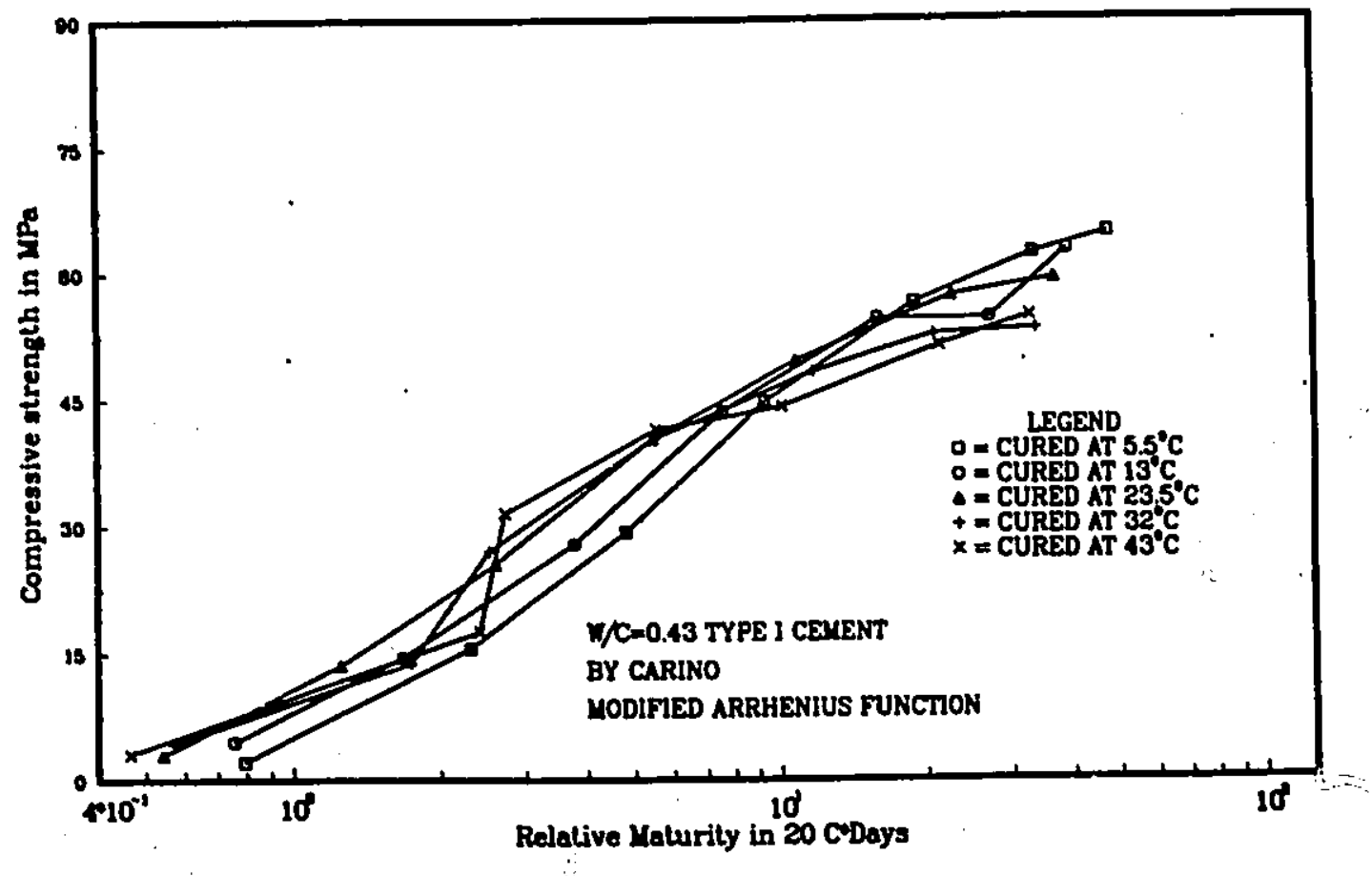

Figure 2.18: Strength vs. equivalent age in $20^{\circ} \mathrm{C}$ days 


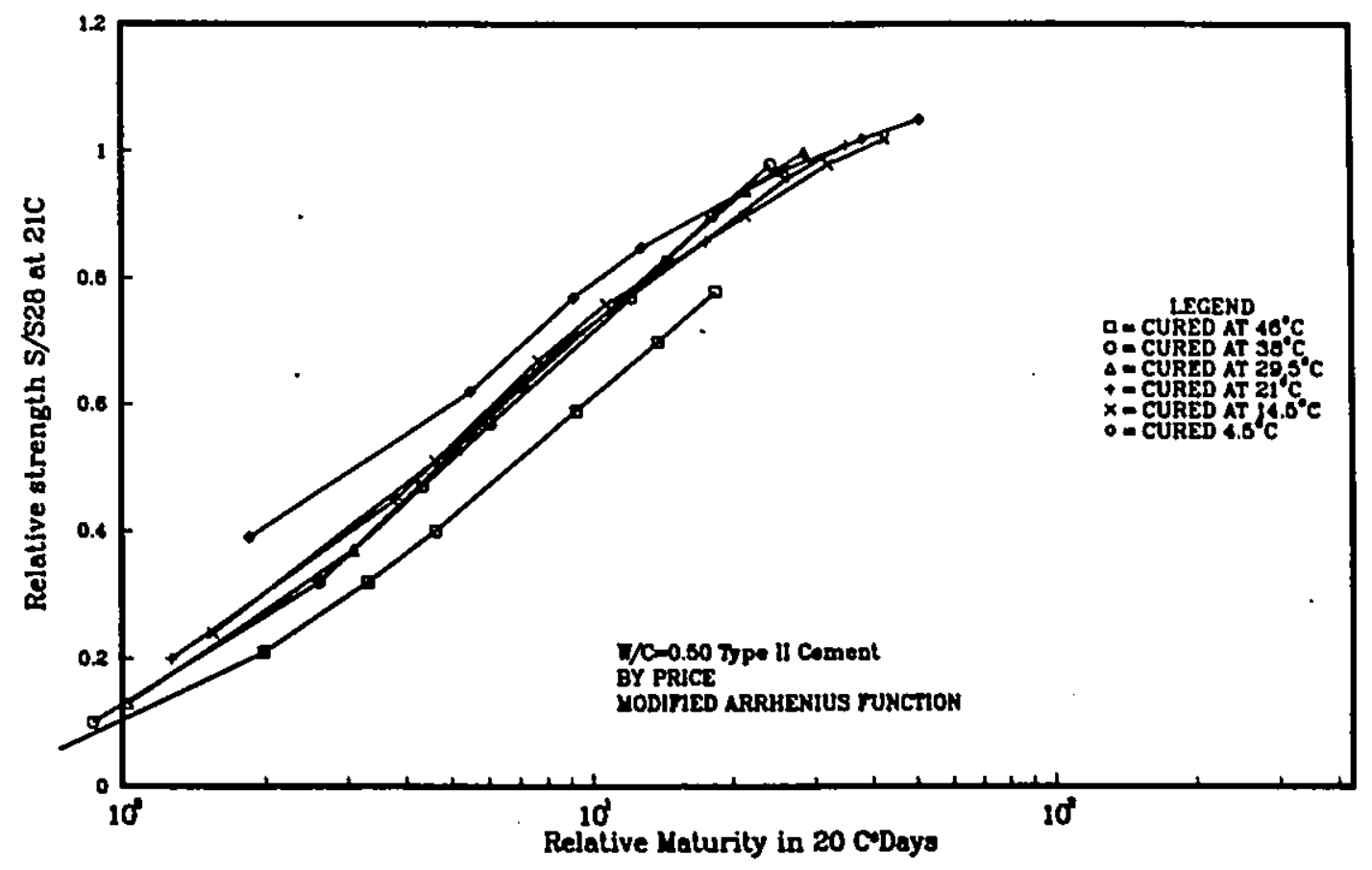

Figure 2.19: Strength vs. equivalent age in $20^{\circ} \mathrm{C}$ days

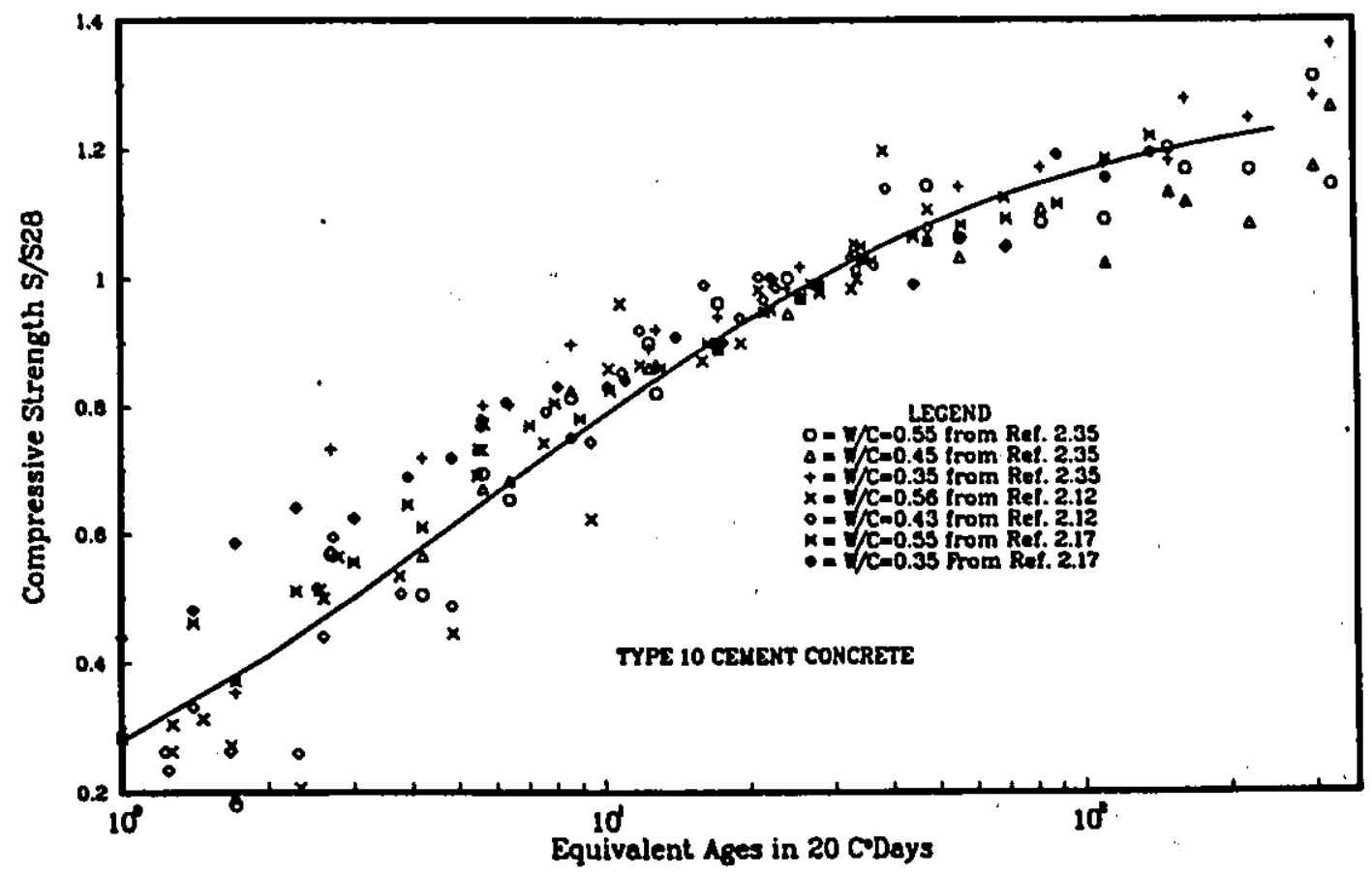

Figure 2.20: Strength gain for CSA Type 10 cement 


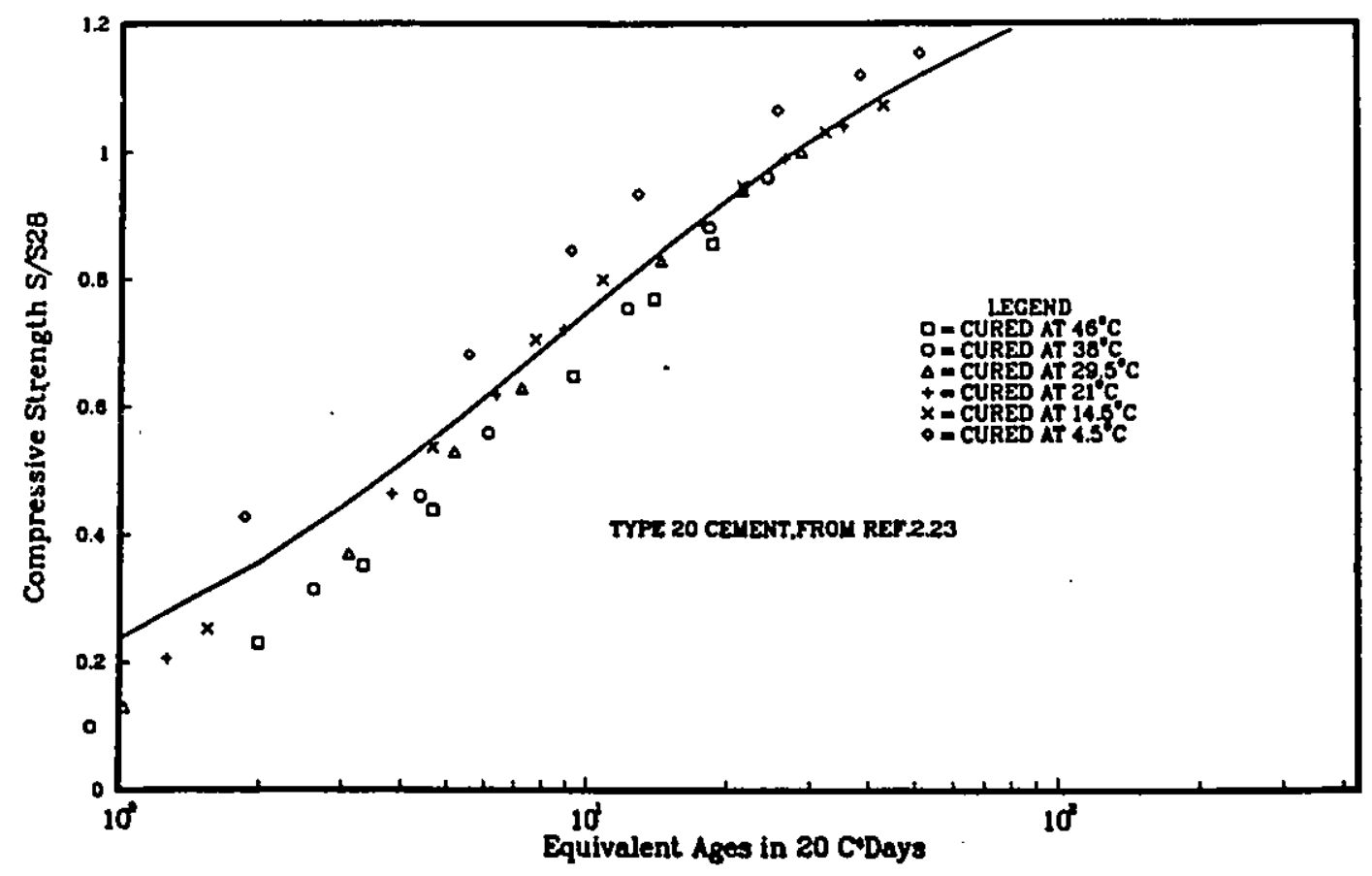

Figure 2.21: Strength gain for CSA Type 20 cement

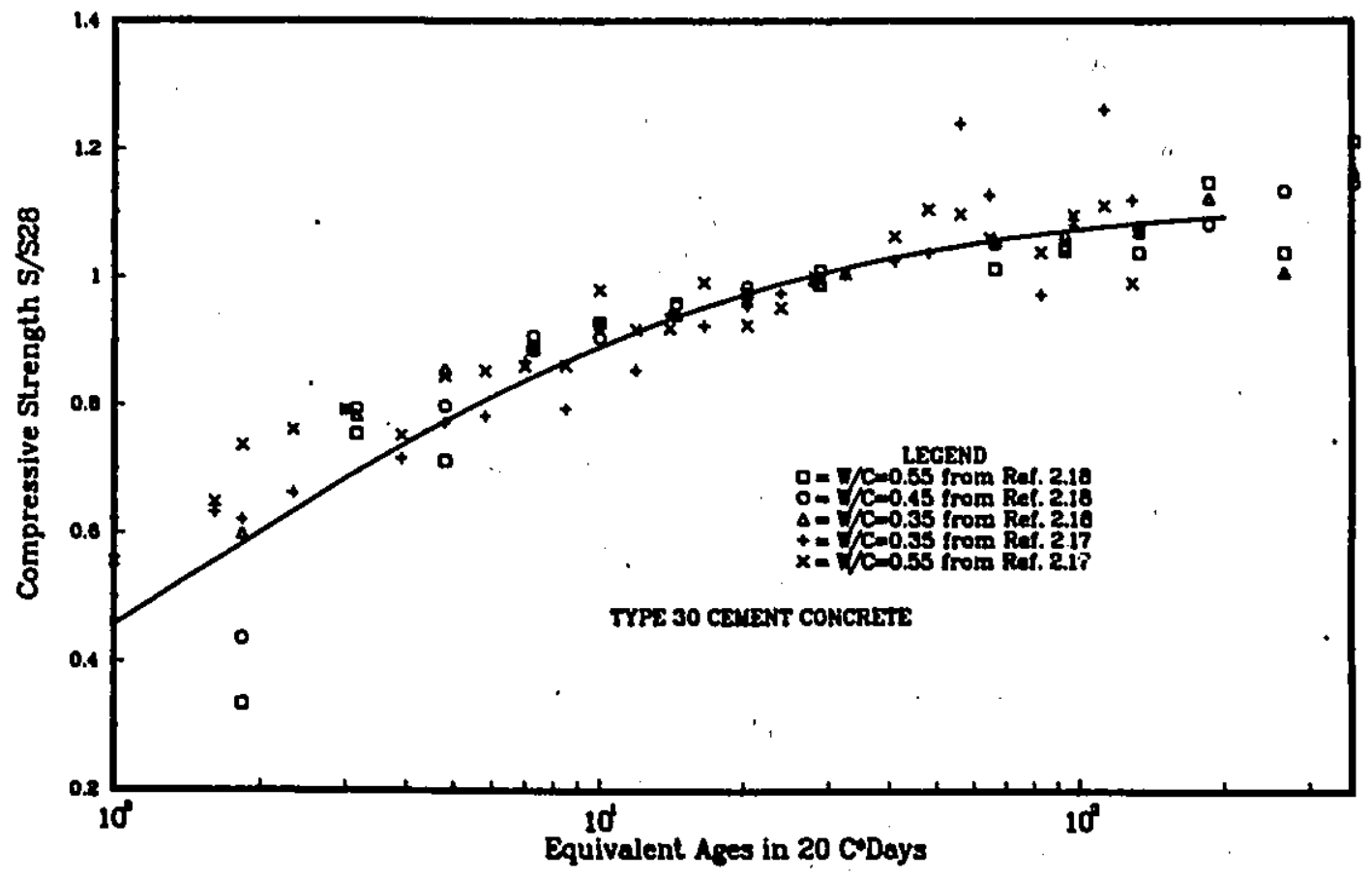

Figure 2.22: Strength gain for CSA Type 30 cement 


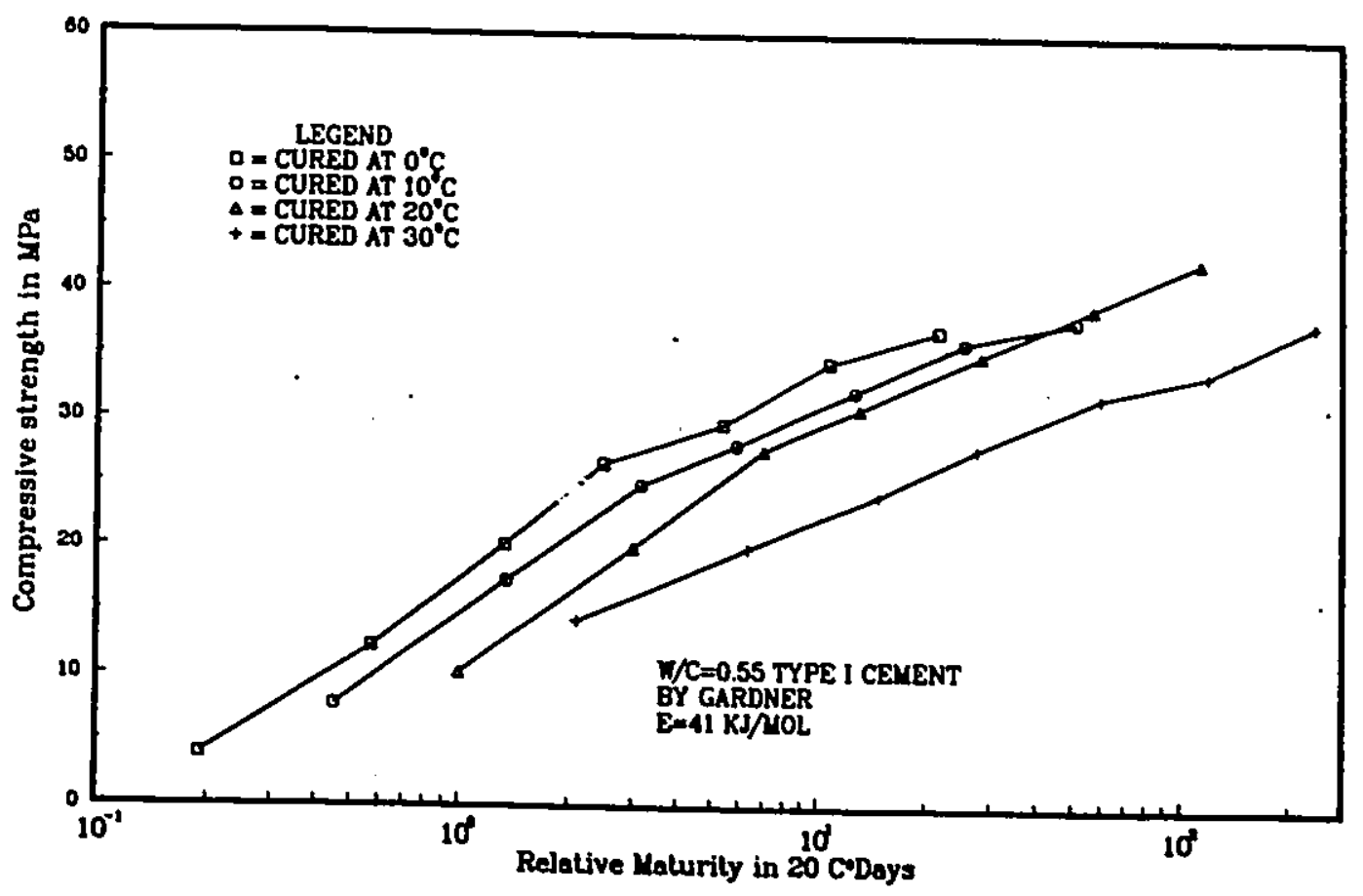

Figure 2.23: Arrhenius function with $E=41 \mathrm{KJ} / \mathrm{mol}$

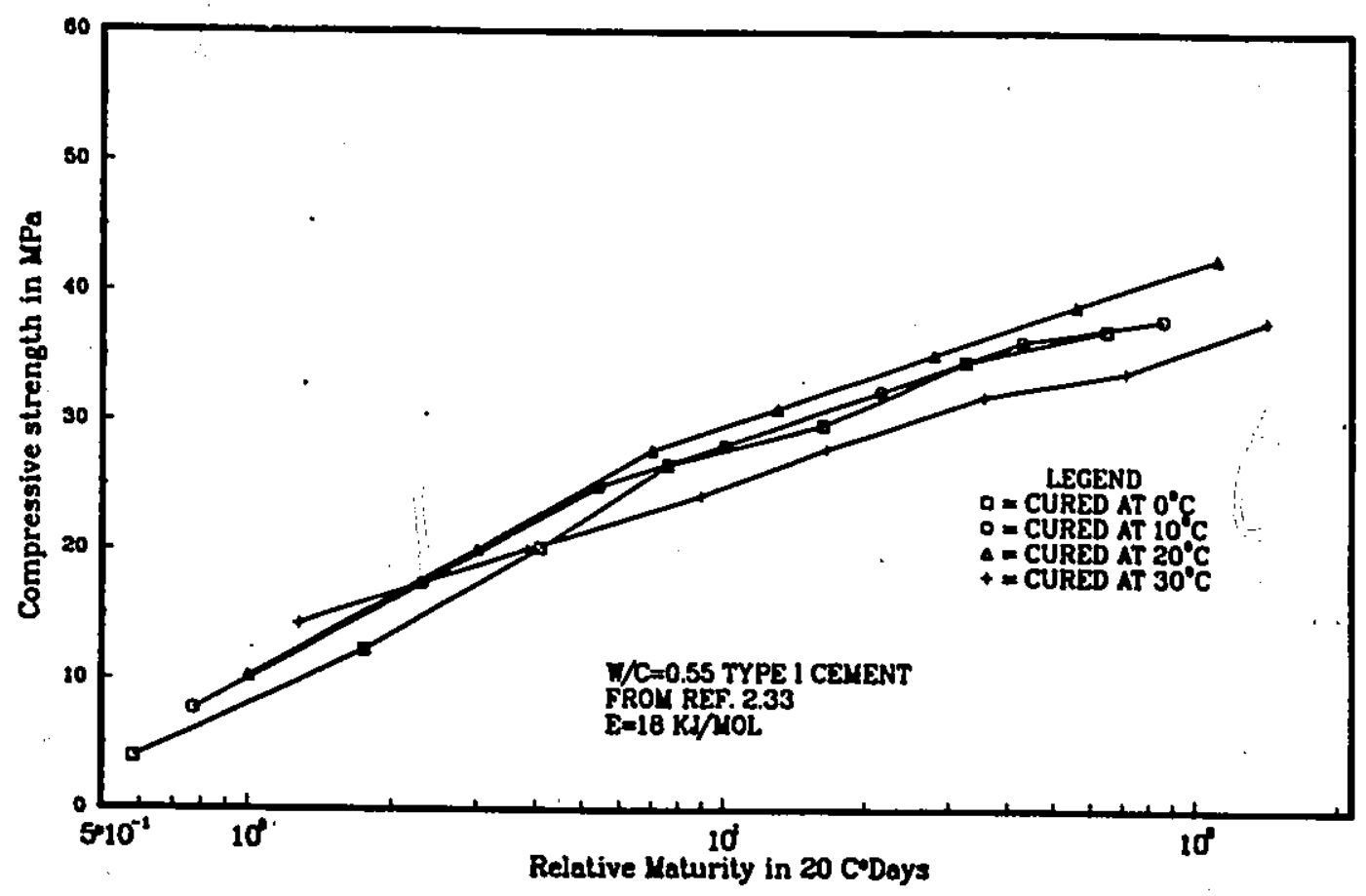

Figure 2.24: Arrhenius function with $E=18 \mathrm{KJ} / \mathrm{mol}$ 


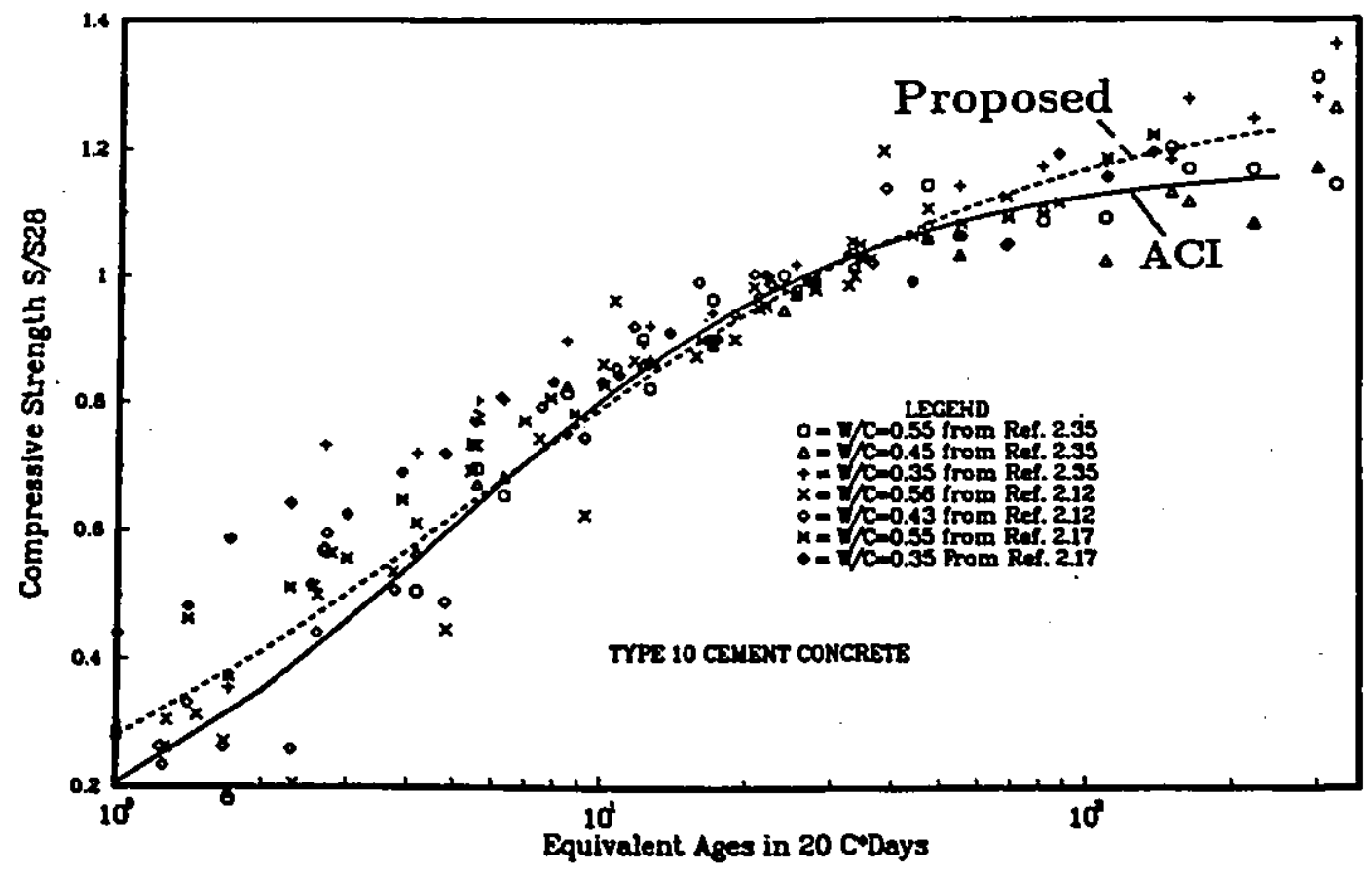

Figure 2.25: Comparison with ACI expression for Type 10 cement

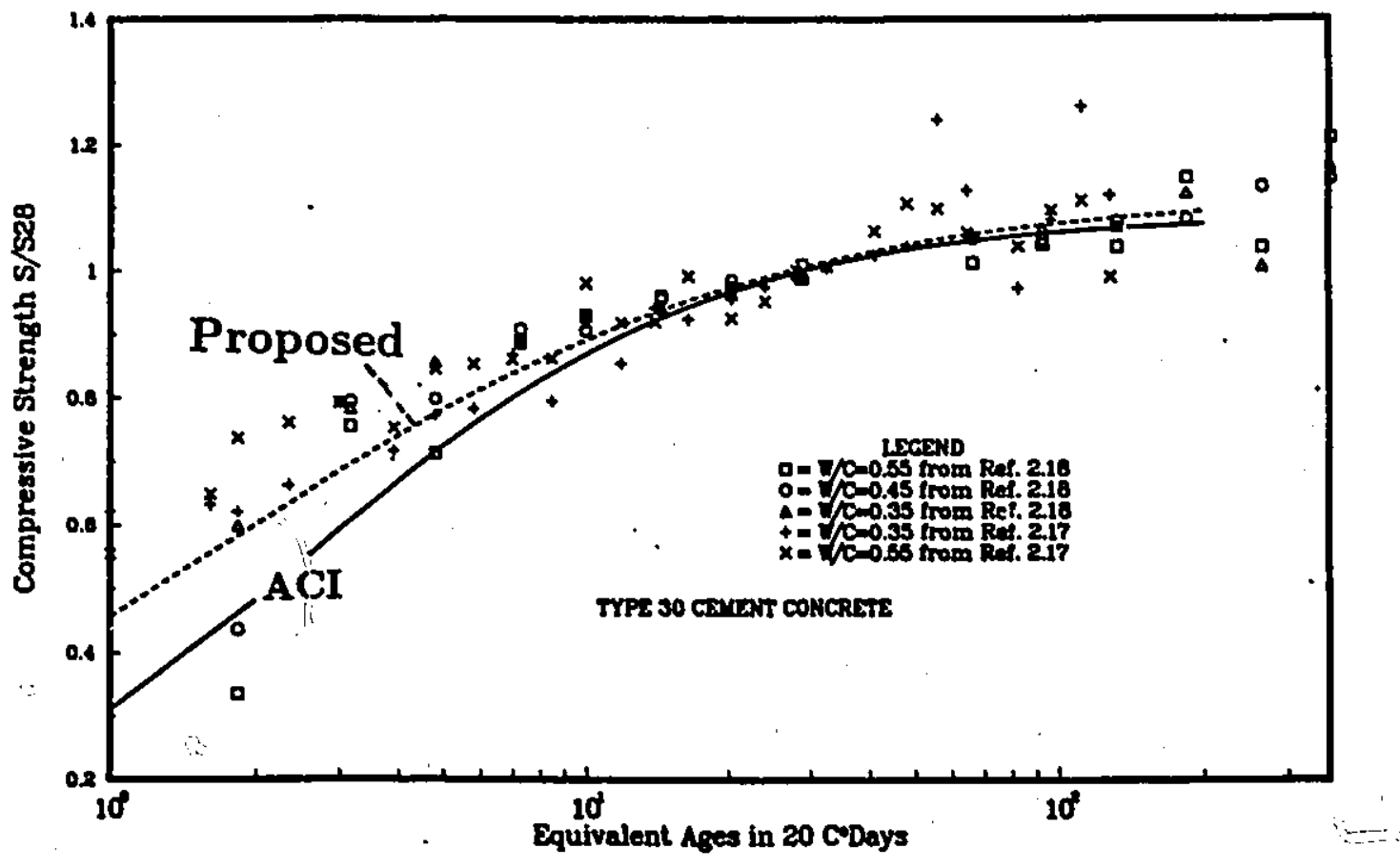

Figure 2.26: Comparison with ACI expression for Type 30 cement 


\section{Chapter 3}

\section{Mechanical :roperties}

\subsection{Modulus of Elasticity}

\subsubsection{Introduction}

Like many other structural materials, concrete is to a certain degree elastic. A typical stress-strain diagram for a concrete specimen loaded and unloaded is shown in Fig. 3.1. It can be seen that the term Young's modulus of elasticity can strictly be applied only to the straight part of the stress-strain curve, or, when no straight portion is present, to the tangent to the curve at the origin. It is called initial tangent modulus.

The increase in strain while the load, or a part of it, is acting is due to creep of concrete. Since the instantaneous strain depends on the speed of loading, it is difficult to make the demarcation between elastic and creep strains. For practical purposes, an arbitrary distinction is made: the deformation occurring during load is considered elastic, and the subsequent increase in strain is regarded as creep. The modulus of elasticity satisfying this requirement is the secant modulus of Fig. 3.1.

The determination of the initial tangent modulus is not easy, but an approximate value of the modulus can be obtained indirectly: the secant of the stress-strain curve on unloading is often parallel to the initial tangent to 
the loading curve. Repeated loading and unloading reduces the subsequent creep, so that the stress-strain curve on the third or fourth loading exhibits only small curvatures; this method is prescribed in ASTM Standard and BS 1981. Since the stress is reduced not to zero, but to a small specified value, the modulus is, strictly speaking, a chord modulus; but the value is very close to the initial tangent modulus.

There is no standard method of determining the secant modulus. In some laboratories, it is measured at stresses ranging from 3 to $14 \mathrm{MPa}$; in others, at stresses representing $15,25,33$ or 50 percent of the ultimate strength $h^{3.19}$. Because the secant modulus decreases with an increase in stress, the stress at which the modulus has been determined should always be stated.

Different methods for determining the modulus have been used in Europe and North America. In CEB-FIP Model Code 1990, the modulus of elasticity is defined as the slope of the stress-strain diagram at its origin, i.e., tangent modulus of elasticity; but in the ACI Code, the modulus of elasticity is determined as the slope of the secant drawn from the origin to a point corresponding to $0.45 f_{c}^{\prime}$ on the stress-strain curve.

Since the early 20th century, civil engineers have considered that the modulus of elasticity of concrete is uniquely related to its compressive strength. This sort of thinking was justified in a classical paper written by Stanton ${ }^{3.23}$ in 1909. Test results of more than 10,000 standard 6 by 12 inch concrete cylinders, showed that the modulus of elasticity had a general relation to the strength of concrete for ages ranging from 7 days to 1 year. The relation was found to be non-linear, although a linear relation was used at that time.

Until the early 60's, a linear relation was proposed by ACI Committee 318 Building Code,

$$
E_{c}=1000 f_{c}^{\prime}
$$

Where,

$E_{c}:$ modulus of elasticity, psi,

$f_{c}^{\prime}$ : compressive strength, psi. 
With the rapid expansion of the use of lightweight aggregate concrete in the early 1960's, $P a u w^{3.17}$ proposed an empirical formula for both normal and lightweight structural concrete. By using statistical analysis, Pauw found that modulus of elasticity was affected by the density and the compressive strength of concrete.

$$
E_{c}=33 w^{3 / 2} \sqrt{f_{c m}^{\prime}}
$$

where,

$E_{c}$ : static modulus of elasticity of concrete in psi, $w$ : air-dry density of concrete at time of test, pcf, $f_{c m}^{\prime}$ : mean compressive strength of concrete at time of test, psi.

Eq. 3.2 was adopted by the $\mathrm{ACI}$ and CSA building/bridge codes, and is still being used in North America.

For normal weight concrete, assuming the density of concrete $w$ is 145 $l b / f t^{3}$, Eq. 3.2 becomes:

$$
E_{\mathrm{c}}=57000 \sqrt{f_{\mathrm{cm}}^{\prime}}
$$

when $E_{c}$ is expressed in $\mathrm{GPa}$ and $f_{c}^{\prime}$ in $\mathrm{MPa}$, the equation is

$$
E_{c}=5.0 \sqrt{f_{c m}^{\prime}}
$$

The approaches in Europe are different. The modulus of elasticity of concrete is regarded as proportional to the cube root of its strength. The CEB expression is based on the specified characteristic cylinder strength $\left(f_{c k}^{\prime}\right)$ at 28 days:

$$
E_{c}=9.5\left(f_{c k}^{\prime}+8\right)^{0.33}
$$

The additional term 8 is introduced to this expression in an attempt to compensate for the difference between the specified characteristic strength and actual mean strength of the concrete produced.

Before 1985, the British Code of Practice for Standard Use of Concrete (CP110-72) tabulated the static modulus of elasticity $E_{c}$ in GPa for various 
values of cube strength $f_{c u}^{\prime}$ in MPa. These can be related by the expression

$$
E_{c}=9.1\left(f_{c u}^{\prime}\right)^{0.33}
$$

The current British Code BS 8110:1985 $5^{3.3}$ presents a linear equation for normal weight concrete:

$$
E_{c, 28}=20+0.2 f_{c u, 28}^{\prime}
$$

where

$E_{c, 28}$ is the static modulus of elasticity at 28 days in $\mathrm{GPa}, f_{c u, 28}^{\prime}$ is the characteristic cube strength at 28 days in $\mathrm{MPa}$.

The modulus of elasticity of concrete at an age $t$ may be derived from the following equation:

$$
E_{c, t}=E_{c, 28}\left(0.4+0.6 f_{c u, t}^{\prime} / f_{c u, 28}^{\prime}\right)
$$

when $t \geq 3$ days.

Substituting Eq. 3.7 into Eq. 3.8, one gets

$$
E_{c, t}=8+0.08 f_{c u, 28}^{\prime}+0.12 f_{c u, t}^{\prime}+1.2 f_{c u, t}^{\prime} / f_{c u, 28}^{\prime} \text {. }
$$

Since $f_{c u, t}^{\prime} / f_{\mathrm{eu}, 2 \mathrm{~g}}^{\prime}$ is a function of the age of the concrete, Eq. 3.9 indicates that the modulus of elasticity is not only a function of its compressive strength, but also a function of its age.

From the introduction one can see that there are two questions regarding the modulus of elasticity of concrete: whether the relationship between the modulus of elasticity of concrete is a unique function of its compressive strength, or, the relation is time dependent; the other question is that for European and American expressions, which one gives a better representation of the modulus of elasticity.

One aim of this study is to provide a better understanding of the above two questions. 


\subsubsection{Test Data}

In searching the literature for data which would be useful in verifying the relations between elastic modulus and compressive strength and modulus and the age of concrete, several difficulties were encountered. The first difficulty was the result of the lack of a standard test for measuring elastic modulus some investigators reported the initial tangent modulus, whereas others, used the secant modulus at some given stress level. In some instances, the method used to determine the static modulus was even not defined. It was also found that in many cases the age of concrete at the time of test was not reported, and therefore, such data could not be considered to verify the influence of concrete age on the strength modulus relation.

In a few instances, cube specimens were tested; these reported data were adjusted by applying the L'Hermite's expression ${ }^{3.16}$

$$
\frac{f_{c}^{\prime}}{f_{c u}^{\prime}}=0.76+0.2 \log _{10} \frac{f_{c u}^{\prime}}{19.6}
$$

where both $f_{c}^{\prime}$ and $f_{c u}^{\prime}$ are in $\mathrm{MPa}$.

The results of 62 tests were obtained from the work reported by Gardner and $S a u^{3.22}$. For compressive strength three $150 \mathrm{~mm} \times 300 \mathrm{~mm}$ cylinders were tested each time according to ASTM standard. The static modulus values reported were based on the initial tangent modulus according to ASTM C18782 standard. The aggregates used were crushed limestone; cements used were CSA Type 10 and Type 30 Portland cements. Material testing was carried out following the guidelines recommended by ASTM and CSA standards. The concrete ages at the time of testing ranged from 3 days to 1 year.

The results of 52 tests reported by Bennett and Collings ${ }^{3.2}$ were also included. The concrete ages at the time of test ranged from 8 hours to 1 year. At most ages, tests were made of twelve 4 in. cubes drawn from several batches and cured in water according to BS 1881. The standard deviation was about $1.7 \mathrm{~N} / \mathrm{mm}^{2}$ and did not vary significantly with strength or age. The modulus of elasticity obtained according to BS 1881 parts 13 and 14, using Eq. 3.10 to 
convert cube strengths into cylinder strengths.

The paper by Lew and Reichard ${ }^{3.13}$ reported 26 tests from 1 day to 42 days. The concrete was supplied by a local ready-mixed concrete company. The mix proportion per cubic yard of concrete were $517 \mathrm{lb}(235 \mathrm{Kg})$ Type I cement; $1365 \mathrm{lb}(619 \mathrm{Kg})$ silica sand; $1750 \mathrm{lb}(794 \mathrm{Kg})$ crushed limestone; and 6 oz $(170 \mathrm{~g})$ air-entraining agent. Test cylinders of $6 \times 12$ in. were cast in waxed cardboard molds. The values of moduli of elasticity were secant moduli of elasticity obtained on the stress levels $0.4 f_{c m}^{\prime}$ from stress-strain curves of the compressive test.

The results of 19 tests reported by Carrasquillo, Nilson and Slate ${ }^{3.4}$ were used. The concretes in three strength range were studied: high strength with compressive strength $f_{\mathrm{cm}}^{\prime}$ of at least $62 \mathrm{MPa}$ at 56 days, medium strength with $f_{c m}^{\prime}$ from 41 to $62 \mathrm{MPa}$, and normal strength with $f_{c m}^{\prime}$ from 21 to $41 \mathrm{MPa}$. Two types of coarse aggregate were used: crushed limestone from a local quarry and gravel from the same glacial alluvial deposit as the sand. The maximum aggregate size was $19 \mathrm{~mm}$ in each case. ASTM Type I cement was used for all mixes. Water-reducing admixture, ASTM C494-71 Type A, was used in the high strength concrete. Tests were made using $4 \times 8$ in. cylinders. A factor 0.9 was used by the authors to convert the values of compressive strengths into these of $6 \times 12$ in. cylinders, regardless of strength and test age. The test ages were from 7 to 95 days. Static moduli were tested according to ASTM standards.

The results of 21 tests reported by Russell and Corley ${ }^{3.21}, 18$ tests reported by Kaar, Hanson and Capell ${ }^{3.12}$, and 17 tests by Perenchio and Klieger ${ }^{3.18}$ were also included. All of these tests were performed according to the ASTM Standards. But unfortunately, no concrete age at the time of testing was reported for these data. 


\subsubsection{Analysis of Data}

It is assumed that the relationship between modulus of elasticity and compressive strength can be represented by an empirical equation of the form

$$
E_{c}=a\left(f_{c m}^{\prime}\right)^{b}
$$

which has been used by most American and European codes, excluding BS 8110:1985.

The method of Least Square was used to determine the values of $a$ and b. Data used were obtained from the reports mentioned above. It should be mentioned that because the qualities of the concretes tested by Stanton ${ }^{3.23}$ were poor comparing with these of today's, those data do not reflect today's concrete, so they were not used in this study. The results from computation showed that

$$
E_{c}=5.81\left(f_{c m}^{\prime}\right)^{0.433}
$$

The correlation coefficient $R=0.90$, and integral absolute error $\mathrm{IAE}=9.4 \%$. The data used and curve given by Eq. 3.12 are shown in Fig. 3.2.

Eq. 3.12 was derived by assuming an empirical relation between $E_{c}$ and $f_{c m}^{\prime}$. From Fig.3.2 one can see that the data from low strengths do not fit the curve quite well. It is obvious that the data can be represented by two curves.

$$
\begin{array}{ll}
E_{c}=3.0\left(f_{c m}^{\prime}\right)^{2 / 3} & \text { when } f_{c m}^{\prime} \leq 27 \mathrm{MPa} \\
E_{c}=9.0\left(f_{c m}^{\prime}\right)^{1 / 3} & \text { when } f_{c m}^{\prime}>27 \mathrm{MPa}
\end{array}
$$

To check whether or not Eq. 3.12 was improved by Eq. 3.13 and Eq.3.14, both correlation coefficient $R$ and integral absolute error IAE were calculated. The results showed that $E q .3 .13$ and $E q .3 .14$ gave a better representation of the experimental data than Eq.3.12 did, because the value of R, which was equal to 0.916, was larger than the value of that obtained from $E q .3 .12$, and the value of $I A E=9.18 \%$, is smaller than that obtained from $E q .3 .13$. The comparison of the two curves can be seen from Fig.3.3. 
In order to verify whether the $E_{c}$ vs. $f_{c}^{\prime}$ relationship is affected by testing time, i.e., whether $E_{q .3 .13}$ and $E q .3 .14$ can be used regardless of concrete ages, the method of Analysis of Variance was introduced. The data were classified into five groups according to concrete ages less than 3 days, 3 to 6 days, 7 to 14 days, 15 to 30 days, and greater than 30 days, respectively. The test null hypothesis was that the mean values of errors between observed and calculated $E_{c}$ by $E q .3 .13$ and $E q .3 .14$ did not vary among each group. The test result showed that on the significance level $\alpha=0.05$, there was no reason to reject the null hypothesis. Therefore, it is believed that $E_{c}$ vs. $f_{c}^{\prime}$ relation is not significantly affected by concrete age at the time of tests. The data classified by concrete ages are shown in Fig.3.4.

Similarly, the data were also classified by their 28-day strength to check if the $E_{\mathrm{c}}$ vs. $f_{\mathrm{c}}^{\prime}$ relation was affected by different types of concretes. The data are shown in Fig.3.5. By using the same procedure, it was found that on the significance level $\alpha=0.05$, there was no reason to reject the null hypothesis, it was accepted that there was no significant difference among the five groups.

Fig.3.3 also shows that the data can be fitted better by using two curves than by using only one empirical curve, and explains why different expressions were developed by different groups. The reason might be that American expression was derived from the data with relatively low compressive strength concrete, ranging from 33 psi to $4700 \mathrm{psi}(0.22 \mathrm{MPa}$ to $32.5 \mathrm{MPa})$, including light weight concretes, so the power of 0.5 was obtained; whereas the European expression was derived by using normal and high strength concretes, so the power of 0.33 , same as $E q .3 .14$, was obtained. Therefore, for the mature concrete, the CEB expression gives a better representation than the ACI-CSA expression.

According to the British Code BS 8110:1985, since the 28-day strength is unlikely less than $20 \mathrm{MPa}, E q .3 .7$ gives a conservative, but reasonable representation. Obviously, it can not be used at early ages. Fig. 3.6 shows a very poor relationship between the relative E-modulus and the relative compressive 
strength to their 2S-day values.

\subsubsection{Summary}

1. The modulus of elasticity of concrete can be expressed by its compressive strength

$$
\begin{array}{ll}
E_{c}=3.0\left(f_{c m}^{\prime}\right)^{2 / 3} & \text { when } f_{c m}^{\prime} \leq 27 \mathrm{MPa} \\
E_{c}=9.0\left(f_{c m}^{\prime}\right)^{1 / 3} & \text { when } f_{c m}^{\prime}>27 \mathrm{MPa}
\end{array}
$$

where $f_{c}^{\prime}$ is the compressive strength of concrete at any age (in MPa), $E_{c}$ is its modulus of elasticity in GPa.

2. For the normal weight concrete, the modulus of elasticity can be uniquely obtained from the above equations, regardless the types of concrete or their ages.

3. For mature concrete, British Code of Practice CP110 and the CEB Code give better representations than the ACI Code or the new British Code BS 8110:1985. The ACI expression overestimates the modulus of elasticity for high strength concrete. BS 8110:1985 formula calculates a high value of modulus of elasticity.

4. None of the codes cited above are accurate enough to be used for early-age concrete. Relatively speaking, American codes give better results for early-age concrete than European codes do, but European codes have a better representation for mature concrete than American codes. 


\subsection{Tensile Strength}

\subsubsection{Introduction}

Direct tension tests of concrete are seldom carried out, mainly because the specimen holding devices introduce secondary stresses that can not be ignored. The most commonly used tests for estimating the tensile strength of concrete are the ASTM C496 split cylinder tension test and the ASTM C78 third-point flexural loading test.

In the split cylinder tension test a $6 \times 12$ in. concrete cylinder is subjected to compression load along two axial lines which is diametrically opposite. The load is applied continuously at a constant rate within the splitting tension stress range of 100 to $200 \mathrm{psi}$ until the specimen fails. The compressive force produces a transverse tensile stress which is uniform along the vertical diameter. The splitting tensile strength is calculated from the formula

$$
f_{t s p}^{\prime}=\frac{2 P}{\pi l d}
$$

where $f_{\text {tap }}^{\prime}$ is the splitting tensile strength, $P$ is the maximum applied load in the test, $l$ and $d$ are length and diameter of specimen. Compared to direct tension, the split cylinder test is known to overestimate the tensile strength of concrete by 10 to 15 percent. In accordance with the operational method recognized by RILEM, 0.90 of the splitting tensile strength is used as direct tension strength.

In the third-point flexural test, a $6 \times 6 \times 12$ in. concrete beam is loaded at a rate of 125 to $175 \mathrm{psi} / \mathrm{min}$. Flexural strength is expressed in term of the modulus of rupture $f_{r}$, which is the maximum stress at rupture computed from

$$
f_{r}=\frac{6 M}{b h^{2}}
$$

where $M$ is the moment, $b$ and $h$ are width and depth of specimen. The results from the modulus of rupture test tend to overestimate the tensile strength of 
concrete by 50 to 100 percent, mainly because the fiexural formula assumes a linear stress-strain relationship in concrete throughout the cross section of the beam. Additionally, in the direct tension test the entire volume of specimen is under applied stress, whereas in the flexural test only a small volume of concrete near the bottom of the specimen is subjected to high stresses.

Because of its accuracy and convenience, the split cylinder text has been introduced and standardized in many countries. ASTM and RILEM have also issued a recommendation for the split cylinder test. In this paper, only splitting tensile strength was studied.

It is known that the tensile and compressive strengths are closely related; however, there is no direct proportionality. As the compressive strength of concrete increases, the tensile strength also increases, but at a decreasing rate.

A number of empirical formulae connecting $f_{t}^{\prime}$ and $f_{c}^{\prime}$ have been suggested, many of them of the type

$$
f_{t}^{\prime}=k\left(f_{c}^{\prime}\right)^{n}
$$

where $k$ and $n$ are coefficients. Previous experiments indicate that $n$ may vary between $1 / 2$ and $3 / 4$. The former value is used by the ACI, but a value of $2 / 3$ is used by CEB.

ACI defines the modulus of rupture for use in calculating deflection as:

$$
f_{r}^{\prime}=0.62 \sqrt{f_{c}^{\prime}}
$$

for strength calculations, the direct tension strength is calculated from:

$$
f_{t}^{\prime}=0.50 \sqrt{f_{c}^{\prime}}
$$

CEB uses only the direct tension strength for calculating both deflection and strength. The tensile strength is expressed as:

$$
f_{t k}^{\prime}=0.30\left(f_{c k}^{\prime}\right)^{2 / 3}
$$

In both Eq. 3.19 and Eq. 3.20, $f_{l}^{\prime}$ is the characteristic tensile strength, and $f_{c}^{\prime}$ is the characteristic compressive trength of cylinders. 
The objective of this study is to determine an appropriate formula for the relationship between tensile and compressive strengths, and determine whether or not, the formula can be used for early-age concrete, i.e., whether or not the relationship is time independent.

\subsubsection{Test Data}

To determine the relationship between tensile and compressive strengths, various data from several reports were used. In searching the data, some difficulties were encountered. The main reason was the result of the different methods used for tension tests; some researchers tested split cylinder strength, and others did flexural tests or direct tension tests. Because the values obtained from different tests vary significantly, these data could not be used together, so in this study, only data from split cylinder tests were used. In some instance the age of concrete at time of test was not reported, therefore, such data could not be used to verify the influence of concrete age on the relationship between tensile and compressive strengths.

To determine the early-age strength development and the relationship between the mechanical properties of concrete when cured in water at different temperatures, a large scale experimental investigation was undertaken by Gardner $^{3.7}$. Six different concretes were considered using respectively Type I cement, Type I cement with $25 \%$ replacement by flyash and Type III cement at water cementious ratios of 0.35 and 0.55 . The curing temperatures were $0^{\circ} \mathrm{C}$, $10^{\circ} \mathrm{C}, 20^{\circ} \mathrm{C}$ and $30^{\circ} \mathrm{C}$. The mechanical properties measured were compressive strength, split cylinder strength and dynamic modulus at ages of $1,3,7,14,28$, 56 and 112 days. For the compressive and tensile strengths, sufficient samples were tested to enable both mean values and small sample standard deviations to be calculated. The compressive strength was taken as the average of five cylinder strengths. The split cylinder tensile strength was taken as the average result of the five specimens. A total of 168 tests were reported. 
Gardner and $P o o n^{3.10}$ described an experimental investigation of the relationship between cylinder strength and split cylinder strength of concrete made of Type I and Type III cement moist cured at $72^{\circ} F$ for 1,3 and $i$ days, and then under extended low temperatures of $55^{\circ} \mathrm{F}$ and $35^{\circ} \mathrm{F}$. The standard compressive strength test as described in ASTM C192 and C39 using the standard $6 \times 12$ in. cylinders was used. The split cylinder tension test was performed accordinig to ASTM C496 standard. Tests were performed at the ages of $1,3,7,14,28$ days and 3 months. The results of 60 tests were reported.

The results of 26 tests by Lew and Reichard ${ }^{3.13}$ were also included. For the compression and split cylinder tests, standard ôx $\times 12$ in. cylinders were cast in cardboard moulds. Type I cement concrete was supplied by a local ready-mixed concrete company. All specimen were cured in three temperaturecontrolled curing chambers. The temperatures within chambers were $22.8^{\circ} \mathrm{C}$, $12.8^{\circ} \mathrm{C}$ and $1.7^{\circ} \mathrm{C}$. Three specimens from each curing regime were tested for each type test at ages of $1,2,3,3,14,21$ and 28 days.

Walker and Bloem ${ }^{3.24}$ reported 48 tests of compressive and splitting tensive strength tested at 28 and 91 days. The cement was a blend of equal amounts of five locally available brands, and four sizes of coarse aggregate were used. Mixing, curing, handling and testing were carried out in strict accordance with applicable ASTM test methods.

The results of 9 tests were obtained from the work reported by Price ${ }^{3.20}$. according to ASTM standards. Unfortunately, no details such as concrete age at the time of test was provided.

The results of 91 tests were also obtained from a report by Gardner ${ }^{3.8}$. The report described an experimental investigation into the strength development and durability of CSA Type 30 cement concretes, 50\% CSA Type 30 cement with $50 \%$ slag concretes, and $75 \%$ Type 30 cement with $25 \%$ flyash concrete, cast at $0^{\circ} \mathrm{C}$ and cured at $0^{\circ} \mathrm{C}$ in sea-water relative to conventionally cast and cured concretes. All concretes used air-entraining agents and had air contents of between $4 \%$ and $6 \%$. The nominal water/cement ratios were 0.35 , 
0.45 and 0.55 . The mechanical properties measured were compressive strength and splitting tensile strength at ages of $3, \tau, 14,28$ days, 3,6 and 12 months.

\subsubsection{Analysis of Data}

Figure 3.7 shows graphically the relationship between tensile and compressive strengths using the data reported by various authors. By using Least Square Analysis, the coefficients $k$ and $n$ were determined to be 0.310 and 0.691 . The correlation coefficient $R=0.964$ and integral absolute error IAE $=7.3 \%$. Therefore, Eq. 3.17 can be expressed as

$$
f_{\text {tsp }}^{\prime}=0.310\left(f_{c m}^{\prime}\right)^{0.691}
$$

where both $f_{\text {top }}^{\prime}$ and $f_{c m}^{\prime}$ are in MPa.

In practice, Eq. 3.21 can be rewritten as:

$$
f_{t s p}^{\prime}=0.33\left(f_{c m}^{\prime}\right)^{2 / 3}
$$

In accordance with the RILEM recommendation, 0.90 of the splitting tensile strength can be related as direct tension strength. Therefore, Eq.3.22 can be converted to Eq. 3.23, which is identical to the CEB formula, Eq. 3.20.

$$
f_{t m}^{\prime}=0.30\left(f_{c m}^{\prime}\right)^{2 / 3}
$$

It is obvious that the CEB formula Eq. 3.20 gives a better $f_{t}^{\prime}$ vs. $f_{c m}^{\prime}$ relationship than the ACI formula Eq. 3.19.

To investigate the effects of concrete age on the $f_{t s p}^{\prime}$ vi. $f_{\mathrm{cm}}^{\prime}$ relation, all the data were classified into five groups, according to concrete ages of less than 2 days, from 2 to 6 days, from 7 to 17 days, from 15 to 30 days, and greater than 30 days, respectively. By using the method of Analysis of Variance, it was found that the relationship was not affected by concrete age, as shown in Fig. 3.S. Therefore, Eq. 3.23 can be used universally. 


\subsubsection{Summary}

1. The relationship between split cylinder tensile strength and compressive strengths of concrete is essentially unchanged by its curing temperature, cement replacement by slag or flyash, or concrete age.

2. The tensile strength formula $f_{t}^{\prime}=0.30\left(f_{c}^{\prime}\right)^{2 / 3}$ can be used in almost any conditions.

3. The CEB Code gives a better representation for the relationship between tensile and compressive strengths than the ACI Code does.

\subsection{Discussion on Punching Shear}

One of the common cause of failures of flat-plate structures during construction is insufficient early-age punching shear capacity under relatively high construction loads. When two-way slabs are supported directly by columns as in flat slabs and flat plates, or when slabs carry concentrated loails, as in footings, shear near the column is of critical importance.

Unlike beam-type shear which leads to diagonal tension failure, punching shear failure surface extends from the bottom of the slab at the support diagonally upwards to the top surface. The angle of the inclination with the horizontal depends on the nature and amount of reinforcement in the slab. Although many equations have been proposed since early 1950's, the failure mechanism is not fully understood.

Many researchers believe that punching failure is caused by the failure of concrete in tension, as in the case of shear failure in beams. Therefore, punching shear capacity proportional to $\sqrt{f_{c}^{\prime}}$ is proposed by the ACT-CSA code because square root is used to calculate the tensile strength. But in Europe, the cubic root relation is widely accepted.

In 1990, Gardner ${ }^{3.9}$ reviewed the most popular recently used formulae 
with his experimental investigation as well as the data reported by Elstner and Hognestad ${ }^{3.6}$, Mowrer and Vanderbilt ${ }^{3.15}$, Bazant and $\mathrm{CaO}^{3.1}$, and $\mathrm{Moe}^{3.14}$. Gardner concluded that the punching shear capacity is proportional to the cubic root of concrete strength and steel ratio, and found that ACI-CSA code equations are too conservative. An equation similar to that of BS8110:1985 Code was proposed as follows:

$$
v_{u}=0.99\left(\rho f_{c}^{\prime}\right)^{1 / 3}(400 / d)^{1 / 4}
$$

where:

$$
\begin{aligned}
& v_{\iota}=\text { shear strength in } \mathrm{MPa} ; \\
& d=\text { effective slab depth in } m m ; \\
& \rho=\text { steel ratio; and } \\
& f_{c}^{\prime}=\text { cylinder strength in } \mathrm{MPa} .
\end{aligned}
$$

In the same year, Grira ${ }^{3.11}$ continued Gardner's investigation by adding his newly-performed experimental data. An equation, which is similar tc that proposed by Gardner, was derived by using statistical anaiysis:

$$
P_{\mathrm{u}}=4.61 A_{\mathrm{c}} \rho^{1 / 4}\left(f_{c}^{\prime} / d\right)^{1 / 3}
$$

where, $P_{u}$ is ultimate punching strength; $\hat{p}_{i} f_{c}^{\prime}$ and $d$ have the same meaning as those in Eq. 3.24; and $A_{c}$ is failure surface, determined by:

$$
A_{c}=2.2 \pi(c+2 d) d
$$

where $c$ is the equivalent diameter of the load area. For a juare column, $c$ is equal to the side length.

Eq. 3.25 indicates that punching stear strength is proportional to the cubic root of concrete strength, pid is affected by steel ratio. The curves given by Grira aiso showed inat this relationship is basically not influenced by the concrete age. That means that the relationship is time-independent.

From the discussion, tia following conclusions were made: 
1. Punching shear capacity is propurtional to the cubic root of concrete strength and steel ratio.

2. ACI-CSA code equation for punching shear strength is too conservative; BS8110:1985 gives a reasonable representation. 


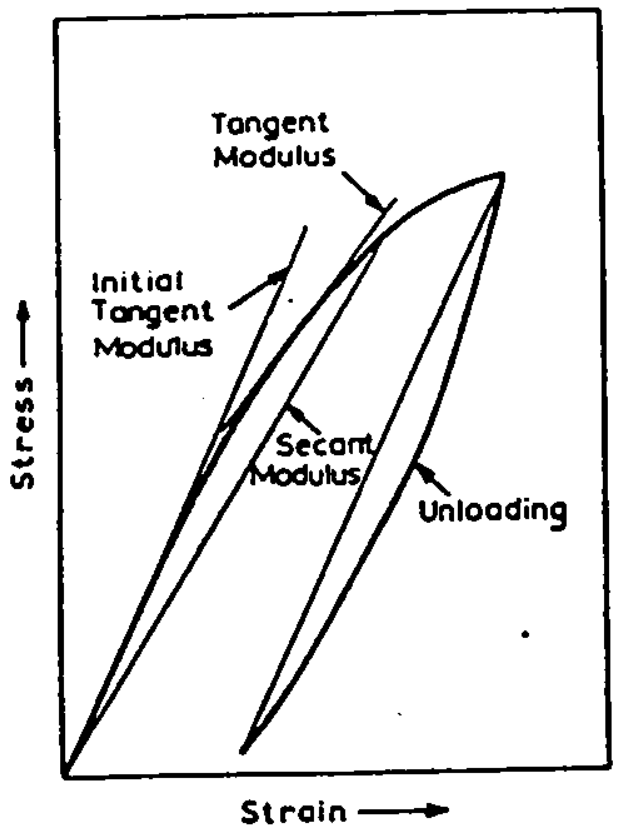

Figure 3.1: Stress-strain relation curve for concrete

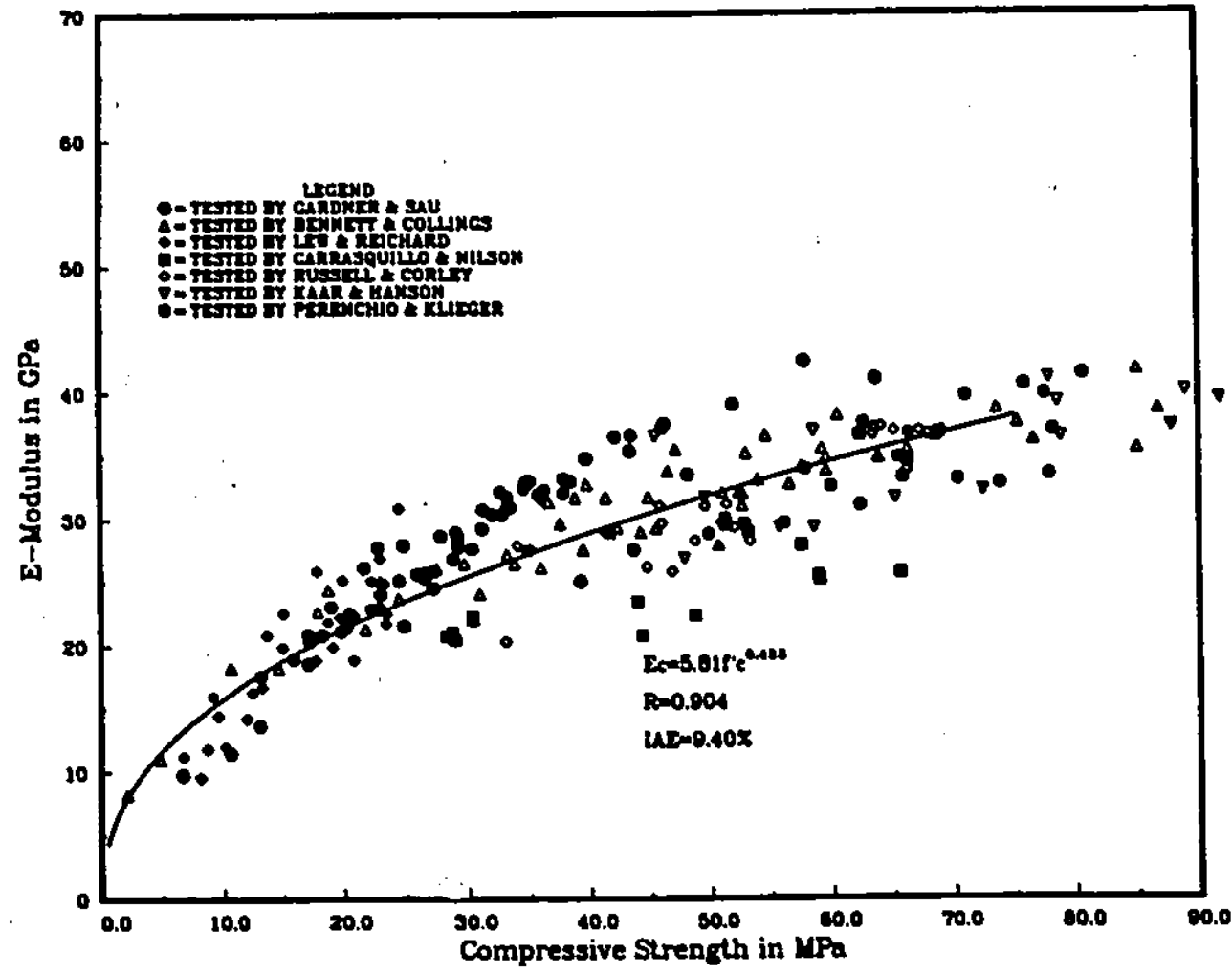

Figure 3.2: The best-fit empirical curve for $E_{c}$ vs. $f_{c}^{\prime}$ relation 


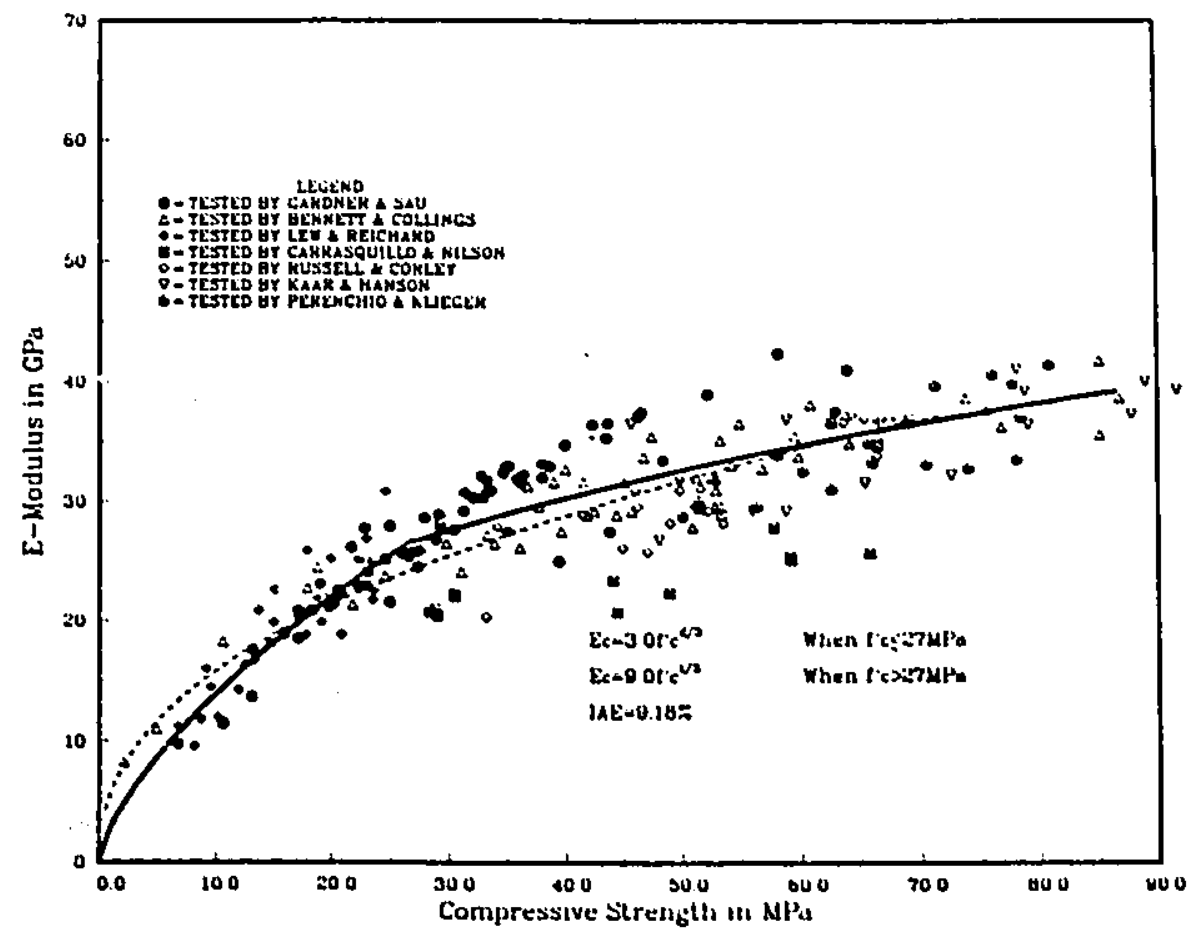

Figure 3.3: The proposed formula for modulus of elasticity

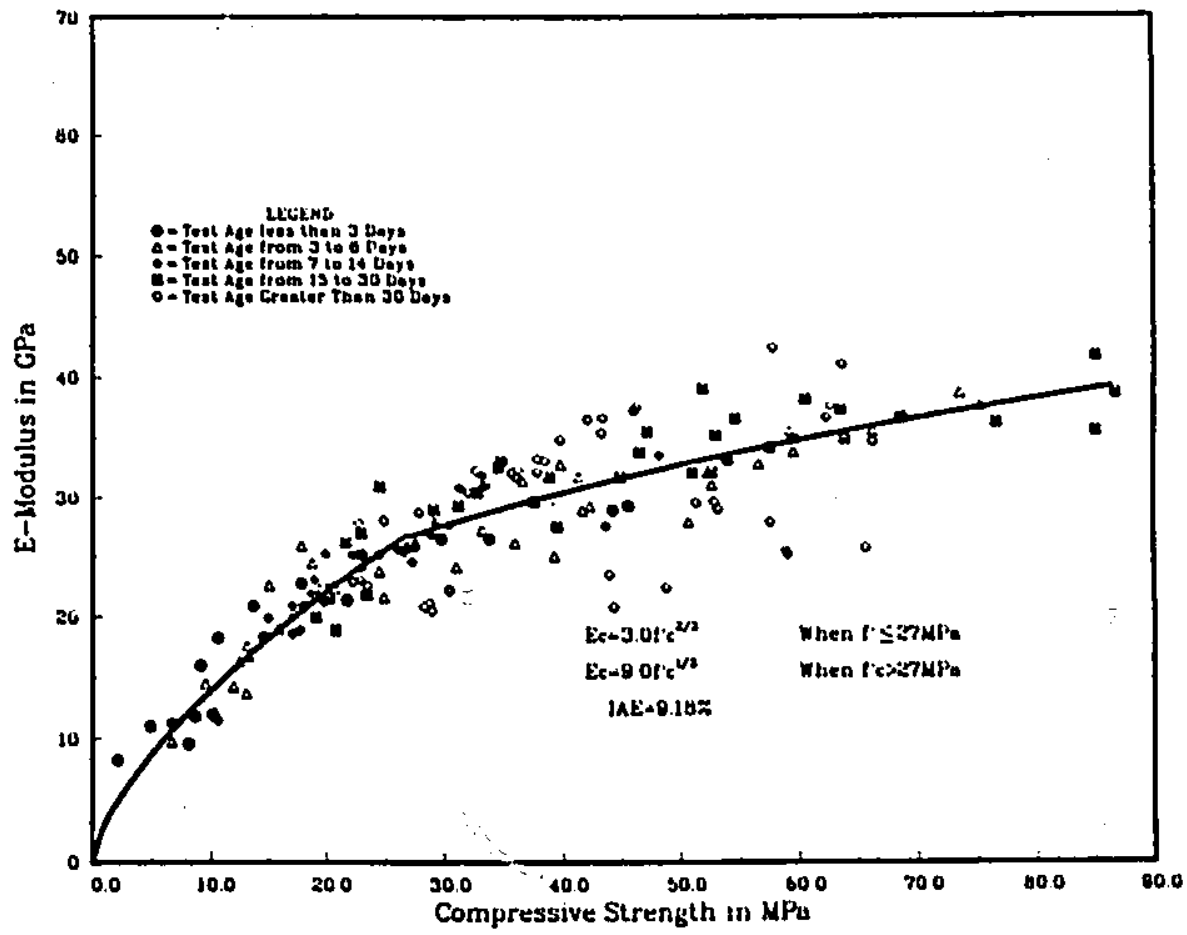

Figure 3.4: Test data classified by the age at testing 


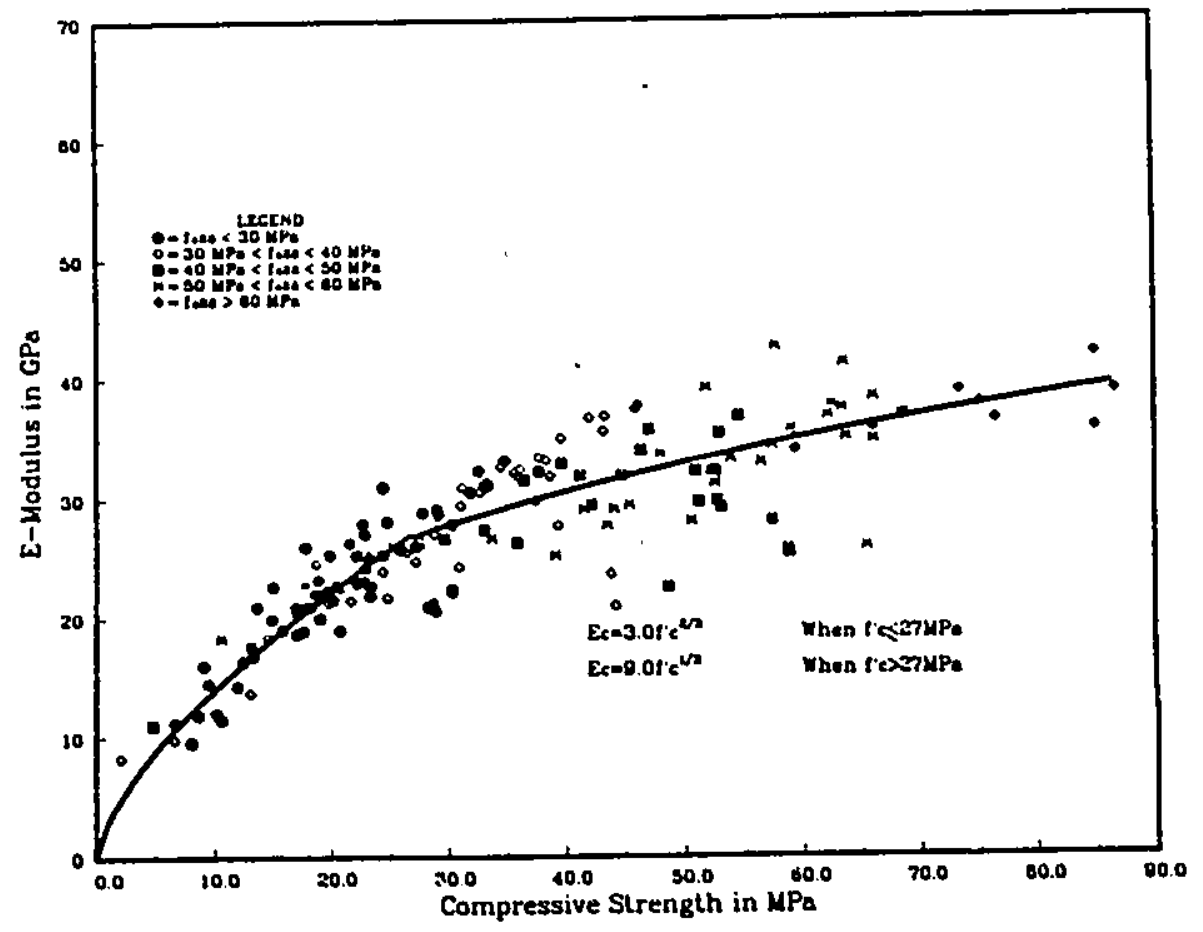

Figure 3.5: Test data classified by the 28-day strength

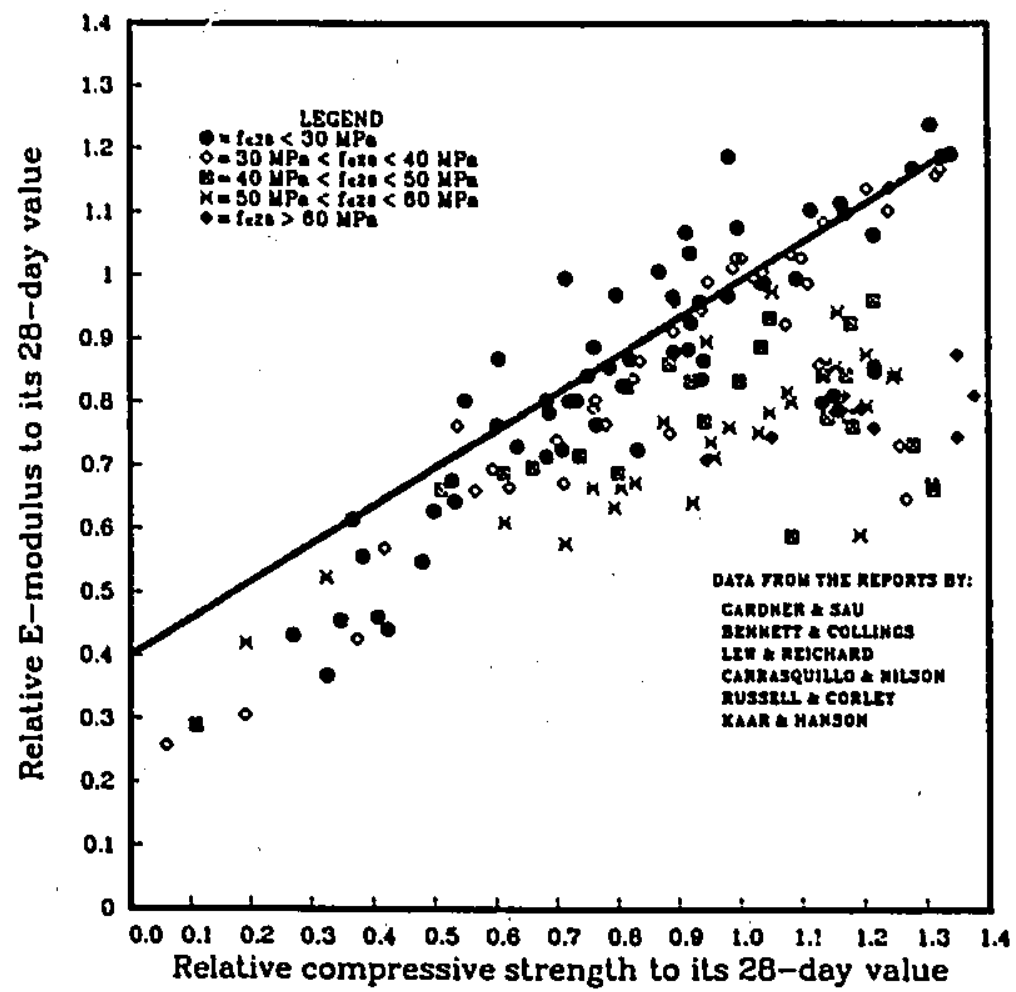

Figure 3.6. Relationship between relative strength and relative modulus 


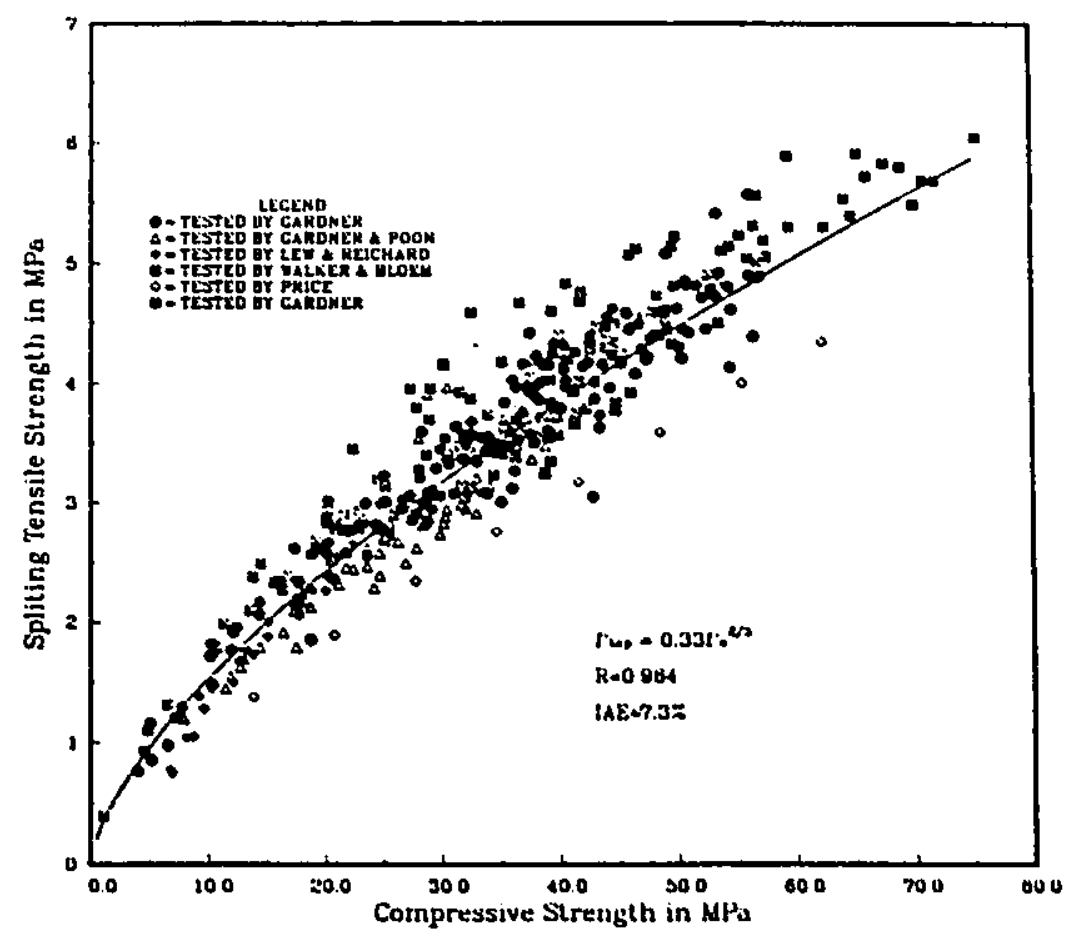

Figure 3.7: Relationship between tensile and compressive strengths

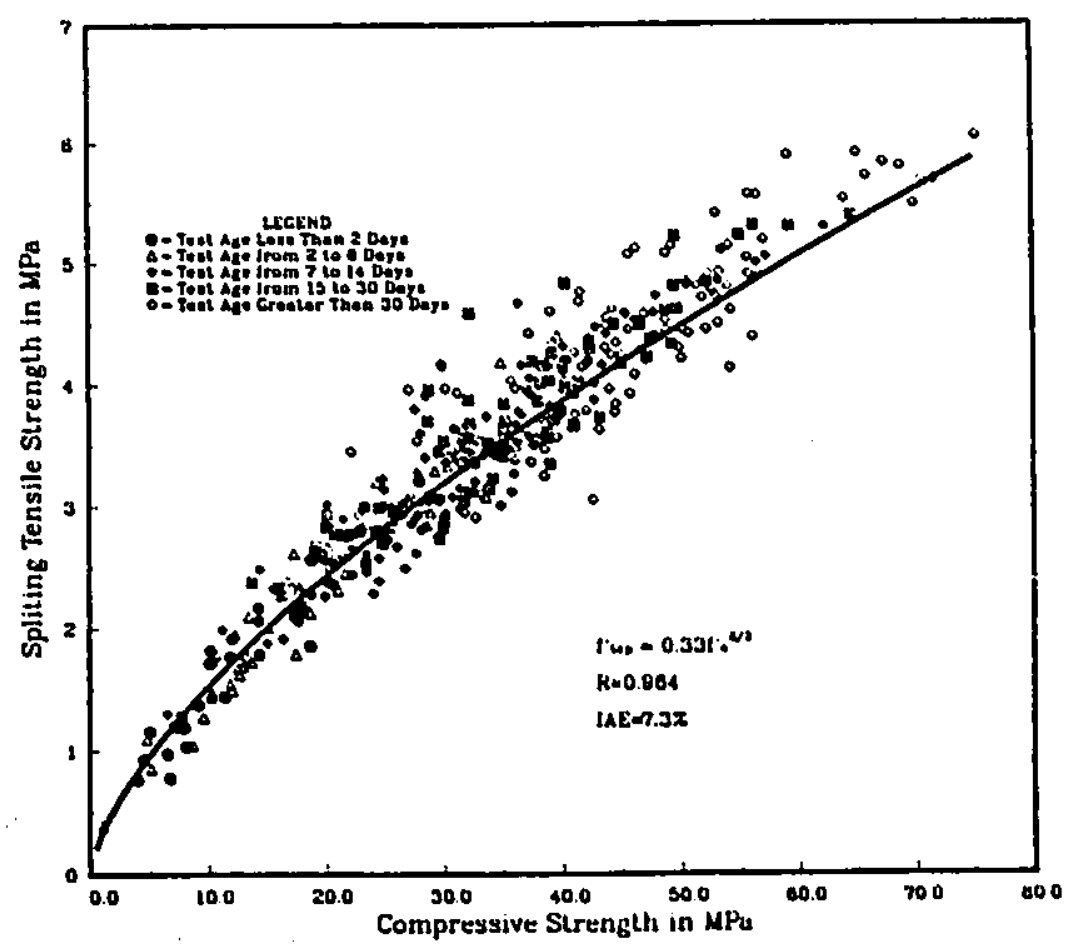

Figure 3.8: Test data classified by the age at testing 


\section{Chapter 4}

\section{Time Dependent Deformation}

To consider the long-term response of a reinforced concrete structure subjected to the early-age load, it is necessary to take account the time dependent effects of shrinkage and creep. Although shrinkage and creep have been studied for decades, the roles are still not fully understood because of the complexities.

Shrinkage which takes place while the concrete is still in the plastic state is known as plastic shrinkage. It undergoes a volumetric contraction whose magnitude is of the order of one percent of the absolute volume of dry cement $t^{4.25}$. Withdrawal of water from hardened concrete stored in unsaturated air causes drying shrinkage. A large part of this contraction is irreversible and should be distinguished from the reversible moisture movement caused by alternating storage under wet and dry conditions.

Although creep is observed for all materials, the fundamental basis for creep of concrete must be quite different from those of metals, because significant volume changes occur at ambient temperatures and the presence of moisture in the material plays an important role. It is commonly assumed that creep and shrinkage are interrelated phenomena because there are a number of similarities in that both are affected by the same phenomena. The strain-time curves are similar, experimental parameters affect creep in much the same way 
as shrinkage, the magnitudes of the strains are same, and include a considerable amount of irreversibility.

In addition, creep and shrinkage are not independent phenomena to which the principle of superposition can be applied, and in fact the effect of shrinkage on creep is to increase the magnitude of creep. However. because all the data on creep were obtained on the assumption of the additive properties of creep and shrinkage, the discussion will consider creep as the deformation in excess of shrinkage. Therefore, the overall increase in strain of a stressed and drying member is assumed to consist of shrinkage (equal to that of a similar unstressed member) and of a change in strain due to creep. The creep is a function of the ambient humidity while concrete is stressed.

For this reason, shrinkage and creep have been studied individually, and many formulae have been developed for the prediction of shrinkage and creep. The most commonly used approaches are those of the ACI and the CEB, in which the principle of superposition is applied.

The objective of this study is to examine the ACI and CEB methods for prediction of shrinkage and creep, particularly with regard to early age phenomena, and to modify the methods to fit the published data.

\subsection{Shrinkage}

\subsubsection{Introduction}

It is known that shrinkage of concrete is influenced by numerous factors, among which the most important are drying-out time, dimensions of the structure, relative humidity and temperature of the environment, method and period of curing, type and quantity of cement, quantity of water, type, quantity and distribution of aggregate, and admixture used. Since it is impossible to take all the factors into account, according to what factors should be consid- 
ered and how to take them into consideration, a number of shrinkage prediction models have been developed during the last two decades. Among these the ones proposed by ACI Committee 209 (1982), the 1978 CEB-FIP Model Code, and the recently proposed CEB-FIP 1990 Model Code are discussed.

\section{ACI 209-82}

In 1982, ACI Committee $209^{4.1}$ proposed an empirical method to predict shrinkage behavior. The shrinkage after 7 days curing for moist cured concrete is given by:

$$
\epsilon_{s h t}=\frac{t}{35+t} \epsilon_{s h u}
$$

similarly, shrinkage after 1 to 3 days curing for steam cured concrete is given by:

$$
\epsilon_{s h t}=\frac{t}{55+t} \epsilon_{s h u}
$$

where $t$ is the time in days after shrinkage is considered, that is, after the end of the initial wet curing; $\epsilon_{\text {sht }}$ is the shrinkage at time $t$, and $\epsilon_{\text {shu }}$ is the ultimate shrinkage

$$
\epsilon_{\text {shu }}=780 \times 10^{-6} \gamma_{\text {sh }}
$$

where, $\gamma_{s h}$ represents the product of correction factors for non-standard conditions, of which ambient relative humidity, member minimum thickness, concrete consistency, fine aggregate content, cement content and air content are considered.

\section{CEB-FIP Model Code 78}

The major relationship between factors in CEB-FIP Model Code $1978^{4.9}$ were originally presented in graphical form. Later, analytical expressions were provided to meet the need for computer calculation. Shrinkage strain developed at time $t$ is expressed by:

$$
s h(t)=s h_{1} \operatorname{sh}_{2}\left[\bar{S}(t)-\bar{S}\left(t_{0}\right)\right]
$$


where:

$t$ : age of concrete at time considered;

$t_{o}$ : age of concrete from which the affect of shrinkage to be considered;

$s h_{1}$ : ultimate shrinkage strain, depending on environmental relative humidity $(\mathrm{RH})$;

$s h_{2}$ : modification factor, depending on the volume to surface area ratio (V/S) of the element and $\mathrm{RH}$;

$\bar{S}(t)$ : time function, with

$$
\bar{S}(t)=\left(\frac{t}{\bar{\Lambda}\left(h_{0}\right)+t}\right)^{K^{\prime}\left(h_{0}\right)}
$$

where:

$$
\begin{array}{r}
K\left(h_{0}\right)=11.8 h_{0}+16 \\
K^{-\prime}\left(h_{0}\right)=\exp \left(-0.0027 h_{0}+0.32 / h_{0}+\ln \left(0.22 h_{\circ}^{0.4}\right)\right) \\
h_{0}=\lambda 2(V / S)
\end{array}
$$

The value of $\lambda$ depends on $\mathrm{RH}$ of the environment, from 1.0 (for $R H=$ $40 \%$ ) to 30.0 (for $R H=100 \%$ ).

\section{CEB-FIP Model Code 90}

The recently proposed CEB-FIP Model Code $1990^{4.10}$ presented the following model for shrinkage prediction:

$$
\varepsilon_{c s}=\varepsilon_{c s o} \beta_{s}\left(t-t_{s}\right)
$$

where:

$\varepsilon_{\text {cso: }}$ notional shrinkage coefficient;

$\beta_{g}$ : coefficient to describe the development of shrinkage with time;

$t$ : age of concrete in days; and

$t_{g}$ : age of concrete in days at the beginning of shrinkage. 
The notional shrinkage coefficient may be obtained from:

$$
\varepsilon_{c s o}=\varepsilon_{s}\left(f_{c m}\right) \beta_{R H}
$$

with

$$
\varepsilon_{s}\left(f_{c m}\right)=\left(250+\beta_{s c}\left(75-f_{c m}\right)\right) 10^{-6}
$$

where:

$f_{c m}$ is the compressive strength of concrete in $N / \mathrm{mm}^{2}$ at the age of 28 days;

$\beta_{s c}$ : coefficient which depends on type of cement, with

$\beta_{s c}=3$ for normal or slowly hardening cement;

$\beta_{s c}=5$ for rapid hardening cement;

$\beta_{s c}=9$ for rapid hardening high strength cement;

and

$$
\begin{array}{ll}
\beta_{R H}=-1.55 \beta_{s R H} \text { for } 40 \% \leq R H<99 \% \\
\beta_{R H}=0.25 \quad \text { for } R H \geq 99 \%
\end{array}
$$

where:

$$
\beta_{, R H}=1-\left(\frac{R H}{100}\right)^{3}
$$

where $R H$ in \%.

The development of shrinkage with time in given by:

$$
\beta_{s}\left(t-t_{s}\right)=\left(\frac{t-t_{s}}{0.035 h_{o}^{2}+t-t_{s}}\right)^{0.5}
$$

where $h_{0}$ is notional size of member in $\mathrm{mm}$, defined as:

$$
h_{0}=\frac{2 A_{c}}{u}
$$

where $A_{\mathrm{c}}$ is the cross-section and $u$ is the perimeter of the member in contact with the atmosphere. 


\section{Bazant \& Panula}

In addition to these code models, the model proposed by Bazant and Panula 4.2 in 1978 has obtained wide acceptance. This model differs from the essentially empirical equations discussed so far in that it combines theory with empiricism. The fundamental theory used in this model is that of diffusion. which, according to the authors ${ }^{4.3}$, is the governing physical model for the drying process of concrete. The model includes detailed concrete composition of mix parameters and a step-wise temperature effect in the estimation of shrinkage. In 1982, ACI Committee 209 recommended the use of some of the formulations in this model for special structures. In this model, shrinkage is estimated from:

$$
s h(t)=s h_{0} K_{R H} S\left(t, t_{s}\right)
$$

where:

$K_{R H}: \mathrm{RH}$ effect on shrinkage;

$s h_{0}$ : ultimate shrinkage, with:

$$
\begin{array}{r}
s h_{0}=s h_{f} \frac{E(\tau+600)}{E\left(t_{s}+A\right)} \\
s h_{f}=1210-\frac{880}{390 Z^{-4}+1} \\
E(t)=E(2 \delta)\left(\frac{t}{4+0.85 t}\right)
\end{array}
$$

where:

$s h_{f}$ : final shrinkage in $10^{-6}$;

A: coefficient, see Eq. 4.20;

$Z$ : a factor depending on concrete mix (except cement content);

$E(t)$ : modulus of elasticity of concrete at age $t$.

The time function

$$
S\left(t, t_{s}\right)=\left(\frac{t-t_{s}}{A+t-t_{s}}\right)^{0.5}
$$


where:

$$
\begin{array}{r}
A=1.06667\left(K_{s} \frac{V}{S}\right)^{2} / C_{1}\left(t_{s}\right) \\
C_{1}\left(t_{0}\right)=C_{7} K_{T}^{\prime}\left(0.05+\left(6.3 / t_{s}\right)^{0.5}\right) \\
C_{7}=\frac{1}{8}(W / C) c-12.0\left(7 \leq C_{7} \leq 21\right) \\
K_{T}^{\prime}=\frac{T}{23} \exp \left(\frac{5000}{296}-\frac{5000}{273+T}\right)
\end{array}
$$

Where, $K_{s}$ is the shape factor, depending on the shape of the cross-section:

$K_{s}=1.00$ for an infinite slab;

$K_{s}=1.15$ for an infinite cylincler;

$K_{\mathrm{s}}=1.25$ for an infinite prism;

$K_{s}=1.30$ for a sphere;

$K_{\Perp}=1.55$ for a cube; and

$c=$ cement content in $\mathrm{kg} / \mathrm{m}^{3}$;

$W / C=$ water/cement ratio;

$T=$ ambient temperature in ${ }^{\circ} \mathrm{C}$.

Because the Bazant-Panula model is too complicated for engineers to be of practical use, a simplified version, which ignores the temperature influence, effects of the increase of modulus of elasticity of concrete with time and modifications of $\mathrm{W} / \mathrm{C}$ and cement content on time function, was developed by the authors in 1980 . The basic structure of the new model remained the same as that proposed in 1978.

The shrinkage strain at time $t$ measured from the commencement of drying is given by

$$
s h(t)=k_{R H} s h_{u}\left(\frac{t}{t_{0}+t}\right)^{1 / 2}
$$

where $k_{R H}$ depends on the relative humidity $R H$ (in percent):

$$
\begin{gathered}
k_{R H}=1-10^{-6} R H^{3} \quad \text { for } R H \leq 99 \text { and } \\
k_{R H}=-0.2 \quad \text { for } R H=100
\end{gathered}
$$


The final shrinkage $s h_{u}$ is expressed as

$$
s h_{u}=(1300-970 y) 10^{-6}
$$

where

$$
\begin{gathered}
y=\left(390 z^{-4}+1\right)^{-1} \\
z=\left(1.25 \sqrt{a / c}+0.5(g / s)^{2}\left(\frac{1+s / c}{w / c}\right)^{1 / 3} 0.381 \sqrt{f_{c}(28)}-12>0.0\right.
\end{gathered}
$$

The cement ccntent $c$ is in $\mathrm{kg} / \mathrm{m}^{3} ; w / \mathrm{c}$ is the water-cement ratio; $a / c$ is the total aggregate-cement ratio; $g / s$ is the gravel-sand ratio; and $s / c$ is the sand-cement ratio. All ratios are proportions by weight. Sand $s$ is defined as aggregate of less than $4.7 \mathrm{~mm}$ size (passing sieve No.4) and remaining aggregate is considered as gravel, $g$. The 28 day cylinder strength $f_{c}(28)$ is in MPa.

$t_{0}$ depends on the size shape of the member and is given by

$$
t_{0}=4\left(k, \frac{V}{S}\right)^{2} \frac{1}{C_{1}\left(t_{s}\right)}
$$

in which V/S is the volume-surface ratio in $\mathrm{mm}$ and $k_{s}$ is a shape factor equal to 1.0 for a slab, 1.15 for a long cylinder, 1.25 for a long square prism, 1.30 for a sphere, and 1.55 for a cube. The coefficient $C_{1}\left(t_{0}\right)$ is proportional to the drying diffusivity at the commencement of drying and is given by

$$
C_{1}\left(t_{0}\right)=2.4+\frac{120}{\sqrt{t_{0}}}
$$

\subsection{Factors Influencing Shrinkage}

Shrinkage of concrete is affected by so many factors that it is impossible, and also not necessary, to be taken into consideration. Therefore, studying these individual influencing factors is essential to developing a shrinkage prediction model. 


\subsubsection{Curing Conditions}

To discuss the influence of curing conditions on shrinkage, both the length of period and temperature of curing are considered.

It is known that the shorter the period of curing, the greater is the plastic shrinkage of concrete. Cracks of concrete members caused by plastic shrinkage due to insufficient curing can be seen in many constructions, but how does the length of the curing period affect the drying shrinkage (shrinkage occurred after one or two days' curing)?

To arrive an understanding of the effect of curing on shrinkage, Kasai and Yokoyama $a^{4.13}$ tested specimens with curing periods of 3, 5, 8 and 24 hours respectively. The results showed that although the total shrinkage was affected by curing period, the long term shrinkage-time curves obtained by placing the age of one day as an origin are nearly identical. This means that curing period does not influence drying shrinkage as long as the specimens have the same values of maturity. The reason might be that after one day's hydration, a matrix of cement gel has formed, and the movement of cement gel particles in concrete accompanied with decreasing water by evaporation no longer occurs. The long term shrinkage will be generated by the drying of capillary water in the cement gel. So the drying shrinkage cured for one day takes the same value as that isred for a shorter period such as 3,5 , and 8 hours because they all have approximately sorne strength after one day, in spite of more capillary wate: being contained in the concrete cured for one day than that in the others.

Another reason is that as far as neat cement paste is concerned, the greater the quantity of hydicted cement, the smaller is the volume of unhydrated cement grains which restrain the shrinkage: thus prolonged curing leads to greater shrinkage ${ }^{4.22}$, but the paste becomes stronger with time and is able to restrain a larger fraction of its shrinkage tendency without cracking. However, if cracking takes place, e.g., around aggregate particles, the overall shrinkage measured on a concrete specimen apparently decreases. It was explained by sieville $e^{4.19}$ that well-cured concrete shrinks more rapidly and therefore the re- 
lief of sh:inkage stresses by creep is smaller; also, the concrete. being stronger. has an inherent low creep capacity. These factors may outweigh the higher tensile strength of well-cured concrete. and may lead to cracks. In view of this explanation it is understandable that the length of curing period is not an important factor in drying shrinkage.

The effect of curing temperature on shrinkage is also a complex phenomena.

With the increase of temperature, the weight loss of concrete becomes greater, but the case for shrinkage affected by temperature is not so simple.

Specimens cured at different temperatures and the same relative humidity were tested by Kasai and Yokoyama ${ }^{4.13}$. They found that shrinkage increased with increased curing temperature from a very early age (about 5 to 10 hours, depending on the temperature), but after that the rate of shrin!.age decreased with the increase of temperature.

For high temperature curing, the hydration rate becomes rapid, the high strength of the gel matrix is abie to restrain a large fraction of its shrinkage tendency. On the other hand, at very early ages, high temperature increases the amount of water loss which develops the plastic shrinkage. Therefore, it is not surprising that contradictory results on the effects of curing temperature have been observed. In general temperature effects the concrete maturity before drying shrinkage begins, and a strong concrete decreases drying shrinkage. On the other hand, a higher temperature after curing increases the process of water diffusion, and therefore, the concrete shrinks faster than in the lower temperature.

\subsubsection{Relative Humidity}

Although it is found that the magnitude of the ultimate shrinkage is largely independent of the rate of drying, the relative humidity of the medium surrounding the concrete greatly affects the magnitude of shrinkage. 


\begin{tabular}{|l|l|l|l|l|l|l|l|}
\hline RH (\%) & 40 & 50 & 60 & 70 & 80 & 90 & 100 \\
\hline ACI 82 & 1.00 & 0.90 & 0.80 & 0.70 & 0.60 & 0.30 & 0 \\
\hline CEB 78 & 1.00 & 0.89 & $0.7 i$ & 0.62 & 0.48 & 0.25 & -0.19 \\
\hline CEB 90 & 1.00 & 0.93 & 0.84 & 0.70 & 0.52 & 0.29 & -0.17 \\
\hline BP 78 & 1.00 & 0.93 & 0.84 & 0.70 & 0.52 & 0.29 & -0.17 \\
\hline AS 88 & 1.00 & 0.83 & 0.67 & 0.50 & 0.33 & 0.17 & 0 \\
\hline PROPOSED & 1.00 & 0.96 & 0.89 & 0.78 & 0.61 & 0.35 & 0 \\
\hline
\end{tabular}

Table 4.1: Relative effect of $\mathrm{R}^{-\top o ̈ n ~ l o n g-t e ̀ r m ~ s h i r i n k a ̀ g e ~}$

It is observed that concrete placed in dry air shrinks, but it swells in water or air with a relative humidity of 100 percent. This would indicate that the vapour pressure within the cement paste is always less than the saturated vapour pressure, and it is logical to expect that there is a certain humidity level at which the paste would be in hydral equilibrium. In fact, Lorman ${ }^{4.16}$ found this humidity to be 94 percent.

To consider the effect of ambient relative humidity on the final shrinkage, ACI Committee 209 (1982) proposed the following shrinkage correction factors for relative humidity greater than 40 percent:

$$
\begin{array}{ll}
\gamma_{\lambda}=1.40-0.010 \lambda & \text { for } 40 \leq \lambda \leq 80 \\
\gamma_{\lambda}=3.00-0.030 \lambda & \text { for } 80<\lambda \leq 100
\end{array}
$$

where, $\lambda$ is percent relative humidity. For an ambient relative humidity lower than 40 percent, value higher than 1.0 shall be used for $\gamma_{\lambda}$.

The relative effects of relative humidity on final shrinkage are listed in Table 4.1, with the final shrinkage at $R H=40 \%$ as the reference.

For CEB 78, CEB 90, and Bazant and Panula models, although the procedures and prediction results are very different from that of the ACI model, the variation of ultimate shrinkage with relative humidity in the different models is almost constant, with the exception that the ACI 82 model fails to predict 
swelling of concrete in a relative humidity of 100 percent.

\subsubsection{Concrete Composition}

In practice, moisture movement in hydrated cement paste, which essentially controls the drying shrinkage, is influenced by numerous simultaneously interacting factors, they are impossible to be studied individually: The main source of moisture-related deformation in concrete is the hydrated cement paste. Therefore, many attempts have been made to obtain expressions relating the drying shrinkage to volume fraction of hydrated cement paste in concrete.

Most theoretical expressions for predicting the drying shrinkage assume that the elastic modulus of cuncrete can provide an adequate measure of the degree of restraint against deformation. From the study in Chapter 3 it is known that the modulus of elasticity of concrete can be uniquely related to its compressive strength. Therefore, all the factors relating to concrete composition, can be expressed by the developed strength.

From this point of view, it is understandable that water or air content of cement affects shrinkage in so far as it reduces the strength of concrete. The fineness or chemical composition of cement is believed not to affect final shrinkage because it does not affect the strength if the maturity at which shrinkage begins is unchanged. This was demonstrated experimentally by Pickett ${ }^{4.21}$.

Lightweight aggregate usually leads to higher shrinkage, largely because the aggregate, having a lower modulus of elasticity, reduces the concrete strength, therefore, offers less restraint to the potential shrinkage of the cement paste.

The grading, maximum size and shape of aggregate have also been suggested as factors influencing the drying shrinkage, this is because these factors affect the modulus of elasticity and the strength of concrete. 


\subsubsection{Geometry of Concrete Member}

Because of resistance to water movement from the interior of concrete to the atmosphere, the rate of water loss is obviously controlled by the length of the path of traveled water, which is expelled during shrinkage. At a constant $\mathrm{RH}$, both the size and the shape of a concrete element determine the magnitude of drying shrinkage. It is convenient to express the size and shape parameters by a single quantity expressed in term of volume to surface area ratio. Because shrinkage is mainly caused by the diffusion of capillary water in cement gel, for the section with the same volume to surface ratio, the shrinkage will be affected slightly by the longitudinal dimension and the section shape.

It is believed that the increase in the dimensions of concrete elements can only delay the process of drying shrinkage, it cannot, however, reduce the ultimate shrinkage, although it is possible that, like size effect on strength, size might affect the ultimate shrinkage slightly. Because there is no enough information on the size effect on the ultimate shrinkage, it is assumed only to affect the shrinkage-time relationship.

\subsubsection{Time}

Diffusion of the adsorbed water and the water held by gel pores (under $50 \mathrm{~nm}$ ) of hydrated cement paste to large capillary voids within the system or the atmosphere is a time-dependent process which takes place over a long period: some movement has been observed even after 28 years ${ }^{4.26}$, but a part of the long term shrinkage may be due to carbonation. The rate of shrinkage decreases rapidly with time ${ }^{4.19}$, typically:

14 to 34 percent of the 20 year shrinkage occurs in 2 weeks;

40 to 80 percent of the 20 year shrinkage occurs in 3 months; and

66 to 85 percent of the 20 year shrinkage occurs in 1 years. 
An increase in the dimensions of concrete members is expected to slow down the relative rate of moisture flow from the interior to the onter surface of concrete. An increase in $\mathrm{RH}$ also slightly affects the relative shrinkige development because it also reduces the diffusion rate.

Traditionally: it is believed that there is an ultimate value for shrinkage within a limited time. However, review of Troxell's data ${ }^{4.26}$ shows that shrinkage does not reach an ultimate limit. but is proportional to $(\ln t)^{1 / 3}$.

\subsection{Shrinkage Prediction}

From the discussion of the previous section it can be seen that shrinkage is influenced by numerous factors. For practical purpose, only $\mathrm{RH}$, concrete relative strength when shrinkage begins, the 28 -day concrete strength, time, and volume to surface area ratio are to be considered.

Shrinkage is predicted by the final shrinkage and time function. The final shrinkage is a function of time, $\mathrm{RH}$, relative strength when shrinkage begins, and the 28-day strength of concrete member; the time function is affected by the geometry of concrete member. Since the final shrinkage itself is a function of time, the meaning of the proposed time function is different from the other time function.

\subsubsection{Final Shrinkage}

Final shrinkage has always been important for researchers and engineers who study the long-term deformation of concrete structures. Unfortunately, there are very few experimental data reported on very long term shrinkage. As discussed previously, shrinkage takes place even after 28 years, so there is no limit for final shrinkage.

Since very limited data are available, it is difficult to propose any model 
taking consideration all the affecting factors. Only the most important factors such as relative humidity and concrete strength were considered. By the use of computer optimization, the formula expressed as following was obtained.

$$
\varepsilon_{s h}\left(t_{f}\right)=\varepsilon_{s} \beta_{R H} l n^{1 / 3}\left(t_{f}-t_{o}\right)
$$

with

$$
\varepsilon_{s}=\left(650-5.5 K_{c} f_{c}\left(t_{0}\right)\right) \times 10^{-6}
$$

where:

$f_{c}\left(t_{0}\right)$ is the $t_{0}$ day (when shrinkage begins) concrete strength in $\mathrm{MPa}$;

$K=1$ for Type 10 cement concrete;

$K=0.5$ for Type 30 cement concrete; and

$\beta_{R H}=1.0-\left(\frac{R H}{100}\right)^{4}, \quad(R H$ in \%).

Table 4.2 shows a comp ison of the calculated final shrinkage by different models with the published data. The error coefficient $E$ was defined by Eq.4.34, and the final shrinkage values were obtained from the different reports. Because the strength tested by Brooks ${ }^{4.5}$ was based on $76 \times 152$ mm cylinders, a factor of 0.9 was used to account the size affect. One can see that the ACI model underestimates ultimate shrinkage in most cases, with $E=7.2 \%$; CEB 78 model pays too much attention to the age at which concrete begins to shrink, but fails to pay any attention to concrete properties, with $E=5.1 \%$. The recently proposed CEB 90 model first introduces the concrete strength as a measurement of concrete properties, but does not consider the concrete strength when shrinkage begins, so the result is not satisfactory, with $E=9.9 \%$; The error coefficient of the proposed model is $3.7 \%$.

It is clear that besides environmental conditions, it is concrete properties, which can be expressed by the 28-day strength, and its maturity when shrinkage begins that play most important roles on the final shrinkage. It should be mentioned that there is no enough information to get the predicted values from $\mathrm{BP}$ model, so there is no comparison with $\mathrm{BP}$ model. 
The error coefficient was defined as:

$$
E=\frac{1}{\bar{c}} \frac{\sqrt{\sum\left(c_{i}^{\prime}-c_{i}\right)^{2}}}{n}
$$

where:
$\bar{c}:$ mean value of observed shrinkage:
$c_{i}^{\prime}$ : estimated value of shrinkage
$c_{i}:$ observed value of shrinkage; and
$n$ : number of observation.

\subsubsection{Time Function}

The shape of time development function for concrete shrinkage is particularly important for extrapolation of short time shrinkage test data, which, if properly used, can greatly reduce predicticn error. The time function is also important when shrinkage strains developed in different periods of time are required, such as when the finite element method is used.

A hyperbolic function is commonly used to describe the time development of shrinkage:

$$
S\left(t, t_{0}\right)=\frac{\left(t-t_{0}\right)^{n}}{f+\left(t-t_{0}\right)^{n}}
$$

For ACI 82 model, $n=1, f=35$ for moist cured concrete and $f=55$ for steam cured concrete. Since the effect of size is not considered, it is not surprising to see that it does not fit the experimental data well (Fig.4.1).

For CEB 78 model, both $n$ and $f$ are functions of $\mathrm{V} / \mathrm{S}$ and $\mathrm{RH}$.

For CEB 90 model, $n=0.5$ and $f=0.14(V / S)^{2}$. The function is compared with experimental data in Fig. 4.2. It can be seen that by considering the $\mathrm{V} / \mathrm{S}$ effect, the time function of $\mathrm{CEB} 90$ gives a much better representation than that of $\mathrm{ACI} 82$, but it seems can be further improved.

Because there is no ultimate shrinkage for the proposed shrinkage prediction formula, the definition of the time function is different. Shrinkage at 


\begin{tabular}{|l|l|l|l|l|l|l|l|l|l|l|}
\hline Tested by & $f_{c m}$ & Type & $t_{\mathrm{o}}$ & $t$ & $\mathrm{RH}$ & Tested & ACI S2 & CEB 78 & CEB 90 & Prop \\
\hline Troxcll. $^{4.26}$ & 17.2 & 10 & 28 & 8400 & 50 & 1131 & 477 & 595 & 411 & 1053 \\
\hline Troxell.26 $^{4.26}$ & 17.2 & 10 & 28 & 7300 & 70 & 830 & 371 & 405 & 309 & 873 \\
\hline Hansen $^{4.11}$ & 41 & 30 & 8 & 1100 & 50 & 950 & 667 & 820 & 570 & 979 \\
\hline Bazant $^{4.4}$ & 32.2 & 10 & 7 & 1000 & 65 & 870 & 585 & 827 & 422 & 812 \\
\hline Bryant $^{4.8}$ & 50.1 & 10 & 8 & 1943 & 60 & 736 & 602 & 816 & 395 & 753 \\
\hline Brooks $^{4.5}$ & 20.8 & 30 & 14 & 3650 & 60 & 970 & 593 & 743 & 633 & 1045 \\
\hline Brooks $^{4.5}$ & 32.9 & 30 & 14 & 3650 & 60 & 933 & 593 & 743 & 560 & 990 \\
\hline Brooks $^{4.5}$ & 34.8 & 30 & 14 & 3650 & 60 & 756 & 593 & 743 & 548 & 951 \\
\hline Brooks $^{4.5}$ & 39.1 & 30 & 14 & 3650 & 60 & 756 & 593 & 743 & 522 & 962 \\
\hline Brooks $^{4.5}$ & 21.5 & 30 & 14 & 3650 & 60 & 1270 & 593 & 743 & 629 & 1042 \\
\hline Brooks $^{4.5}$ & 29.4 & 30 & 14 & 3650 & 60 & 990 & 593 & 7.3 & 581 & 1006 \\
\hline Brooks $^{4.5}$ & 31.8 & 30 & 14 & 3650 & 60 & 870 & 593 & 743 & 566 & 995 \\
\hline Brooks $^{4.5}$ & 38.9 & 30 & 14 & 3650 & 60 & 750 & 593 & 743 & 523 & 963 \\
\hline Keeton $^{4.14}$ & 45.2 & 30 & 8 & 897 & 20 & 1100 & 889 & 875 & 613 & 1017 \\
\hline Keeton $^{4.14}$ & 45.2 & 30 & 8 & 365 & 20 & 1205 & 1123 & 940 & 614 & 996 \\
\hline Keeton $^{4.14}$ & 45.2 & 30 & 8 & 365 & 20 & 1070 & 889 & 875 & 613 & 959 \\
\hline Keeton $^{4.14}$ & 45.2 & 30 & 24 & 365 & 20 & 980 & 632 & 638 & 541 & 932 \\
\hline Keeton $^{4.14}$ & 45.2 & 30 & 8 & 897 & 20 & 1015 & 1123 & 940 & 614 & 993 \\
\hline Keeton $^{4.14}$ & 45.2 & 30 & 8 & 897 & 50 & 1055 & 667 & 820 & 541 & 955 \\
\hline Keeton $^{4.14}$ & 45.2 & 30 & 3 & 365 & 50 & 1120 & 842 & 881 & 541 & 935 \\
\hline Keeton $^{4.14}$ & 45.2 & 30 & 8 & 365 & 50 & 1010 & 667 & 820 & 541 & 900 \\
\hline Keeton $^{4.14}$ & 45.2 & 30 & 24 & 365 & 50 & 935 & 632 & 638 & 541 & 875 \\
\hline Keeton $^{4.14}$ & 45.2 & 30 & 8 & 897 & 50 & 965 & 667 & 820 & 541 & 932 \\
\hline Keeton $^{4.14}$ & 45.2 & 30 & 8 & 897 & 75 & 775 & 482 & 813 & 358 & 696 \\
\hline
\end{tabular}

Table 4.2: Calculated final shrinkage by different models. $\left(\times 10^{-6}\right)$. 
any time $t$ can be calculated from:

$$
\varepsilon_{s h}(t)=\varepsilon_{s}, 3_{R H} \ln ^{1 / 3}\left(t-t_{0}\right) S\left(t . t_{v}\right)
$$

For long term shrinkage $\left(t=t_{f}\right) . S\left(t, t_{0}\right)=1$,

$$
\varepsilon_{s h}\left(t_{f}\right)=\varepsilon_{s} 3_{R H} \ln ^{1 / 3}\left(t_{f}-t_{0}\right)
$$

By comparing Eq. 4.36 with Eq. 4.3 , one gets:

$$
S\left(t, t_{0}\right)=\frac{\varepsilon_{s h}(t)}{\varepsilon_{s h}\left(t_{f}\right)}\left(\frac{\ln \left(t_{f}-t_{0}\right)}{\ln \left(t-t_{0}\right)}\right)^{1 / 3}
$$

To obtain the best fit time function with the experimental data, based on the theory of diffusion, it was assumed that

$$
f=A(V / S)^{2}
$$

where $A$ is a constant to be determined.

Since there are only two variables $A$ and $n$ in Eq.4.35, for a given value $A$, the best-fit value of $n$ with the experimental data can be easily determined using the error coefficient $E$ as the criterion of goodness. When value of $A$ changes, the result of $n$ value and $E$ value will change with $A$. The best-fit value of $A$ and $n$ occur at the point where $\mathrm{E}$ has the minimum value. By using computer optimization, it was found that the time function fits the data best when $A=0.02$ and $n=1.0$.

The comparison of the best-fit time function with experimental data is shown in Fig.4.3.

From Eq. 4.38 one can find that if the short-term shrinkage at time $t$ is known, the long-term shrinkage $\varepsilon_{s h}\left(t_{f}\right)$ can be calculated regardless the concrete properties.

\subsubsection{Proposed Method}

Shrinkage at any time $t$, starts from $t_{0}$, can be calculated by:

$$
\varepsilon_{s h}(t)=\varepsilon_{s} \beta_{R H} l^{1 / 3}\left(t-t_{o}\right) S\left(t, t_{o}\right)
$$


where $S\left(t, t_{0}\right)$ is time development function, expressed as:

$$
S\left(t, t_{0}\right)=\frac{\left(t-t_{0}\right)}{0.02\left(\frac{l^{*}}{S}\right)^{2}+\left(t-t_{0}\right)}
$$

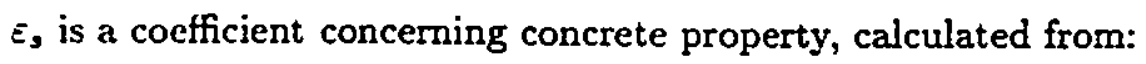

$$
\varepsilon_{s}=\left(650-5.5 K^{-} f_{c}\left(t_{0}\right)\right) \times 10^{-6}
$$

where:

$f_{c}\left(t_{0}\right)$ is the $t_{0}$ day (when shrinkage begins) concrete strength in $\mathrm{MPa}$;

$K=1$ for Type 10 cement concrete;

$K=0.5$ for Type 30 cement concrete; and

$\beta_{R H}=1.0-\left(\frac{R H}{100}\right)^{4}, \quad(R H$ in \%).

The comparison of the proposed shrinkage prediction model with the published experimental data is shown in Fig. 4.4 to Fig. 4.9.

\subsection{Creep}

\subsubsection{Introduction}

The relation between stress and strain for concrete is a function of time: the gradual increase in strain with time under loading is due to creep. Creep can then be defined as the increase in strain under a sustained stress. Since this increase can be several times larger than the strain on loading, creep is of considerable importance in structural design and analysis.

Usually, total creep is classified into basic creep and drying creep. Basic creep is defined as the increase in strain under sustained load without diffusion of water $-\mathrm{ie}$, the creep occurring at a relative humidity of $100 \%$. Consequently, basic creep has no size dependency. Drying creep is defined as the creep in addition to the basic creep due to the diffusion of water under the sustained 
stress. Obviously, drying creep depends upon the relative humidity and the member size.

The phenomenon of creep is ext remely complicated. Many theories have been proposed to describe the mechanism of creep in concrete ${ }^{4.19}$. However, no single theory accounts for all the observed phenomena. It is generally agreed that creep is attributable. in varying degrees, to a number of mechanisms, including:

(a) Sliding of the colloidal sheets in the cement gel between the layers of absorbed water (viscous flow);

(b) The expulsion and decomposition of the interlayer water within the cement gel (seepage);

(c) Elastic deformation of the aggregate and gel crystals as viscous flow and seepage occur within the cement gel (delayed elasticity); and

(d) Local fracture within the cement gel involving the breakdown (and formation) of physical bonds (microcracking).

The magnitude of creep and its rate of development are influenced by many factors. Some are properties of the concrete mix, while others depends on the environmental and loading conditions. The major influencing factors are:

- relative strength when loaded

- sustained loading time

- concrete composition

- moisture state

- temperature

Basically the factors influencing sl.rinkage will influence creep in the same way, but the curing history of concrete, 'temperature of exposure, and the magnitude of applied stress are known to affect creep more than shrinkage; probably because of a greater influence of these factors on the transition-zone 
characteristics. An increase in concrete strength causes a decrease in creep; higher stren; ih, better quality concrete creeps less. Creep also depends on the water-cement ratio, cement type, aggregate type and size as these influence concrete strength. Depending on the curing history of a concrete member, creep strains in practice may be significantly different from those in a laboratory test carried out at a constant humidity. For instance, drying cycles can increase microcracking in the transition zone and thus increase creep.

The temperature to which concrete is exposed can have two counteracting effectors on creep. If a concrete member is exposed to a higher than normal temperature during the curing process before it is loaded, the strength will increase and the creep strain will be less than that of a corresponding concrete stored at a lower temperature. On the other hand, exposure to high temperature dirring the period under load can increase creep. Neville $e^{4.19}$ found that in a range 70 to $160^{\circ} \mathrm{F}$, the 350-day creep increased approximately 3.5 times with temperature.

Numerous experiments on hardened concrete reported by Neville 4.19 show that creep is approximately proportional to the stress for stress levels up to $40 \%$ of the strength at the time of loading. This means that creep deformation can be superpositioned because the actual stresses in a conventionally designed structural member is unlikely to exceed this value.

Another important investigation, in which the loading age varied from 0.5 to about 5000 days, was carried out by RILEM Cammittee $42-C E A^{4.23}$. The comparison was made by dividing the creep deformation obtained for different loading ages by the creep deformation obtained at an age of 28 days. The result showed a significant dependency on loading age, particularly at an early age. There was a considerable spread at early ages, mainly caused by the fact that the differences in degree of hydration are more marked at an early age.

A large number of empirical equations have bien developed for the prediction of creep in concrete. Under various conditions of loading and drying, 
these methods may range from simple equations to quite complex relationships that require a computer for iheir analysis. There is considerable disagreement concerning the different mathematical approaches to creep prediction because of differences in the choice of function used to represent different aspects of creep. Among those, the approaches proposed by ACI, C.B and Bazant and Panula ${ }^{4.2}$ are most commonly used models.

\section{ACI Committee 209-82}

For a loading age of 7 days and moist-cured concrete, the creep coefficient $\phi(t)$ at time $t$ can be estimated from

$$
\phi(t)=\frac{\left(t-t_{o}\right)^{0.6}}{10+\left(t-t_{o}\right)^{0.6}} \phi_{u}
$$

where:

$t_{0}$ is the age of concrete at time of load in days; and

$\phi_{u}$ is the value of the ultimate creep coefficient.

Like shrinkage, the problem lies in selecting a suitable value for $\phi_{u}$. ACI Committee 209 recommends an average value of 2.35 if experimental data are not available for an estimation of $\phi_{u}$ in the standard condition. Correction factors can be used to adjust for different conditions: relative humidity and age at loading:

$$
K_{R H}=1.27-0.0067 R H
$$

where $R H$ is the relative humidity in \%, and

$$
K_{l a}=1.25 t_{0}^{-0.118}
$$

Under sustained st.ess, the strain increase with time due to creep and the total strain - instantaneous plus creep - a.t time $t\left(>t_{0}\right)$, can be calculated from

$$
\varepsilon_{c}(t)=\frac{\sigma_{o}\left(t_{o}\right)}{E_{c}\left(t_{o}\right)}\left(1+\phi\left(t, t_{o}\right)\right)
$$

where $\sigma_{c}\left(t_{o}\right)$ is the concrete stress and $E_{c}\left(t_{0}\right)$ is the modulus of elasticity of concrete at age $t_{0}$, the time of application of the stress. 


\section{CEB-FIP 1978}

In Europe the creep coefficient has a different meaning from that employed in North American. The total strain at time $t$, instant aneous plus creep, due to a constant stress $\sigma_{c}\left(t_{0}\right)$ introduced at time $t_{o}$ is calculated as:

$$
\varepsilon_{c}(t)=\frac{\sigma_{c}\left(t_{0}\right)}{E_{c}\left(t_{0}\right)}\left(1+\frac{E_{c}\left(t_{o}\right)}{E_{c}(2 \delta)} \phi\left(t, t_{0}\right)\right)
$$

where $E_{c}\left(t_{o}\right)$ and $E_{c}(28)$ are the moduli of elasticity at ages of $t_{o}$ and 28 days; $\phi\left(t, t_{0}\right)$ is creep coefficient.

Creep depends upon the age at loading $t_{o}$ and the length of the period $t_{0}$ to $t$ when the value of creep is considered. When the ambient temperature is different from $20^{\circ} \mathrm{C}$, or when special cement is used, the actual ages to be used in the creep equation must be adjusted by the Nurse-Saul maturity function. The adjusted age is given by:

$$
t_{\mathrm{o}} \text { or } t=\frac{\alpha_{c}}{30} \sum\left(\left(T_{i}+10\right) \Delta t_{i}\right)
$$

where $T_{i}$ is the average daily temperature in ${ }^{\circ} C ; \Delta t_{i}$ is the number of days during which the average daily temperature is $T_{i}$. The coefficient $\alpha_{c}$ depends on the type of cement:

$$
\begin{aligned}
& \alpha_{c}=1 \text { for normal or slow hardening cement; } \\
& \alpha_{c}=2 \text { for rapid hardening cement; and } \\
& \alpha_{c}=3 \text { for rapid hardening high-strength cement. }
\end{aligned}
$$

Creep depends upon a notional thickness of the element, defined by:

$$
h_{\circ}=\lambda \frac{2 A_{c}}{u}
$$

where $\lambda$ is a coefficient depending on the ambient relative humidity; $A_{c}$ and $u$ are the area of concrete cross section of the element and the length of its perimeter in contact with the atmosphere.

The creep coefficient $\phi\left(t, t_{0}\right)$ is given by:

$$
\phi\left(t, t_{0}\right)=\left(\beta_{a}\left(t_{o}\right)+0.4 \beta_{d}\left(t, t_{0}\right)+\phi_{f}\left(\beta_{f}(t)-\beta_{f}\left(t_{o}\right)\right)\right.
$$


where:

$$
\begin{array}{r}
\beta_{a}\left(t_{o}\right)=0.8\left(I-\frac{f_{c}\left(t_{0}\right)}{f_{c}(\infty)}\right) \\
\beta_{d}\left(t-t_{0}\right)=1-\exp \left(-0.02\left(t-t_{0}\right)\right) \\
\beta_{f}(t)=\left(\frac{t}{t+t_{f}}\right)^{1 / 3}
\end{array}
$$

where $t_{f}$ is a period of time in days depending on the effective thickness $h_{0}$.

$$
\phi_{f}=\phi_{f 1} \phi_{f 2}
$$

where $\phi_{f 1}$ and $\phi_{f 2}$ are dimensionless coefficients which respectively depend on the ambient relative humidity $R H$ and effective thickness $h_{0}$.

$$
\begin{gathered}
\phi_{f 1}=\frac{1}{9}\left(0.0002 R H^{3}-0.043 R H^{2}+2.57 R H\right)-2.2 \\
\phi_{f 2}=1.12\left(1+\exp \left(-0.44 h_{0}^{0.58}\right)\right)
\end{gathered}
$$

\section{CEB-FIP 1990}

The recently proposed creep prediction model in CEB-FIP Model Code 1990 is similar to the 1978 model, but is significantly simplified. The creep coefficient, which has the same meaning as that in CEB 78, may be calculated from:

$$
\phi\left(t, t_{0}\right)=\phi_{o} \beta_{c}\left(t-t_{0}\right)
$$

where:

$\phi_{0}:$ notional creep coefficient (Eq. 4.59)

$\beta_{c}$ : coefficient to describe the development of creep with time after loading (Eq. 4.63)

The age of concrete at loading $t_{0}$ should be adjusted by Arrhenius function:

$$
t_{0}=\sum \exp \left(-\frac{4000}{273+T\left(\Delta t_{i}\right)}-13.7\right) \Delta t_{i}
$$

where $T\left(\Delta t_{i}\right)$ is temperature in ${ }^{\circ} \mathrm{C}$ during the time period $\Delta t_{i}$. 
The notional creep coefficient may be estimated from:

$$
\phi_{0}=\phi_{R H} \partial\left(f_{c} m\right) \beta\left(t_{0}\right)
$$

with

$$
\begin{array}{r}
\phi_{R H}=1+\frac{1-R H / 100}{0.08 h_{\circ}^{1 / 3}} \\
\beta\left(f_{c m}\right)=\frac{21 . S}{3+\sqrt{f_{c m}}} \\
\beta\left(t_{o}\right)=\frac{1}{0.1+t_{o}^{0.18}}
\end{array}
$$

where $R H, f_{c m}$ and $h_{0}$ have the same meaning with those in CEB 78.

The time development function of creep is given by:

$$
\beta_{c}\left(t-t_{0}\right)=\left(\frac{t-t_{0}}{\beta_{H}+t-t_{0}}\right)^{0.3}
$$

with

$$
\beta_{H}=1.5\left(1+0.00012\left(\frac{R H}{50}\right)^{18}\right) h_{\circ}+250 \leq 1500 \mathrm{~mm}
$$

\section{Bazant and Panula}

Creep is separated into basic creep and drying creep components. It is pointed out that experimental measurements for basic creep normally increase at a constant or increasing slope in long-term for the duration of the test. There is no experimental justification for the assumption that basic creep approaches a final limiting value. Accordingly, a double power law with no limiting value is used to model basic creep.

Because of the difficulty in separating instantaneous and creep strains during loading, the basic creep function $\Phi_{b}(t, \tau)$ (which is the instantaneous strain plus creep strain at time $t$ caused by a sustained unit stress first applied at age $\tau$ ) is expressed as

$$
\Phi_{b}(t, \tau)=\frac{1}{E_{o}}\left(1+\phi_{h o}(t, \tau)\right)
$$

The modulus $E_{0}$ is much higher than the actual elastic modulus and is termed the asymptotic modulus. $E_{o}$ is the left-hand asymptote of the creep 
versus log-time curve for short duration loading. For load duration $t-\tau>1$ day:

$$
\frac{1}{E_{o}}=\left(0.0145+3.447 /\left(f_{c}(28)\right)^{2}\right) \times 10^{-3}(\mathrm{MPa})^{-1}
$$

The basic creep coefficient is expressed as

$$
\phi_{b o}(t, \tau)=\phi_{1}\left(\gamma^{-m}+0.05\right)(t-\tau)^{n}
$$

where

$$
\begin{gathered}
\phi_{1}=0.30+152.2\left(f_{c}(28)\right)^{-1.2} \\
m=0.28+47.541\left(f_{c}(28)\right)^{-2} \\
n=0.115+0.61\left(f_{c}(28)\right)^{3} \times 10^{-6}
\end{gathered}
$$

The basic creep coefficient $\phi_{b}(t, \tau)$ used with the elastic modulus $E_{c}(\tau)$ is therefore

$$
\phi_{b}(t, \tau)=E_{c}(\tau) \Phi_{b}(t, \tau)-1
$$

The total creep function $\Phi(t, \tau)$, which is the instantaneous strain plus basic creep and drying creep strains at time $t$ caused by a sustained unit stress first applied at age $\tau$, is obtained by adding a dryirg creep coefficient to the right hand side of Eq. 4.72:

$$
\Phi(t, \tau)=\frac{1}{E_{\mathrm{o}}}\left(1+\phi_{\mathrm{bo}}(t, \tau)+\phi_{\mathrm{do}}\left(t, \tau_{s h}\right)\right)
$$

When shrinkage commences prior to the application of load (i.e. when $\left.r>t_{s h}\right):$

$$
\phi_{d o}\left(t, \tau, t_{s h}\right)=\bar{\phi}_{d} k_{h} \tau^{-m / 2}\left(1+\frac{3 \tau}{t-\tau}\right)^{-0.35}
$$

where

$$
\begin{gathered}
\bar{\phi}_{d}=\left(1+\frac{\tau-t_{s h}}{10 \tau_{s h}}\right)^{-1 / 2} \phi_{d} \varepsilon_{s h} \times 10^{6} \\
\phi_{d}=0.0056+\frac{0.0189}{1+0.7 r^{-1.4}} \quad \text { if } r>0.0 \\
\phi_{d}=0.0056 \quad \text { if } r \leq 0.0 \\
r=0.56\left((s / a) f_{c}(28)\right)^{0.3}(g / s)^{1.3}\left(\frac{1610(w / c)}{\varepsilon_{s h} \times 10^{6}}\right)^{1.5}-0.85
\end{gathered}
$$


and

$$
k_{h}=1-10^{-3} h^{1.5}
$$

in which $s / a$ is the sand to total aggregate ratio by weight; $h$ is the humidity in percent; and all other symbols are as defined for shrinkage prediction.

The total creep coefficient used with elastic modulus at age $\tau$ is

$$
\phi(t, \tau)=E_{c}(\tau) \Phi(t, \tau)-1
$$

\subsubsection{Creep Coefficients}

It is well known that basic creep is the increase in strain under sustained load without losing water, j.e., the tests are performed on a sealed specimen. The size dependency of basic creep is very limited. If the same specimen is tested while it is dried, the additional strain is called drying creep, which depends on the concrete member size and moisture state. In theory, total creep can be divided into basic creep and drying creep, as done by Bazant and Panula. On the other hand, because basic creep and drying creep are different phenomena, failing to separate them, as in most existing codes, logically causes a very significant error. For this reason, basic creep and drying creep are studied individually.

The creep coefficient is affected by numerous factors among which the most important factors can be classified into two groups. The factors in the first group , including age at loading, concrete composition and curing temperature, will affect the properties of concrete as well as the maturity when it is stressed, so they will affect basic creep as well as drying creep. Those in the second group, such as size of structural member and ambient humidity, will only affect drying creep. 


\section{Relative Strength}

Traditionally; as far as the loading age and the curing conditions are concerned, the creep coefficient is treated as a function of age at loading. To consider the effect of curing temperature, equivalent age from maturity function is introduced. From the previous studies, those factors can be related to the relative strength at loading. To verify this idea, the experimental data reported by fifteen researchers were studied by Parrott ${ }^{4.20}$. Parrott's data was reinterpreted converting the the age at loading into relative strength by using the proposed maturity formula discussed previously. The data reported by Brycnt and Vadhanavikkit ${ }^{4.8}$ were also inciuded. All the data were summarized in Fig. 4.10. It was concluded that creep coefficient can be related to relative strength at loading by means of maturity concept.

By dividing creep strains for various strengths at loading by the value corresponding to loading at age of 28 days, the creep coefficient due to relative strength was obtained:

$$
\phi_{f}=2-\left(\frac{f_{c}\left(\dot{t}_{o}\right)}{f_{c}(2 \delta)}\right)^{3 / 2}
$$

A similar conclusion was also reported by Ulitski.28, as shown in Fig. 4.11.

\section{Relative Humidity}

The influence on creep by the relative humidity of the air in which the concrete is exposed has been known for a long time. It is observed that drying concrete creeps at a higher rate and achieves higher long-term creep than concrete which remains wet, but the effect decreases with an increase in size of the concrete member. Humidity affecting the long-term creep value is obvious, but whether or not it also affects the relative rate of creep still remain uncertain. The effect of humidity on creep rate will be discussed with the size effect later, here only its effect on the long-term value of creep was considered. Of course, relative humidity can only affect drying creep.

Because relative humidity might also affect creep rate, in order to discuss 
its effect on the long-term drying creep value, only very long term or small size drying creep data were useful. The data reported by Troxell $^{4.26}(4 \times 14 \mathrm{in}, 2 \mathrm{~S}$ years) and Keeton ${ }^{4.14}$ ( $3 \times 9$ in, 2.5 years) were used, as shown in Fig. 4.12 , with relative humidity of $75 \%$ as reference. By using computer optimization, a formula, which is shown in Fig. 4.12. was obtained as:

$$
\phi_{h}=1.46\left(1-h^{4}\right)
$$

\section{Stress Level}

It is generally accepted that for stress level $\sigma_{i} \hat{f}_{c m}<0.5$, the creep is proportional to the applied stress, which means that creep is independent of stress level. It was found ${ }^{4.24,} 4.5$ that when $\sigma>0.5 f_{c m}$, the creep per unit stress at the higher levels of stress was significantly greater than that at the lower levels because of the increasing of microcracking.

To investigate the stress level on the long-term creep, a large series of tests were performed by Feeton ${ }^{4.14}$. Specimens with different sizes, under stress levels varying from 0 to $60 \% f_{\mathrm{cm}}$, were tested in relative humidity from $20 \%$ to $100 \%$. The result showed that for stress level $\sigma<0.5 f_{\mathrm{cm}}$, creep was directly proportional to the applied load.

\section{Duration of Loading}

Many investigations have been concerned with the effect of time on creep. To estimate long-term creep from short-term measured data, numerous mathematical expressions relating creep and time have been suggested. One of the most convenient is the hyperbolic expression introduced by Lorman ${ }^{4.16}$. The creep $c$ after time $t$ under load as

$$
c=\frac{t}{a+b t}
$$

when $t=\infty, c=1 / b$ is the ultimate value of creep. $a$ and $b$ are constants determined from experimental results: by plotting $t / c$ against $t$, a straight line of slope $b$ is obtained, and the intercept of the $t / c$ axis is equal to $a$. 
The recent investigations by Brooks and Neville.6 and Brooks $s^{4.5}$ showed that for the majority of concrete. regardless of the water/cement ratio, type of cement and agzregate, or size of the concrete member, creep at the age $t, C_{t}$, can be related to the creep after $2 S$ day's under load by the expression:

$$
C_{t}=C_{28}(-6.19+2.15 \ln t)^{0.38}
$$

To use this formula, the creep of 28 days after loading has to be determined experimentally.

From the above two equations it can be seen that some investigators believe that creep eventually goes to a final value, but sthers do not give a limit for creep. To verify this, Troxell' $s^{4.26}$ experimental data, which extended over 28 years, was studied. It was found that up to 28 years, there was no sign of a limit for either basic creep or drying creep, but after 10 years, drying creep developed much more slowly than basic creep did. That means that time effect on basic and drying creep are different, so their effects should be studied separately.

\section{Member Size}

Large specimen size slows down the process of diffusion of the absorbed water, therefore, delays or decreases drying creep. Some researchers use "delay" because they believe drying creep will eventually goes to a final values witiin structure life time, but others do not think so. Troxell ${ }^{4.26}$ stated in his paper "These values (tested over 9.5 years) definitely show that creep decreases as the size of the specimen increases". A series of tests with various sizes reported by Bryant ${ }^{4.8}$ also came to the same conclusion.

Since member size affects the free escape of moisture under load, it is logical to consider that in addition to the long-term creep, if the relative humidity also affects the creep rate, as member size does. It was found by numerical analysis from Keeton's data that humidity did not affect the creep rate; it only affected the absolute drying creep value. 


\subsubsection{Creep Prediction}

As discussed previously; basic creep and drying creep have to be studied individually.

Assume that total creep strain

$$
\varepsilon_{c r}=\varepsilon_{i}\left(\Phi_{b}+\Phi_{d}\right)
$$

where $\varepsilon_{i}$ is the instantaneous strain when loaded, $\Phi_{b}$ and $\Phi_{d}$ are basic creep coefficient and drying creep coefficient respectively.

The basic creep coefficient is only a function of relative strength of concrete when loaded, as indicated by Eq. 4.80 , and the sustained loading time $t, \mathrm{si} s \mathrm{can}$ be expressed by:

$$
\Phi_{b}=K_{b} \phi_{f}(\ln t)^{m}
$$

To get the values of $m$ and $K_{b}$, experimental data reported by Troxell ${ }^{4.26}$, Bryant ${ }^{4.8}$, Brooks $^{4.6}$ and Keeton ${ }^{4.14}$ were used. By using computer optimization, it was found that $m=0.75$ and $K_{b}=0.290$, with a very low error coefficient of $9.1 \%$. The calculated values of $K_{b}$ are listed in Table 4.3. 


\begin{tabular}{|l|l|l|l|l|l|}
\hline Tested by & $\varepsilon_{i}$ & $\varepsilon_{B c r}$ & $f\left(t_{0}\right) / f_{c m}$ & $t$ & $I_{b}^{-}$ \\
\hline Troxell $^{4.26}$ & $27 \bar{i}$ & 420 & 1.00 & 8400 & 0.293 \\
\hline Bryant $^{4.8}$ & 246 & 420 & 0.85 & 1943 & 0.308 \\
\hline Keeton $^{4.14}$ & 370 & 460 & 0.72 & 897 & 0.213 \\
\hline Brooks $^{4.5}$ & 347 & 656 & 0.85 & 3650 & 0.321 \\
\hline Brooks $^{4.5}$ & 336 & 504 & 0.85 & 3650 & 0.254 \\
\hline Brooks $^{4.5}$ & 672 & 1120 & 0.85 & 3650 & 0.283 \\
\hline Brooks $^{4.5}$ & 358 & 676 & 0.85 & 3650 & 0.320 \\
\hline Brooks $^{4.5}$ & 379 & 689 & 0.85 & 3650 & 0.308 \\
\hline Brooks $^{4.5}$ & 338 & 628 & 0.85 & 3650 & 0.315 \\
\hline Brooks $^{4.5}$ & 370 & 644 & 0.85 & 3650 & 0.295 \\
\hline Brooks $^{4.5}$ & 354 & 670 & 0.85 & 3650 & 0.321 \\
\hline
\end{tabular}

Table 4.3: Coefficient for basic creep from tests

Drying creep coefficient is much more complicated than basic creep coefficient, it is a function of relative strength when loaded, relative humidity, member size and time of sustained loading, and can be assumed by:

$$
\Phi_{d}=K_{d} \phi_{f}\left(1-h^{4}\right)\left(\frac{25}{f_{c m}}\right)^{n}(\ln t)^{\alpha} \frac{t^{\beta}}{A\left(\frac{V}{S}\right)^{2}+t^{\beta}}
$$

The same data were used to get $n, A, \alpha, \beta$ and $K_{d}$. It was found that when $n=0.5, A=0.12, \alpha=0.33$, and $\beta=1.0, K_{d}$ has a minimum value of error coefficient of $10.4 \%$, with average $K_{d}=1.47$. The tested values of $K_{d}$ are listed in Table 4.4. 


\begin{tabular}{|l|l|l|l|l|l|l|l|l|}
\hline Tested by & $\varepsilon_{i}$ & $\varepsilon_{D c r}$ & $f\left(t_{0}\right) / f_{c m}$ & $f_{c m}$ & $\mathrm{~h}$ & $\mathrm{~V} / \mathrm{S}$ & $\mathrm{t}$ & $K_{d}$ \\
\hline Troxell $^{4.26}$ & 275 & 500 & 1.00 & 17.2 & 0.50 & 25.4 & 5000 & 1.65 \\
\hline Troxell $^{4.26}$ & 275 & 600 & 1.00 & 17.2 & 0.70 & 25.4 & 5000 & 1.53 \\
\hline Bryant $^{4.8}$ & 246 & 680 & 0.85 & 50.1 & 0.60 & 25.0 & 1943 & 1.55 \\
\hline Bryant $^{4.8}$ & 246 & 590 & 0.85 & 50.1 & 0.60 & 37.0 & 1943 & 1.78 \\
\hline Bryant $^{4.8}$ & 246 & 480 & 0.85 & 50.1 & 0.60 & 50.0 & 1943 & 1.54 \\
\hline Bryant $^{4.8}$ & 246 & 370 & 0.85 & 50.1 & 0.60 & 75.0 & 1943 & 1.35 \\
\hline Bryant $^{4.8}$ & 246 & 270 & 0.85 & 50.1 & 0.60 & 100. & 1943 & 1.21 \\
\hline Bryant $^{4.8}$ & 246 & 610 & 0.85 & 50.1 & 0.60 & 50.0 & 1943 & 1.95 \\
\hline Bryant $^{4.8}$ & 246 & 415 & 0.85 & 50.1 & 0.60 & 75.0 & 1943 & 1.55 \\
\hline Bryant $^{4.8}$ & 246 & 340 & 0.85 & 50.1 & 0.60 & 100. & 1943 & 1.52 \\
\hline Bryant $^{4.8}$ & 246 & 220 & 0.85 & 50.1 & 0.60 & 150. & 1943 & 1.46 \\
\hline Bryant $^{4.8}$ & 246 & 130 & 0.85 & 50.1 & 0.60 & 200. & 1943 & 1.25 \\
\hline Keeton $^{4.14}$ & 413 & 740 & 0.72 & 45.2 & 0.75 & 19.1 & 897 & 1.41 \\
\hline Keeton $^{4.14}$ & 413 & 1000 & 0.72 & 45.2 & 0.50 & 19.1 & 897 & 1.39 \\
\hline Keeton $^{4.14}$ & 413 & 1095 & 0.72 & 45.2 & 0.20 & 19.1 & 897 & 1.42 \\
\hline Keeton $^{4.14}$ & 550 & 770 & 0.72 & 45.2 & 0.75 & 38.2 & 897 & 1.25 \\
\hline Keeton $^{4.14}$ & 550 & 960 & 0.72 & 45.2 & 0.50 & 38.2 & 897 & 1.14 \\
\hline Keeton $^{4.14}$ & 550 & 1040 & 0.72 & 45.2 & 0.20 & 38.2 & 897 & 1.16 \\
\hline Brooks $^{4.5}$ & 329 & 1017 & 0.85 & 20.9 & 0.60 & 19.1 & 3650 & 1.45 \\
\hline Brooks $^{4.5}$ & 349 & 955 & 0.85 & 39.1 & 0.60 & 19.1 & 3650 & 1.84 \\
\hline ren $^{4}$ & & & & & \\
\hline
\end{tabular}

Table 4.4: Coefficient for drying creep from tests 


\subsubsection{Proposed Formula}

The total creep strain at time $t$ after loading. due to a constant stress $\sigma$ loaded at time $t_{o}$, can be estimated as following:

$$
\varepsilon_{c r}(t)=\frac{\sigma_{c}\left(t_{o}\right)}{E_{c}\left(t_{o}\right)}\left(\Phi_{b}+\Phi_{d}\right)
$$

The basic creep coefficient $\Phi_{b}$ may be calculated from:

$$
\Phi_{b}=0.30 \phi_{f}(\ln t)^{0.75}
$$

and the drying creep coefficient can be obtained from:

$$
\Phi_{d}=1.5 \phi_{f} \phi_{h} \sqrt{\frac{25}{f_{c m}}}(\ln t)^{1 / 3} \frac{t}{0.12\left(\frac{V}{S}\right)^{2}+t}
$$

where, if $f_{\mathrm{cm}}<30 \mathrm{MPa}$, use $f_{\mathrm{cm}}=30 \mathrm{MPa} ; \phi_{f}$ is a coefficient cuncerning the relative strength at loading, and can be obtained by:

$$
\phi_{S}=2-\left(\frac{f\left(t_{0}\right)}{f_{c m}}\right)^{3 / 2}
$$

and $\phi_{h}$ is a coefficient concerning the influence of the ambient relative humidity on drying creep, asid is given by:

$$
\phi_{h}=1-h^{4}
$$

\subsubsection{Discussion}

To perform a finite element analysis of time-dependent behaviour, suitable analytical expressions must be selected for creep prediction because the experimental data for a structure are usually unknown and always incomplete. The proposed model is based on the idea that creep at any time can be divided into basic creep and drying creep. By theoretically analyzing the influencing factors, a formulation was obtained statistically using existing test data. This model has a clear physical meaning and a simple mathematical format that can be easily calculated by hand. 
To check accuracy, results calculated using the proposed method are compared with the laboratory test data ${ }^{4.8}$ covering a wide range of independent variables. It can been seen from Fiy.4.13 to Fig. 4.17 that the predicted values fit the experimental data quite well. With this simple model, one can then predict the creep for any time. The only requirement is to know the concrete design strength, loading history and the ambient relative humidity.

The ACI and CEB 90 models are also compared with the test data. It can be seen from Fig.4.18 to Fig.4.23 that neither of them represents the data satisfactorily and they tend to underestimate creep.

Although Bazant-Panula's model is very complicated, it also seems not able to predict creep with enough satisfaction, as shown in Fig. 4.24.

\subsection{Summary}

1. Shrinkage and creep develop with time in a similar way: both are affected by the volume to surface area ratio of the concrete member and ambient relative humidity.

2. The errors in the prediction of shrinkage and creep are large no matter which model is used. This can be attributed to the fact that the shrinkage and creep are affected by numerous factors, most of which are dependent on the others.

3. The most important factors influencing long-term shrinkage are the 28-day strength of the concrete member, maturity when shrinkage begins, cement type and the amilient relative humidity.

4. ACI time development function for shrinkage does not represent the experimental data well, so it is unlikely to accurately predict the long-term values with short-term tests. The time function in CEB 90 basically fits the experimental data.

5. Creep is significantly affected by the relative strength at the time of 
loading. The value of the relative strength can be estimated by using the maturity function. So the loading history can not be ignored for creep prediction.

6. For stress level $\sigma / f_{c m}<0.5$, creep is proportional to the applied load. The principle of superposition is valid for time-dependent strain due to any stress history. The time-dependent strain should be calculated according to its stress and maturity history.

7. Both ACI and CEB 90 models underestimate creep, especially the long term values.

8. The proposed creep and shrinkage prediction model is very simple and practical. Since the parameters are statistically determined, it gives a satisfactory result for a wide range of independent variables. 


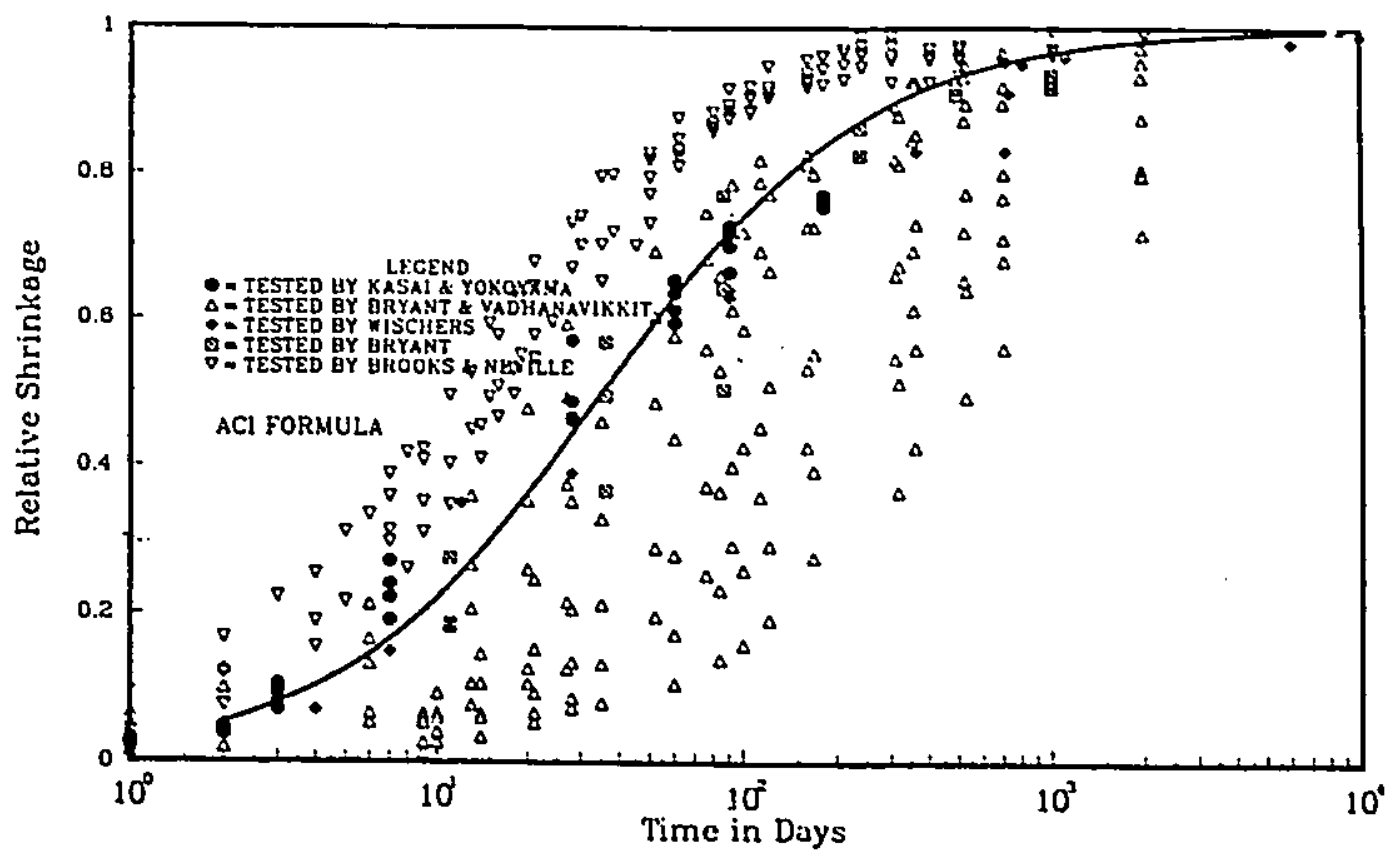

Figure 4.1: Time development function for shinkiage proposed by ACI

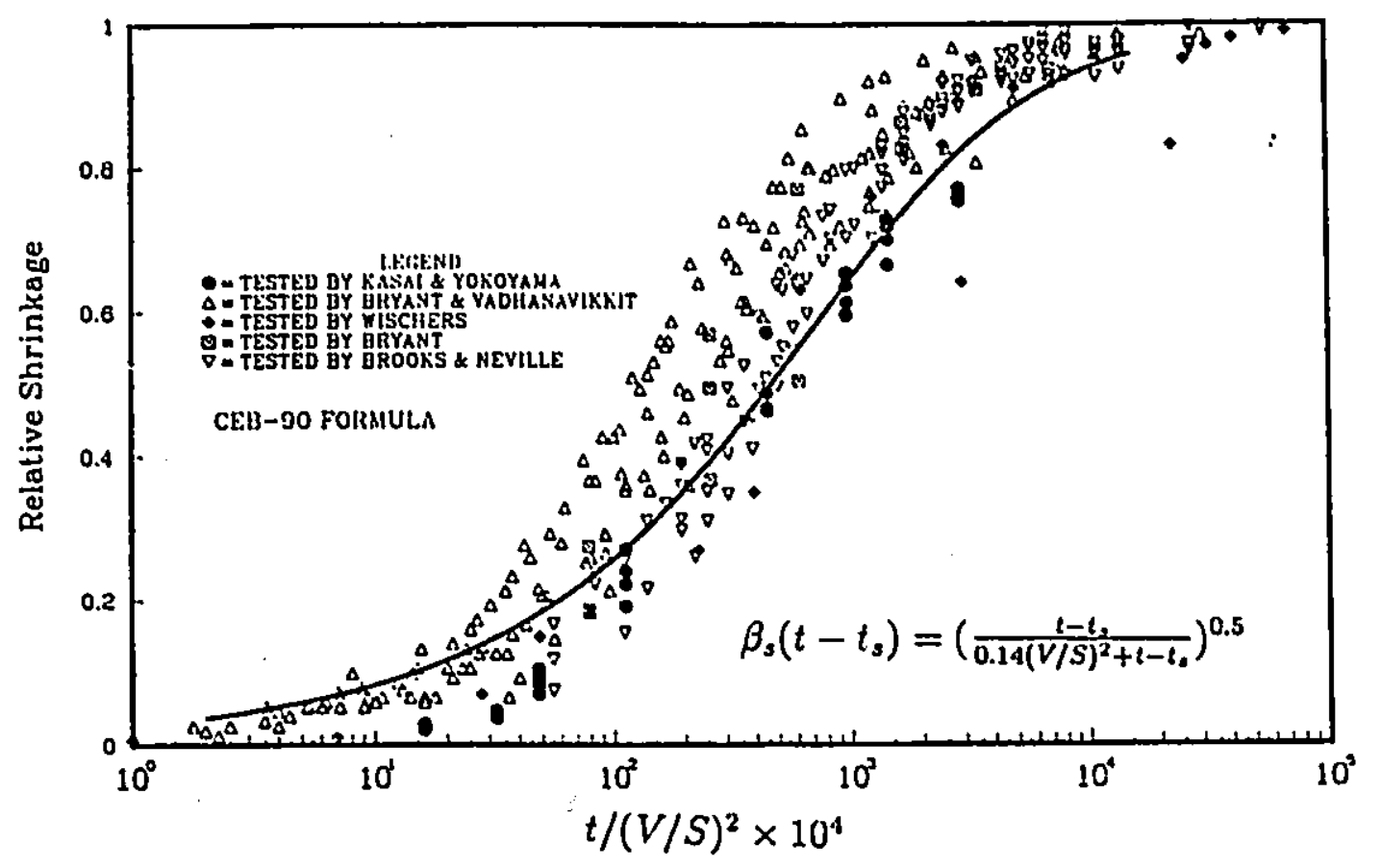

Figure 4.2: Time development function for shrinkage proposed by CEB-90 


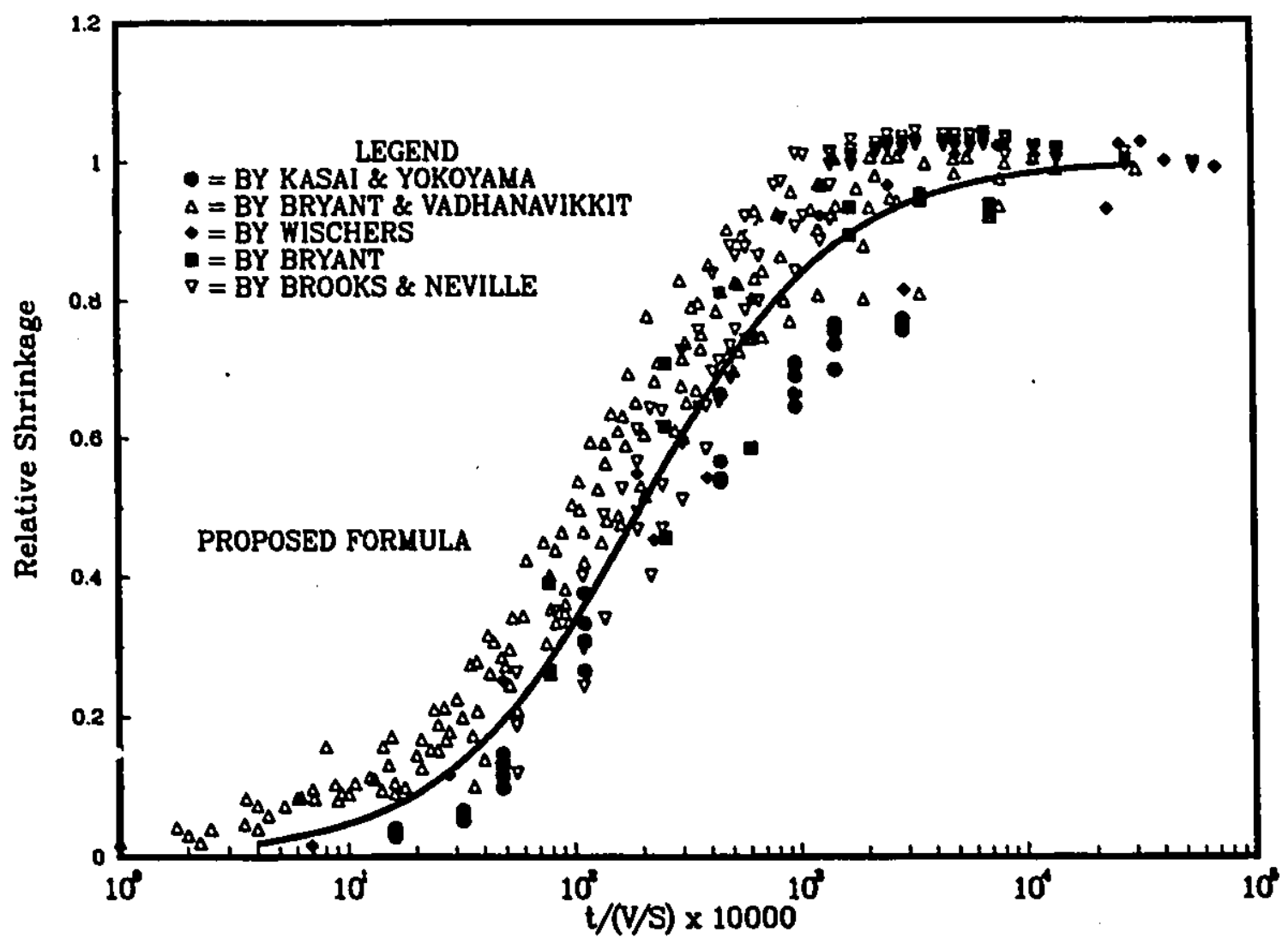

Figure 4.3: Proposed time development function for shrinkage 


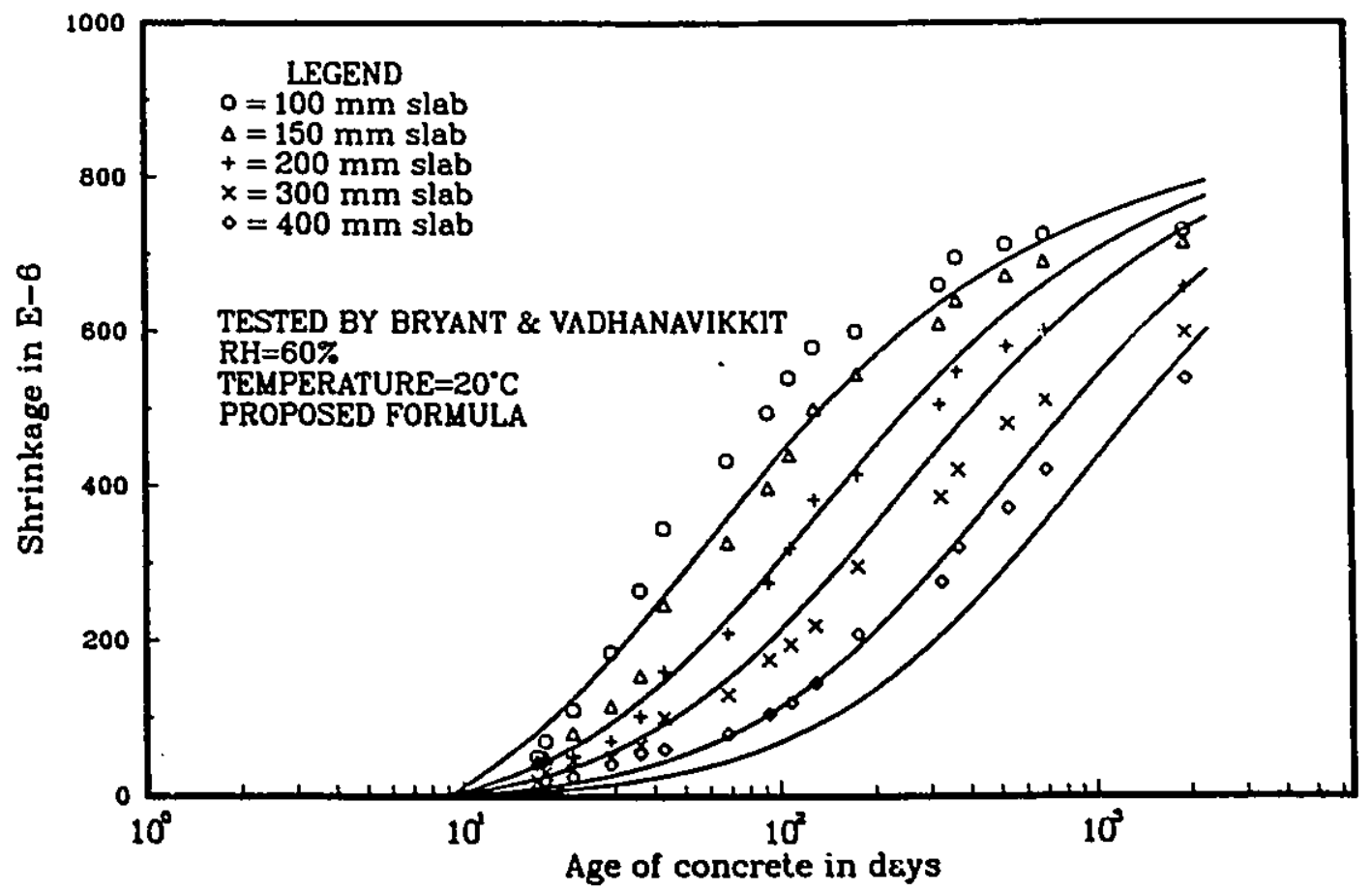

Figure 4.4: Comparison of the proposed shrinkage prediction model with the published experimental data

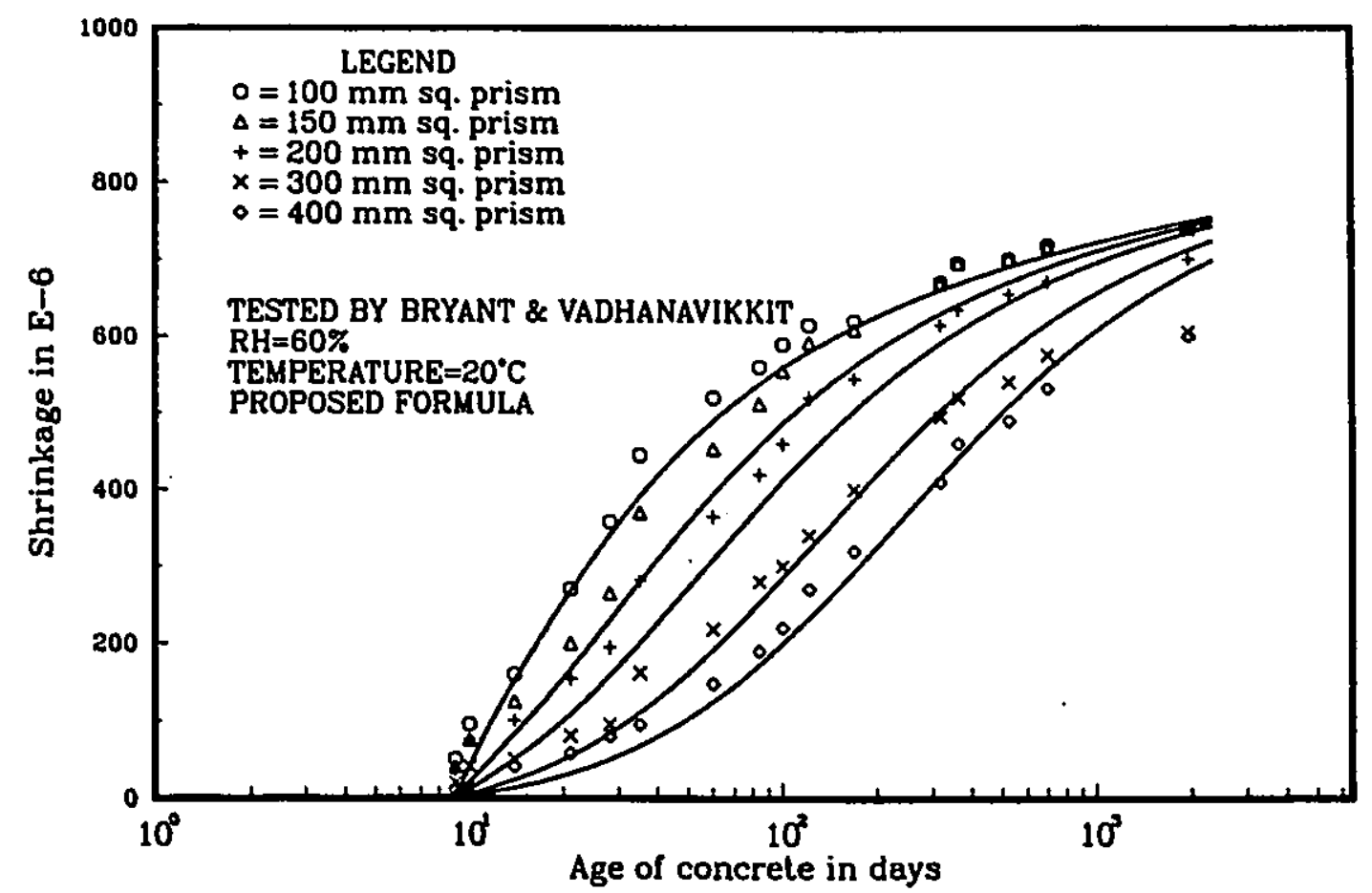

Figure 4.5: Comparison of the proposed shrinkage prediction model with the published experimental data 


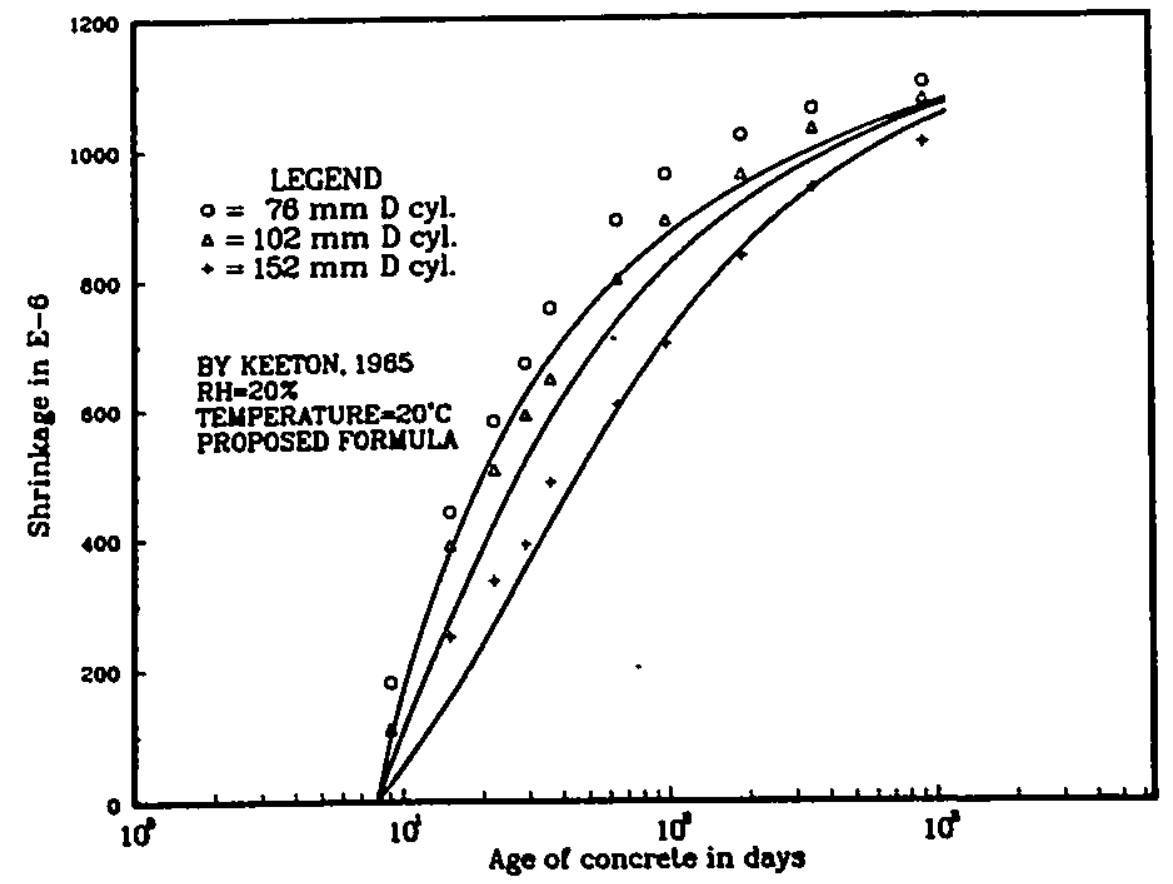

Figure 4.6: Comparison of the proposed shrinkage prediction model with the published experimental data

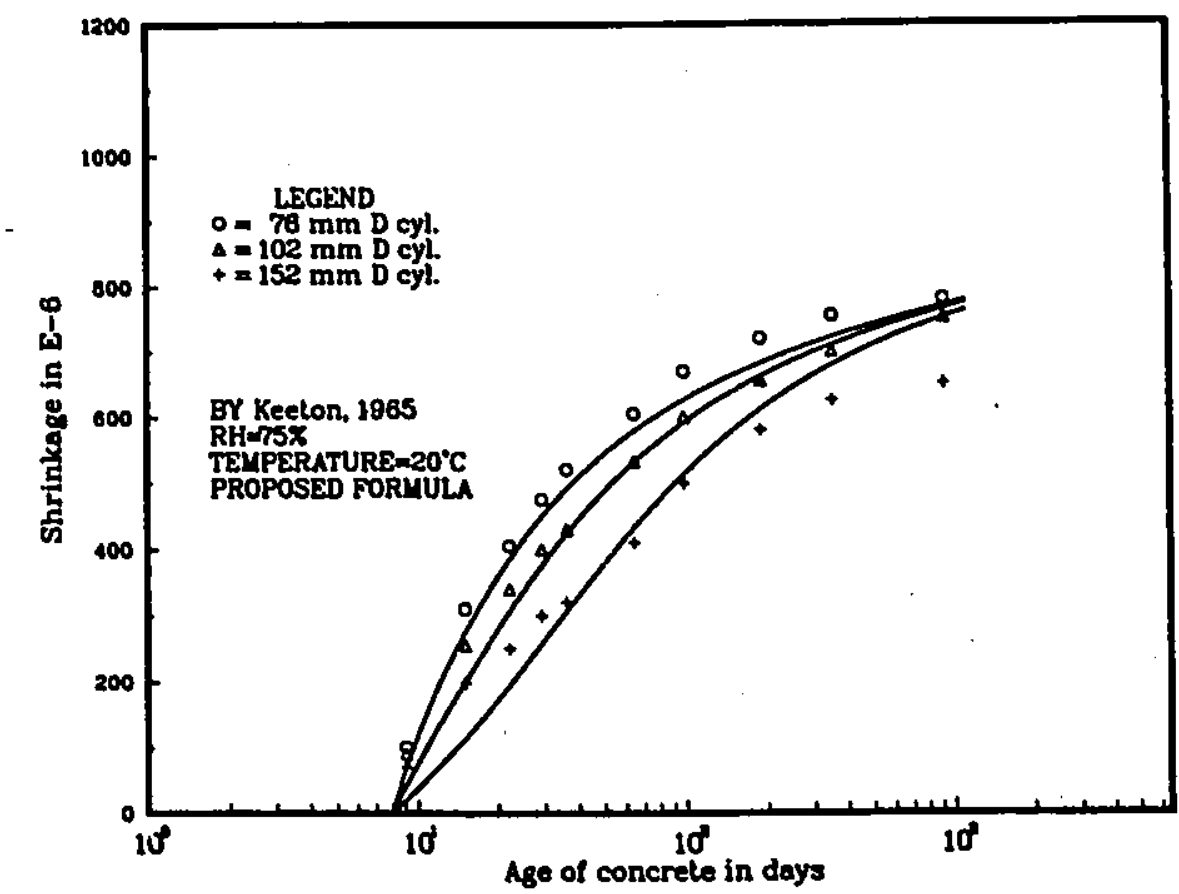

Figure 4.7: Comparison of the proposed shrinkage prediction model with the published experimental data 


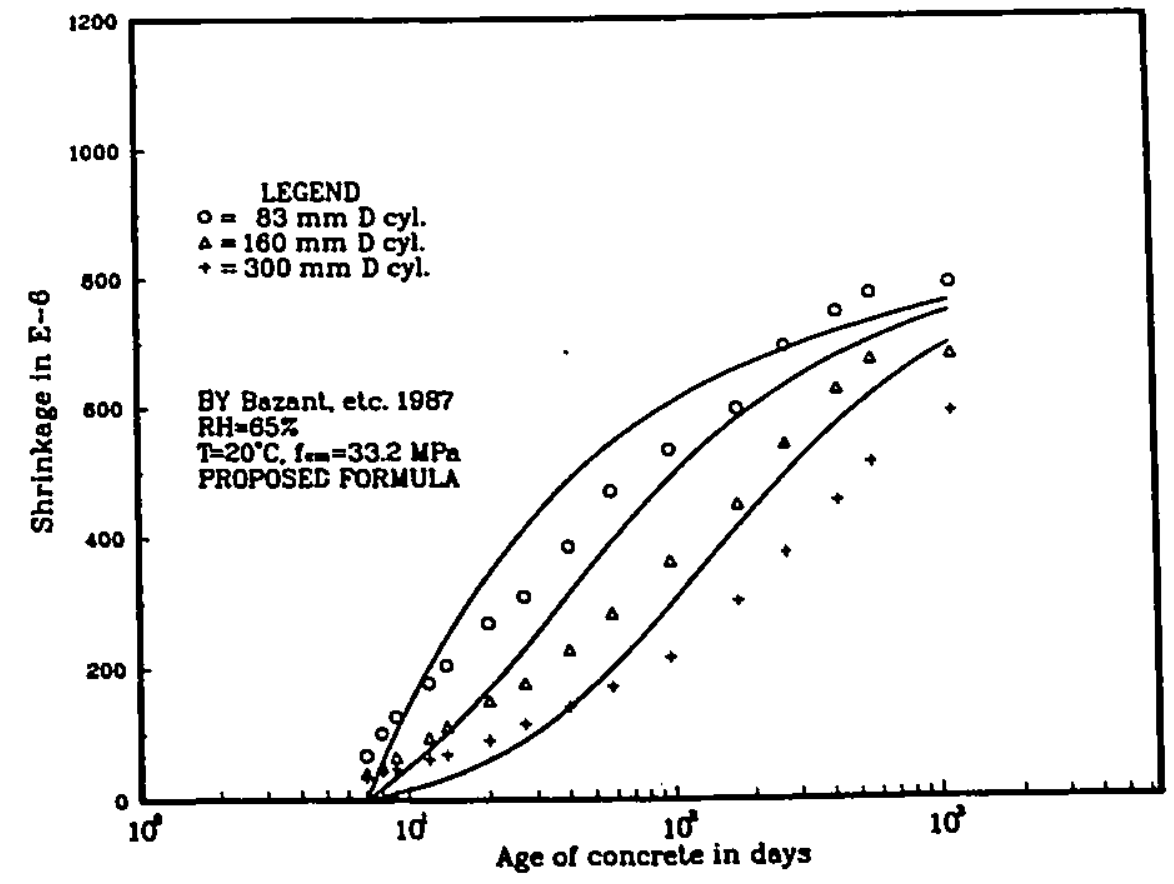

Figure 4.8: Comparison of the proposed shrinkage prediction model with the published experimental data

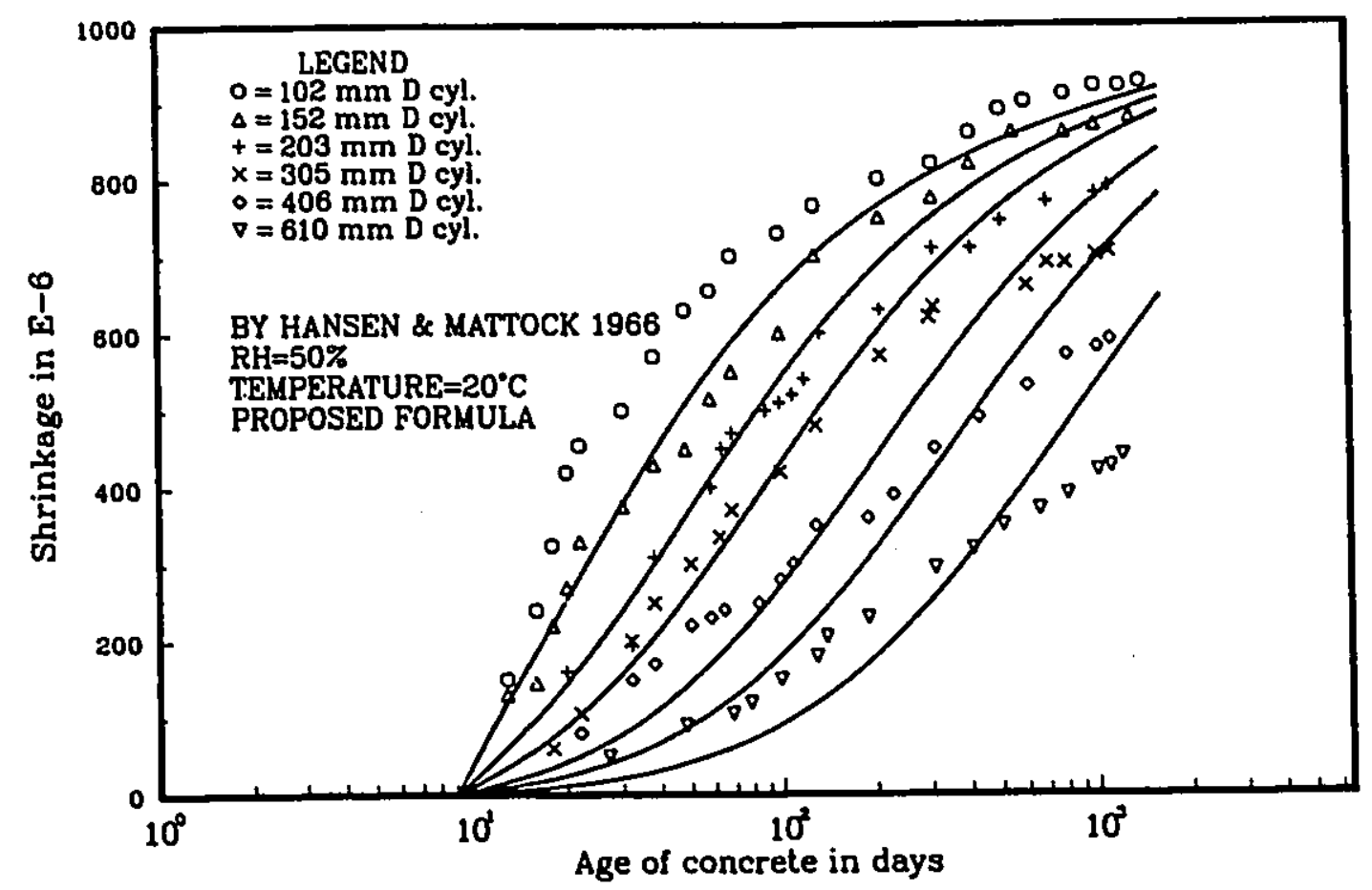

Figure 4.9: Comparison of the proposed shrinkage prediction model with the published experimental data 


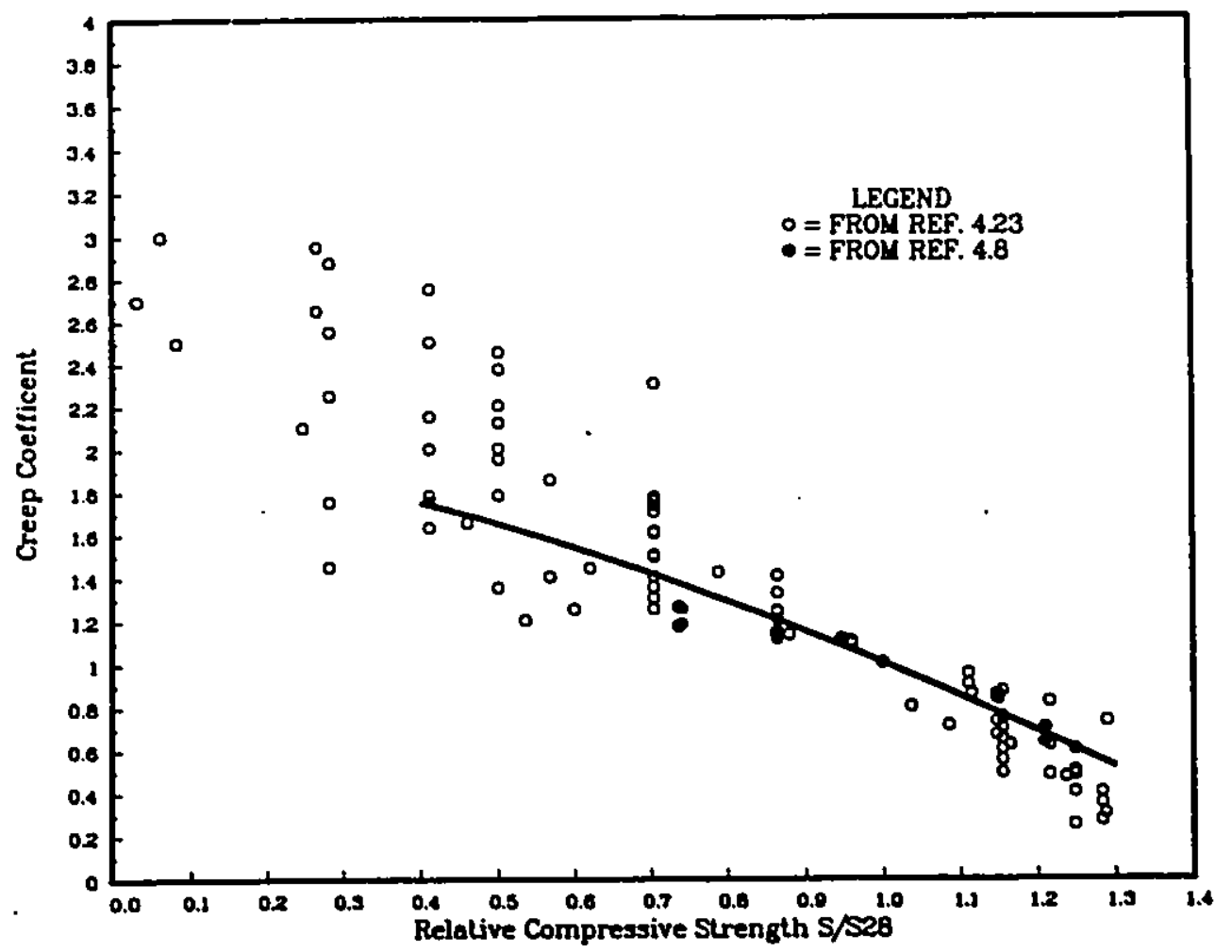

Figure 4.10: Effect of relative strength when loaded on long-term creep

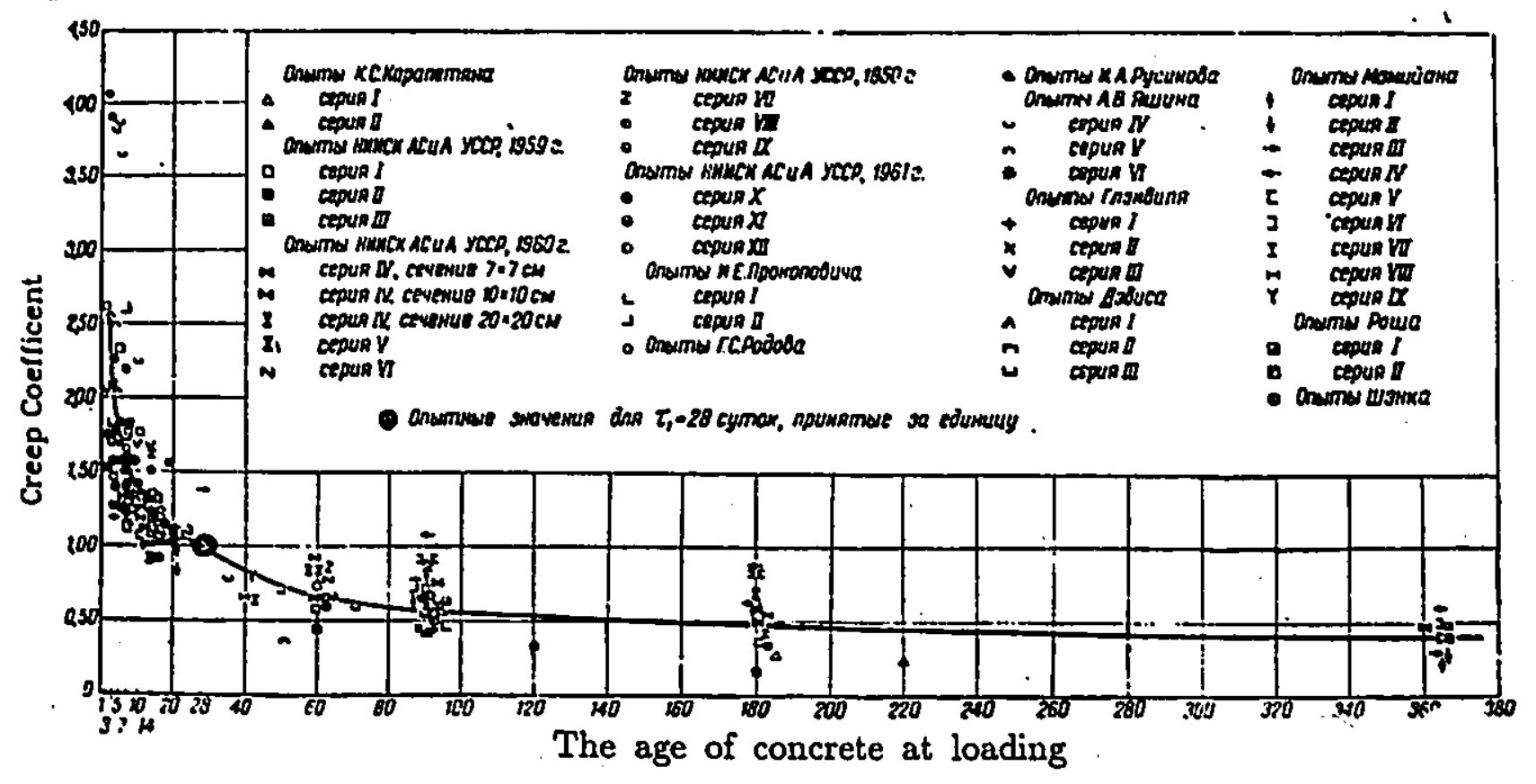

Figure 4.11: Effect of concrete age when loaded on long-term creep, from Reference 4.28. 


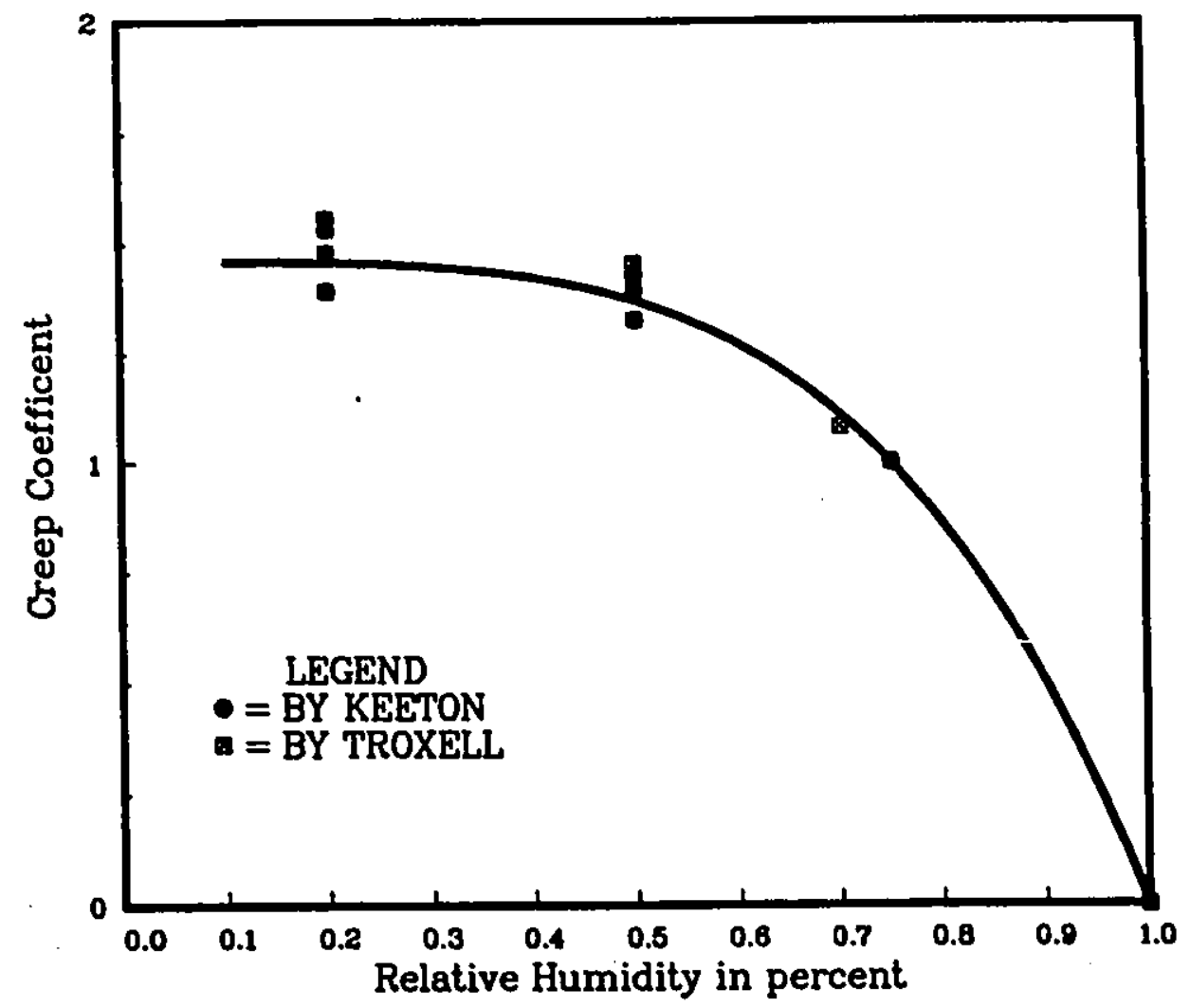

Figure 4.12: Effect of relative humidity on long-term drying creep 


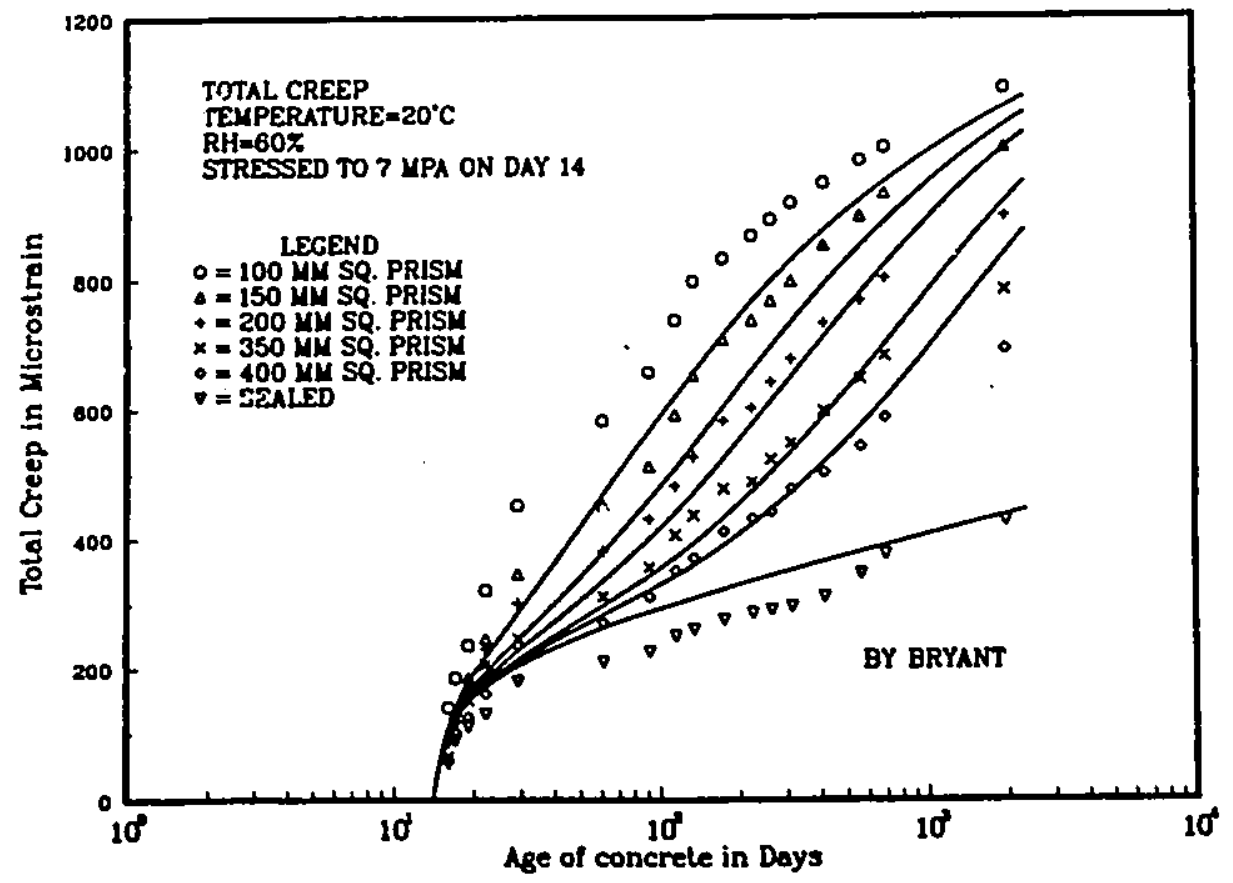

Figure 4.13: Comparison of the proposed creep prediction model with the experimental data

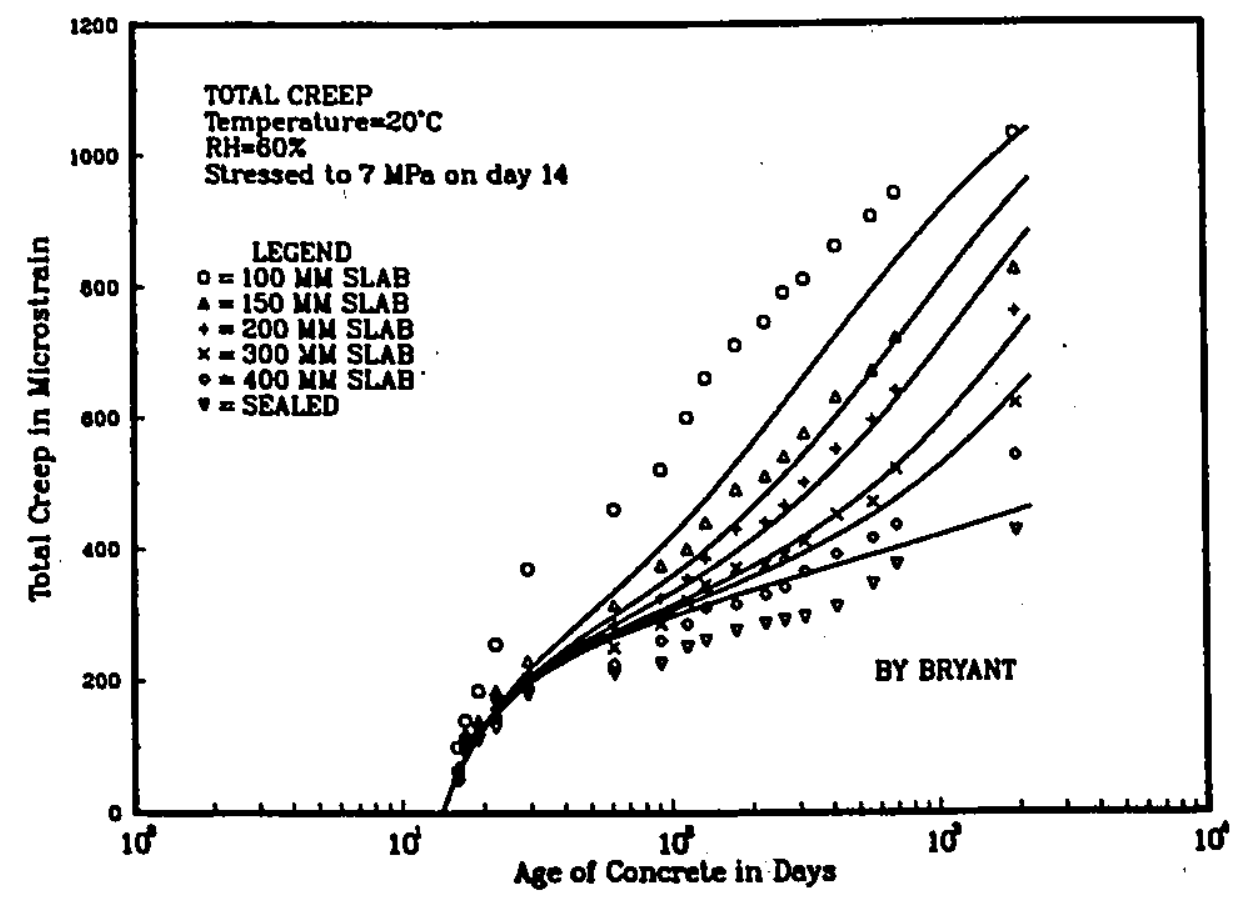

Figure 4.14: Comparison of the proposed creep prediction model with the experimental data 


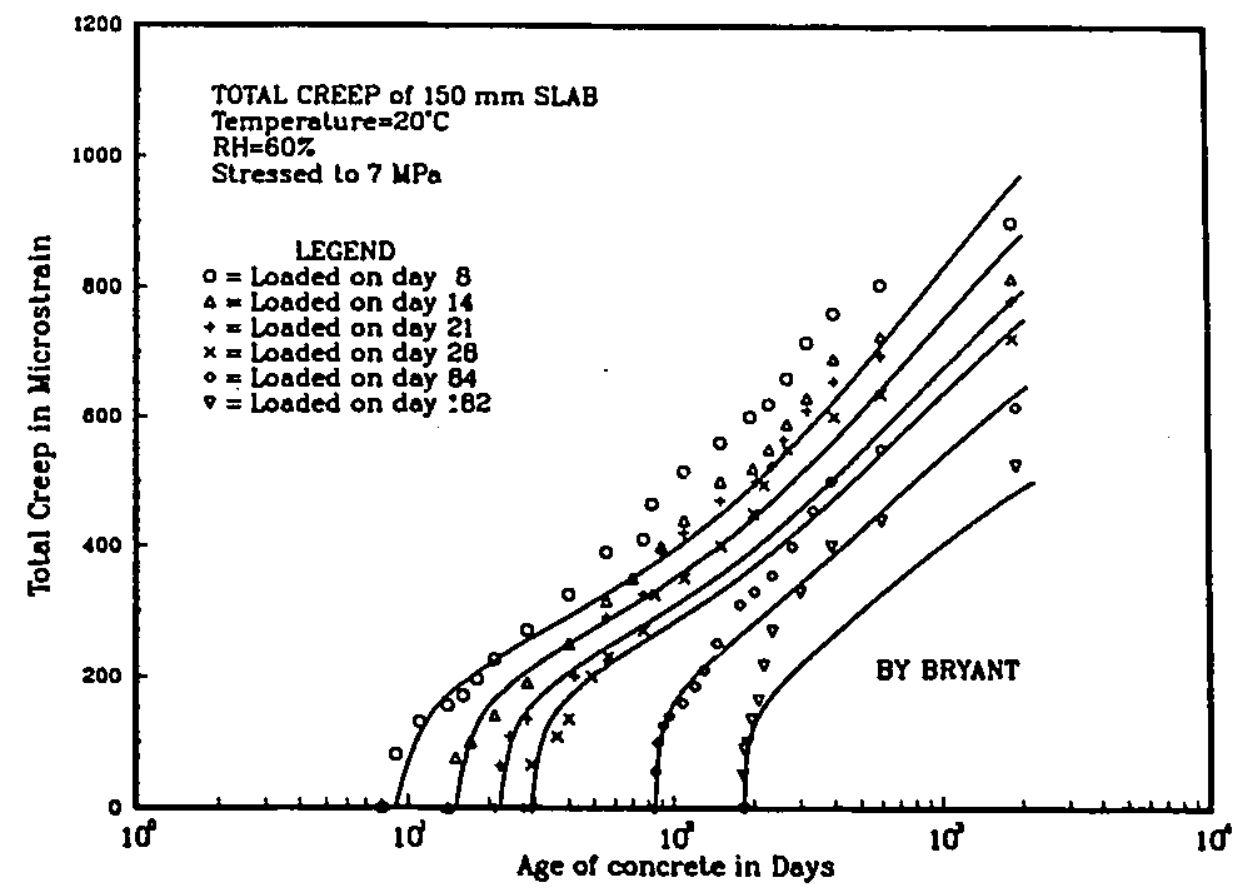

Figure 4.15: Comparison of the proposed creep prediction model with the experimental data

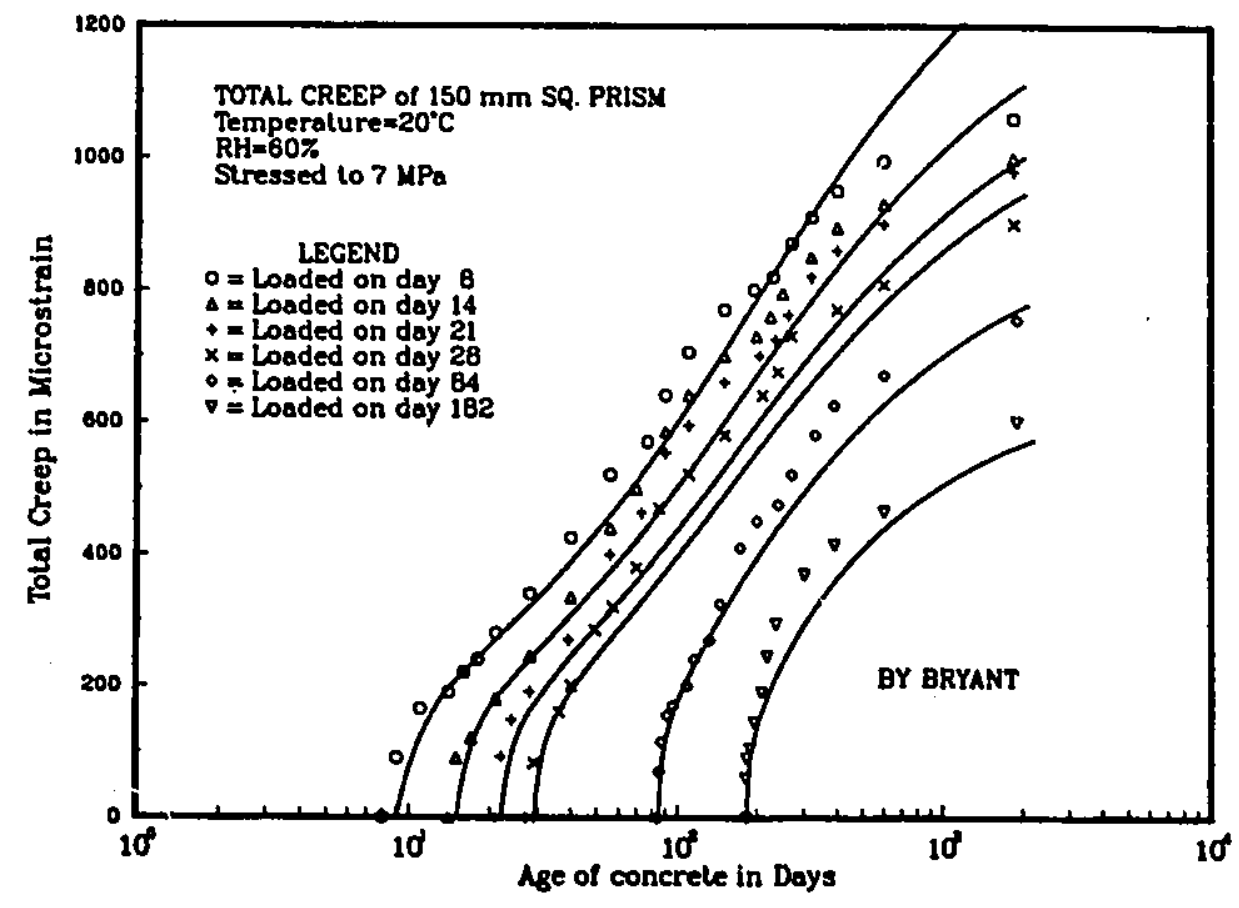

Figure 4.16: Comparison of the proposed creep prediction model-with the experimental data 


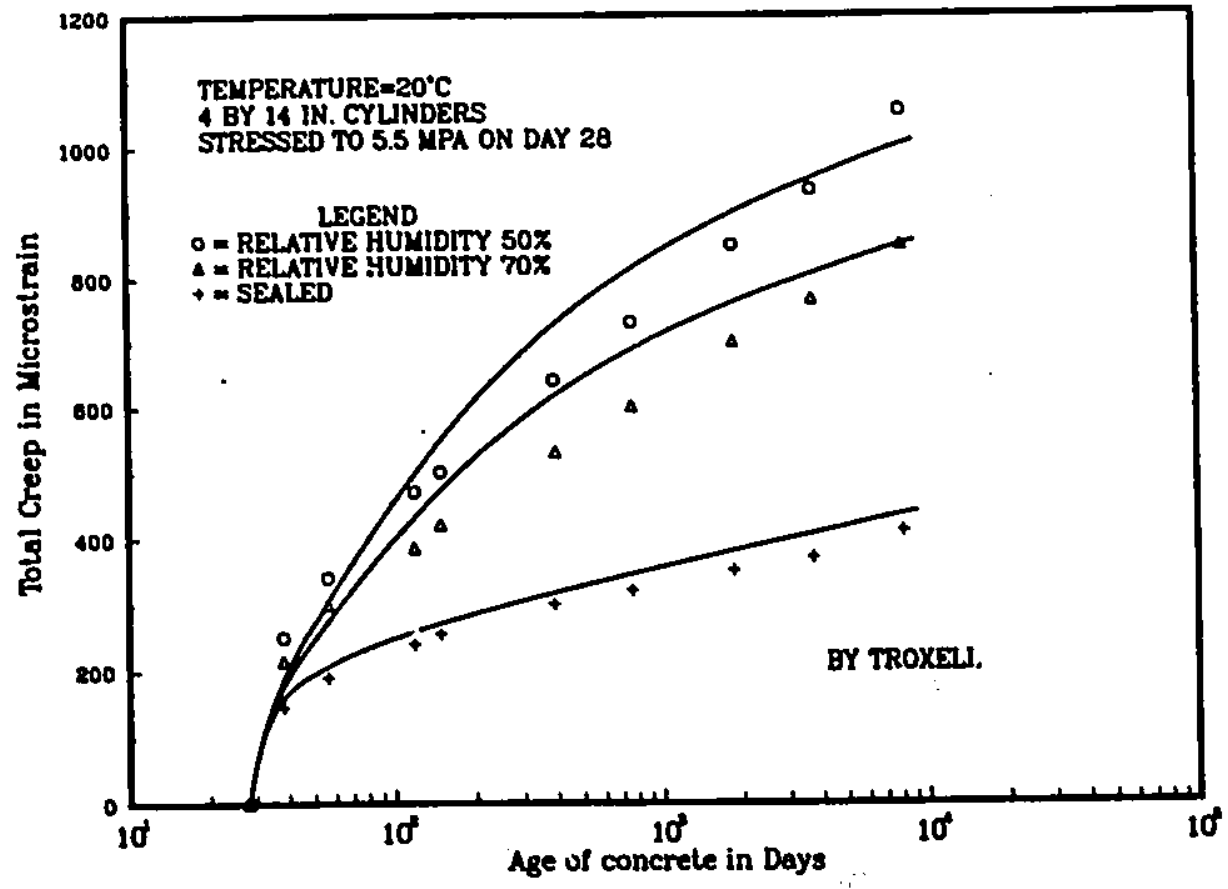

Figure 4.17: Comparison of the proposed creep prediction model with the experimental data 


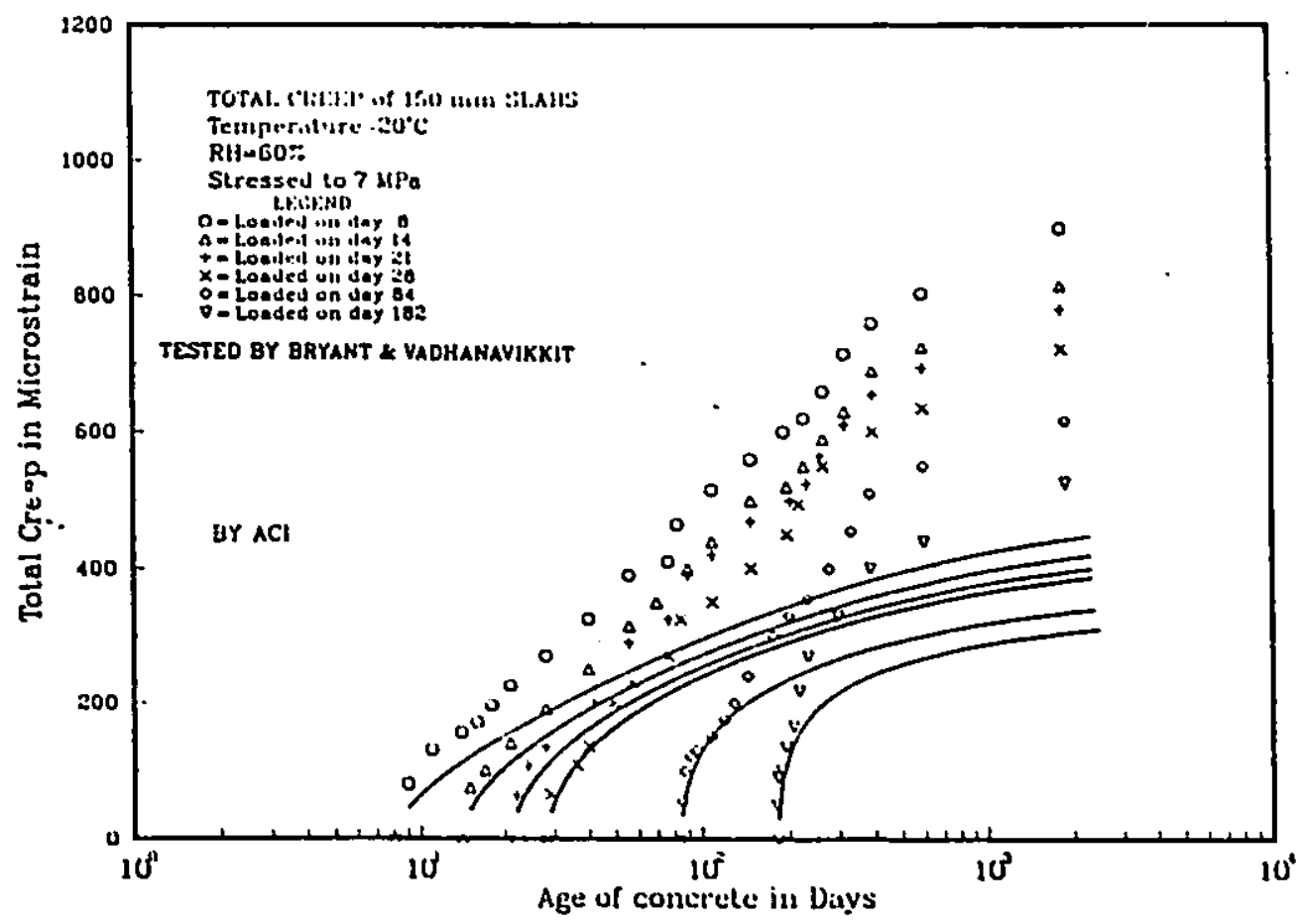

Figure 4.18: Comparison of the creep prediction model proposed by $\mathrm{ACI}$ with the experimental data

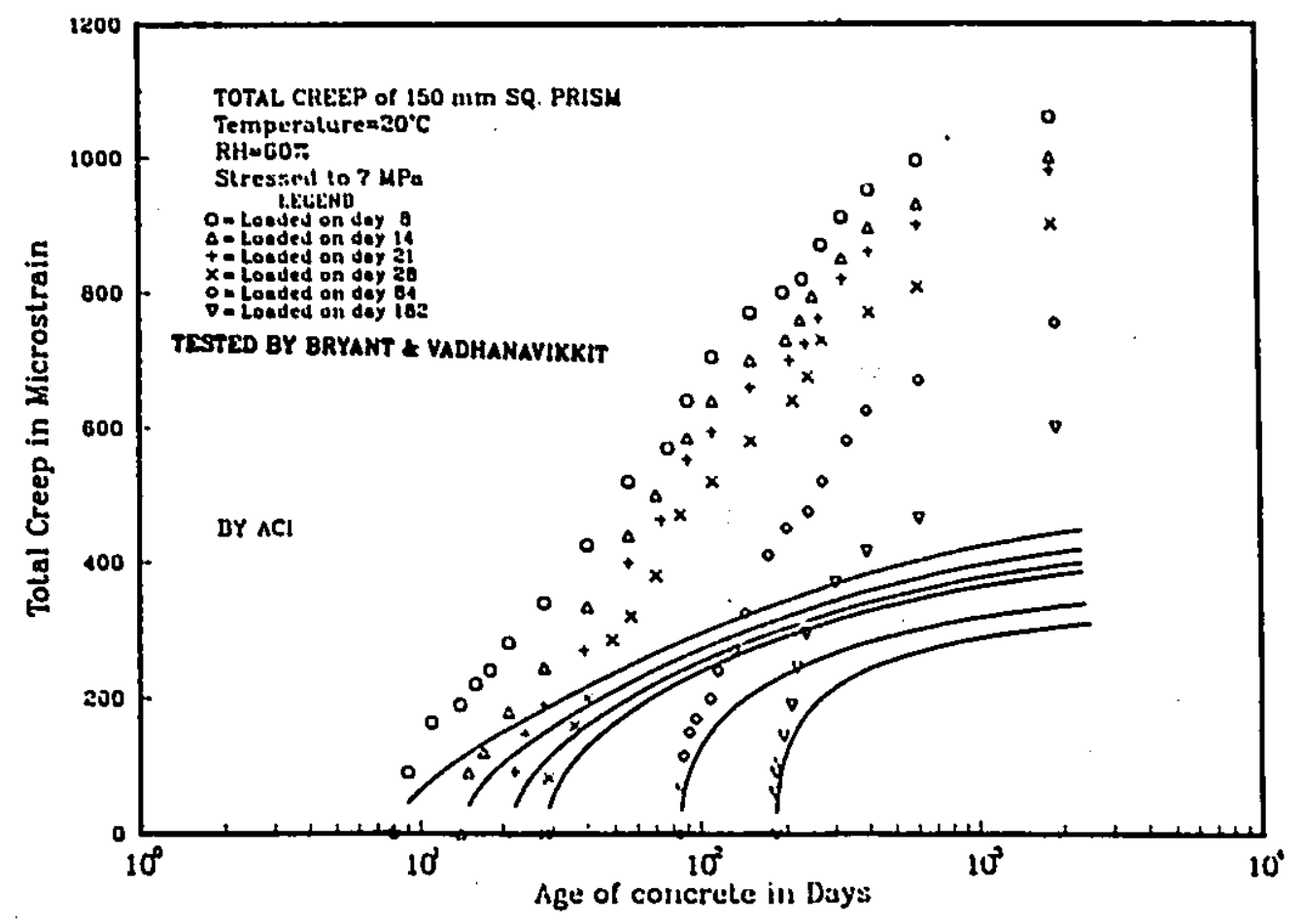

Figure 4.19: Comparison of the creep prediction model proposed by $\mathrm{ACI}$ with the experimental data 


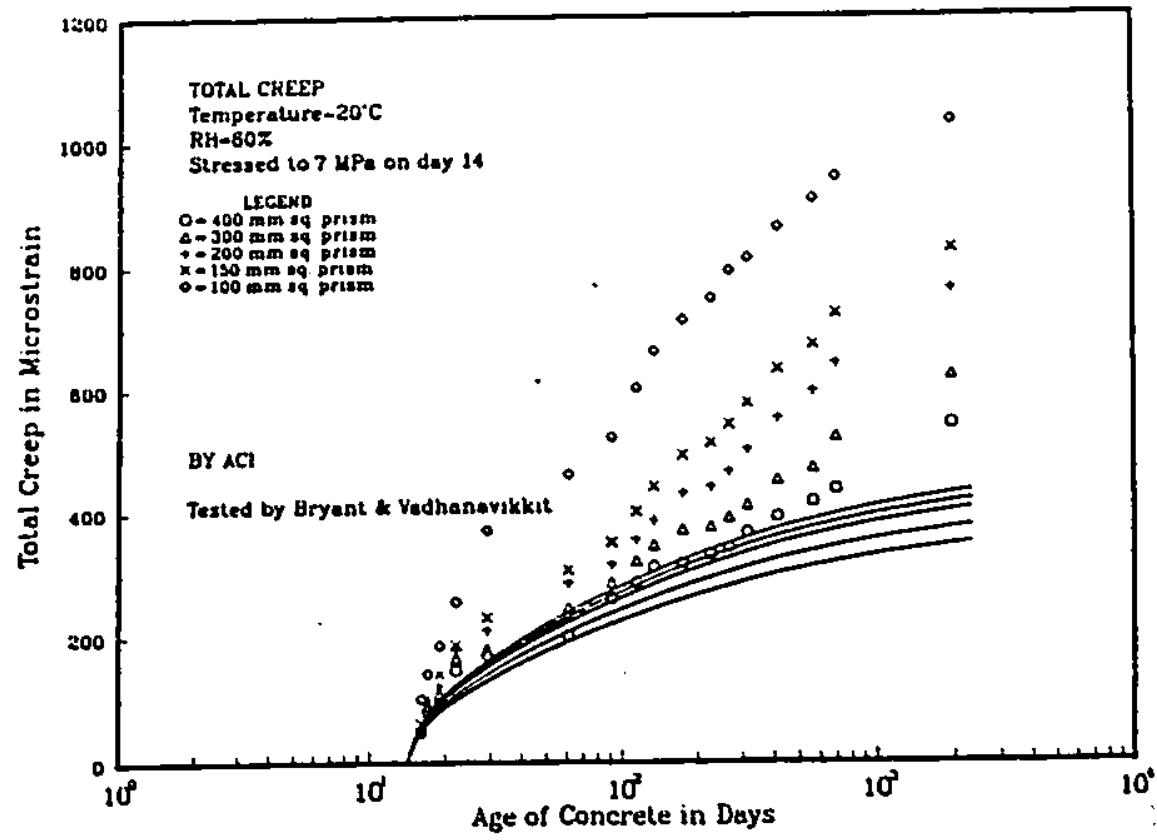

Figure 4.20: Comparison of the creep prediction model proposed by ACI with the experimental data

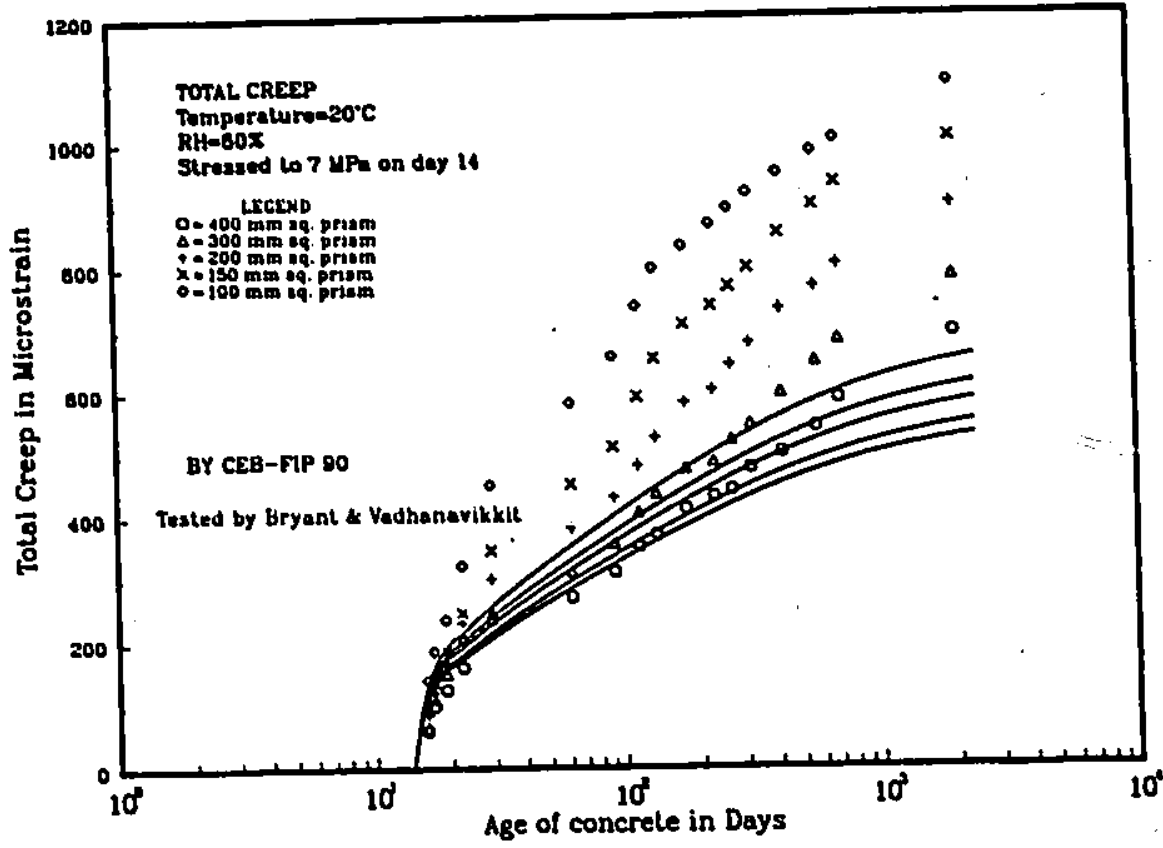

Figure 4.21: Comparison of the creep prediction model proposed by CEB-90 with the experimental data 


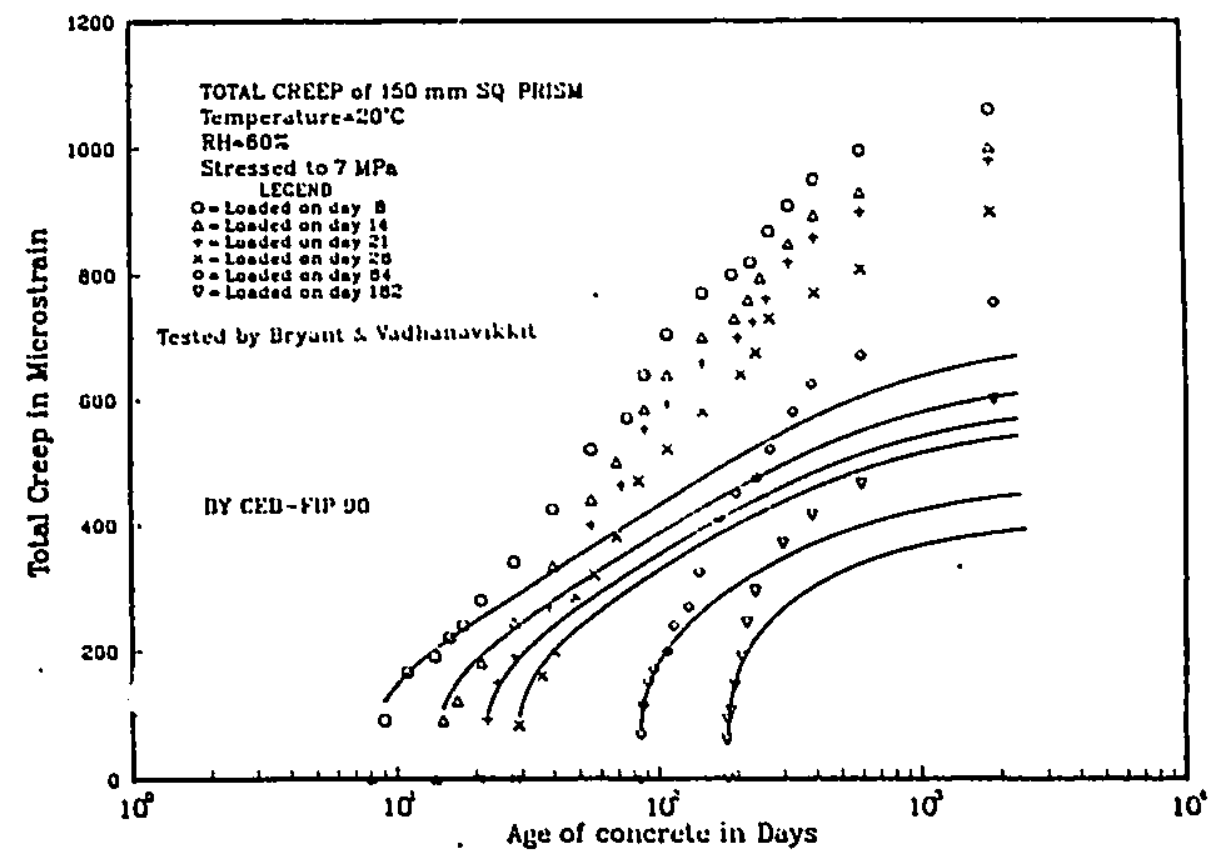

Figure 4.22: Comparison of the creep prediction model proposed by CEB-90 with the experimental data

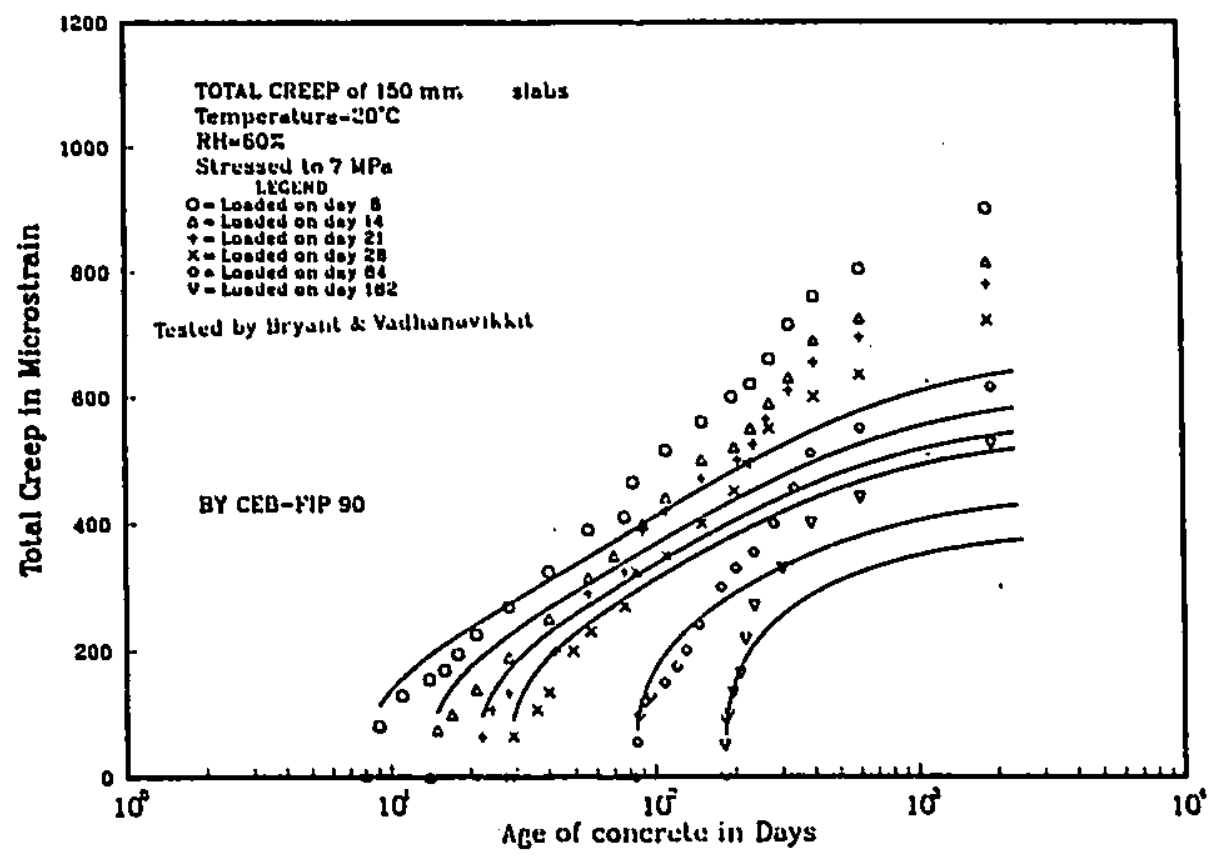

Figure 4.23: Comparison of the creep prediction model proposed by CEB-90 with the experimental data 


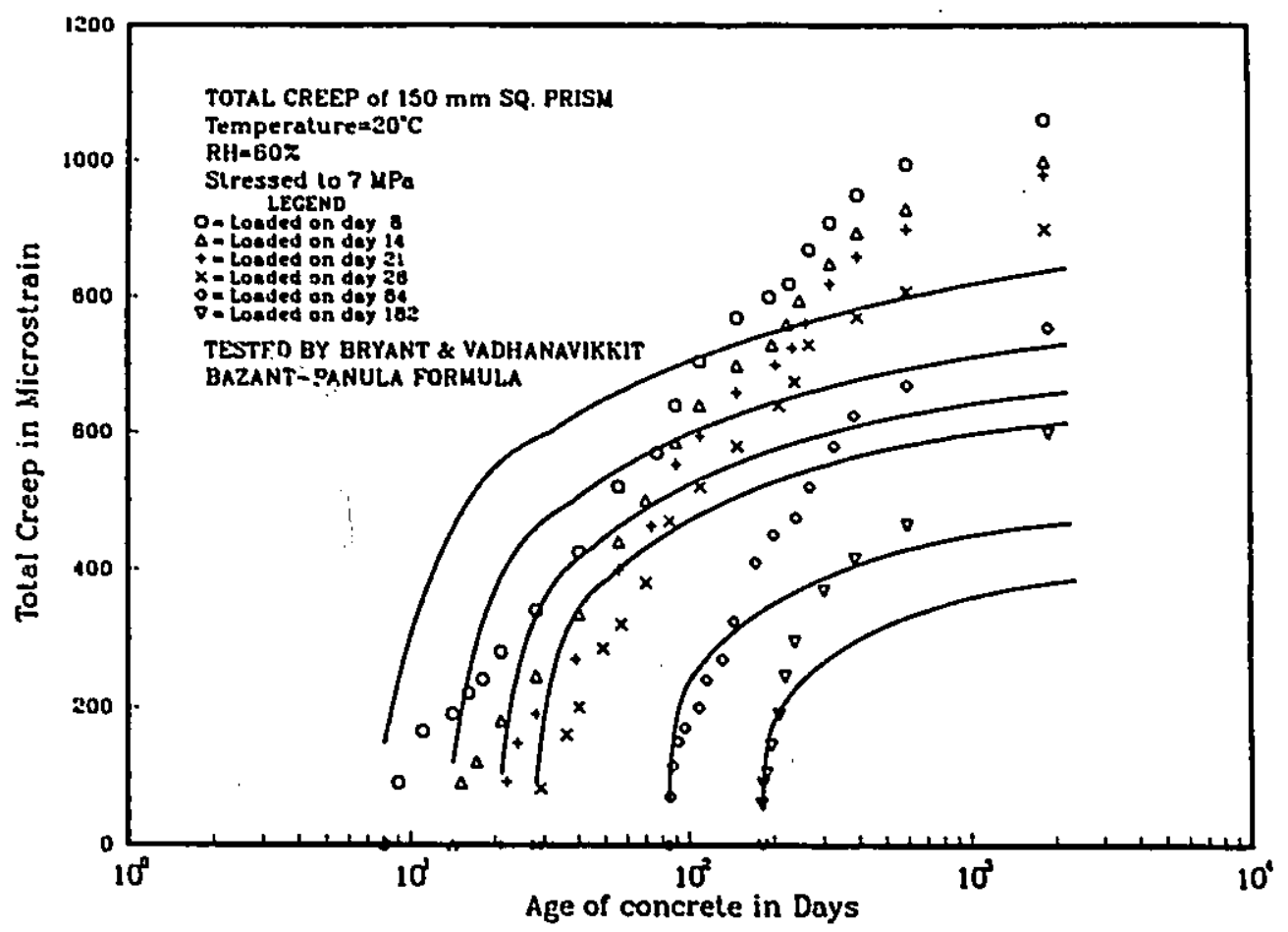

Figure 4.24: Comparison of the creep prediction model proposed by Bazant-Panula with the experimental data 


\section{Chapter 5}

\section{Conclusions and}

\section{Recommendations}

Concrete structures are frequently exposed to high loads at an early age during construction. The result of such exposure may affect the performance of the finished structure. Examples of such situations are early form stripping, slip form construction, prestressed structures, stresses and strains due to heat of hydration, etc.

The primary purpose of this investigation was to summarize existing knowledge and understanding of the mechanical properties (strength and deformation) of concrete at an early age.

\subsection{Conclusions}

On the basis of the results from the present study and from the literature, the following conclusions may be made.

1. Maturity method gives a satisfactory representation of strength gain with time under isothermal conditions.

2. Nurse-Saul maturity function can only be used for normal temperature, while Arrhenius function can be used for a relatively wide range of 
temperature.

3. The basic difference between the Nurse-Saul and Arrhenius maturity functions is different ways of modeling the $k-T$ relation. The Arrhenius function can be modified by using different activation energy for each hydration stage to represent the $\mathrm{k}-\mathrm{T}$ relation.

4. Ultimate strength of concrete is affected by casting and curing temperature, especially when water cement ratio is high.

5. The relationship between early age strength to 28 -day strength ratio and its maturity varies with type of cement, but is affectingly independent of water cement ratio and curing temperature.

6. For Portland cement concrete at any age, the modulus of elasticity can be uniquely related to the compressive strength, regardless the composition of the concrete.

7. CEB Code gives a better representation for prediction of E-modulus for mature concrete than the ACI-CSA codes.

8. Neither the ACI-CSA nor CEB code relationships are accurate enough to be used for prediction of E-modulus of concrete at early ages.

9. The relationship between tensile and compressive strength of concrete is essentially unchanged by its curing temperature, concrete composition or age.

10. The CEB Code gives a better representation for the relationship between tensile and compressive strengths than the ACI code.

11. Punching shear strength is proportional to the cube root of concrete strength, and is also proportional to the steel ratio. European code formulae fit the experimental data very well, while the ACI-CSA equations are too conservative.

12. Shrinkage and creep develop with time in a similar way: both are affected by the volume to surface area ratio of the concrete member and the ambient relative humidity.

13. The most important factors influencing long-term shrinkage are the 28-day strength of concrete member, the maturity when shrinkage begins, ce- 
ment type and its ambient relative humidity.

14. The errors in the prediction of shrinkage or creep are large no matter which model is used. This can be attributed to the fact that the shrinkage and creep are affected by numerous factors, most of which are related to the others.

15. Creep is significantly affected by the relative strength at the time of loading. So the loading and maturity history of the structure member can not be ignored for creep prediction.

16. There is no final value for creep. For long-term strain, basic creep develops much faster than drying creep after five to ten years of loading.

17. For $\sigma / f_{c m}<0.5$, creep is proportional to the applied load. But if $\sigma>0.5 f_{c m}$, creep develops faster than the applied stress.

18. ACI time development functions for shrinkage and creep do not represent the experimental data well, so are unlikely to accurately predict the long-term values from short-term test data. The time functions in CEB 90 model basically fit the experimental data.

19. Both $\mathrm{ACI}$ and $\mathrm{CEB} 90$ models underestimate shrinkage and creep values, especially the long-term values.

20. All early-age mechanical properties of concrete can be related to its compressive strength, no matter what age it is at. Therefore, they are all time-independent. 


\subsection{Recommendations}

1. In order to avoid extensive cracking ?nd thus high immediate and long term deflection of flat slabs, it is desirable to determine the exact variations in magnitude of dead and live loads that may occur during construction as well as the available strength at the time of removal of forms.

2. The following formulae can be used to estimate the available compressive strength:

$$
\frac{f_{c}^{\prime}(t)}{f_{c}^{\prime}(28)}=\frac{\left(t_{20}\right)^{3 / 4}}{A+B\left(t_{20}\right)^{3 / 4}}
$$

where:

$f_{c}^{\prime}(t)$ : the mean strength at age of $t$ days;

$f_{c}^{\prime}(28)$ : the mean design 28-day strength;

$t_{20}$ : equivalent age of concrete using modified Arrhenius function.

$A$ and $B$ are constants depending on the type of concrete:

for Type 10 cement, $A=2.8, B=0.77$;

for Type 20 cement, $A=3.5, B=0.71$;

for Type 30 cement, $A=1.2, B=0.90$.

3. For normal weight concrete, modulus of elasticity at any age can be calculated by:

$$
\begin{aligned}
& E_{c}=3.0\left(f_{c}^{\prime}\right)^{2 / 3} \text { when } f_{c}^{\prime} \leq 27 M P a \\
& E_{c}=9.0\left(f_{c}^{\prime}\right)^{1 / 3} \text { when } f_{c}^{\prime}>27 M P a
\end{aligned}
$$

4. The tensile strength formula proposed by CEB-FIP 1990 can be used for all concrete, regardless of type of cement or concrete age.

$$
f_{t}^{\prime}=0.30\left(f_{c}^{\prime}\right)^{2 / 3}
$$

5. The BS8110:1985 Code is recommended to calculate the punching shear strength.

6. To predict long-term shrinkage of concrete by short-term tests, the time development function expressed by Eq.4.41 can be used. If no experi- 
mental data are available, Eq. 4.40 can be used to estimate shrinkage at any time.

7. Creep may be estimated based on the basic creep and drying creep, according to the loading and maturity history, concrete member properties and the ambient relative humidity. Equations 4.57 to 4.91 may be used. 


\section{References}

1.1 Byfors, J., Plain Cement at Early Ages, Swedish Cement and Concrete Research Institute, 1980.

1.2 Gardner, N.J., Shoring, Reshoring, and Safety, Concrete International, April 1985, pp. 28-34.

1.3 Gardner, N.J. and Fu, H.C., Effects of high construction loads on long term deflections of flat slabs, ACI Structural Journal, V.84, No.4, pp. 349-360.

1.4 Powers, T.C., Structural and Physical Properties of Hardened Portland Cement Paste, J. Am. Ceram. Soc., Vol. 41, No.1, pp. 1-6, 1958.

2.1 ACI Committee 209, Prediction of Creep, Shrinkage and Temperature Effects on Concrete Strengths, Designing for Creep and Shrinkage in Concrete Structures, ACI Publication SP-76, pp.193-300, 1982.

2.2 ACI Committee 306, Cold Weather Concreting, Chapter 7, ACI Journal, pp.178-179, May, 1978.

2.3 Aitcin, P., Cheung, M.S. and Shah, V.K., Strength Development of Concrete Cured Under Arctic Sea Conditions, ASTM STP-858, pp.1-20, 1985.

2.4 Avrami, M., Kinetics of Phase Change, III, J. Chem. Phys., $\overline{9}$, pp.177-184, 1941.

2.5 Bergstrom, S.G., Curing Temperature, Age and Strength of Concrete, Magazine of Concrete Research 5, No.14, pp.61-66,

2.6 Bernhardt, C.T., Hardening of Concrete at Different Temperatures, RILEM Symposium on Winter Concreting, Copenhagen, 1956. 
2.7 Bresson, J., Prediction of Strength of Concrete Products, Proceedings of the RILEM International Conference on Concrete at Early Ages, Vol.I, pp.157-162, Paris, 1982.

2.8 Byfors, J., Research Report F0-3-19S0, Swedish Cement and Concrete Research Institute, Slockholm, 1950.

2.9 Carino, N.J., Maturity functions for concrete, Proceedings of the RILEM International Conference on Concrete at Early Ages, Vol.I, pp.157-162, Paris, 1982.

2.10 Carino, N.J., The Maturity Method: Theory and Application, National Bureau of Standards, USA, 1984.

2.11 Carino, N.J. and Lew, H.S., Temperature Effects on Strength-Maturity Relations of Mortar, ACI Journal, pp.177-182, May-June, 1983.

2.12 Carino, N.J., Lew, H.S. and Volz, C.K., Early Age Temperature Effects on Concrete Strength Prediction by Marurity Method, ACI Journal, pp.93-101, March-April, 1983.

2.13 Cauthier, E. and Regourd, M., The Hardening of Cement in Function of Temperature, Proceedings of the RILEM International Conference on Concrete at Early Ages, Vol.I, pp.157-162, Paris, 1982.

2.14 Cements Research Process 1979, Chapter.13, National Bureau of Standards, USA.

2.15 Chin, F.K., Relation Between Strength and Maturity of Concrete, ACI Journal, pp.196-203, March, 1971.

2.16 Erofeyer, B.V., A Generalized Equation of Chemical Kinetics and its Application in Reaction involving Solids, Comptes Rend. Acad. Sci., URSS, L11(6), 511-514, 1946. (From Ref. 2.14) 
2.17 Gardner, N.J., Early-age mechanical properties of Type I, Type III and Type I/flyash concretes with temperature, Department of Civil Engineering, Univ. of Ottawa, Canada.

2.18 Gardner, N.J., Study of Strength and Durability of Type 30, Slag Cement and Flyash Concrete Cast and Cured at Arctic Marine Temperatures (phase II), Final Report of Contract 05SV.EN280-4-2787, Public Works Canada.

2.19 Gardner, N.J. and Poon, S.M., Time and Temperature Effects on Tensile, Bond and Compressive Strengths, ACI Journal, Vol. 73, pp.405-409, July, 1976.

2.20 Guo, C., Maturity of Concrete: Method for Predicting Early-Stage Strength, ACI Materials Journal, Vol. 86, No.4, pp.341-353, July-August, 1987.

2.21 Hansen, P. and Pedersen, J., Maturity Computer for Controlled Curing and Hardening of Concrete, Nordish Betong, Vol.1, pp.19-34, 1977.

2.22 Hummel, A., Dus Beton-ABC, Berlin, W. Ernst, 1959. (From Ref. 2.28)

2.23 Kasai, Y., Method of Estimation for Compressive Strength of Concrete at Early Ages, Proceedings of the RILEM International Conference on Concrete at Early Ages, Vol.I, pp.157-162, Paris, 1982.

2.24 Klieger, P., Effect of Mixing and Curing Temperature on Concrete Strength, ACI Journal, pp.1063-1082, June, 1958.

2.25 McIntosh, J.D., Electrical Curing of Concrete, Magazine of Concrete Research 1, No.1, pp.21-28, Jan., 1949.

2.26 McIntosh, J.D., RILEM Symposium on Winter Concreting, Copenhagen, 1956.

2.27 Naik, T.R., Maturity Functions for Concrete Cured During Winter Conditions, ASTM STP-585, pp.107-117, 1985. 
2.28 Neville, A.M., Properties of Concrete, Pitman Publishing Inc. pp.29S$301,1981$.

2.29 Nurse, R.W., Steam Curing of Concrete, Magazine of Concrete Research, No.2, pp.79-88, June, 1949.

2.30 Nykanen, A., RILEM Symposium on Winter Concreting, Copenhagen. 1956.

2.31 Plowman, J.M., Maturity and the Strength of Concrete, Magazine of Concrete Research 8, No.22, pp.13-22, March, 1956.

2.32 Discussion of Reference 2.31, Magazine of Concrete Research 8, No.24, 00.169-183, Nov., 1956.

2.33 Price, W.H., Factors Influencing Concrete Strength, ACI Journal, pp.417432, Feb., 1951.

2.34 Rastrup, E., RILEM Symposium on Winter Concreting, Copenhagen, 1956.

2.35 Sau, P., A study on the effect of casting and curing temperature on mechanical properties of concrete, M.Eng. Thesis, Dept. of Civil Engineering, Univ. of Ottawa, Canada, 1984.

2.36 Saul, A.G.A., Principles Underlying the Steam Curing of Concrete at Atmospheric Pressure, Magazine of Concrete Research 2, No.6, pp.127140, March, 1951.

2.37 Swenson, E.G., Estimation of Strength Gain of Concrete, Engineering Journal, pp.27-32, September, 1967.

2.38 Tenoutasse, N. and DeDonder, A., The Kinetics and Mechanism of Tricalcium Silicate Hydration, Silicates Ind., No.35, pp.301-309, 1970. 
2.39 Urzhenko, A. and Usherov-Marshak,A., Hydration Kinetics of $3 \mathrm{CaO} . \mathrm{SiO}_{2}$ Between $20^{\circ} \mathrm{C}$ and $80^{\circ} \mathrm{C}$, Izv. Akad. Nauk SSR, Neorg. Mater., No.10(5) 888-892, 1974. (From Ref. 2.14)

3.1 Bazant, Z.P. and Cao, Z., Size Effect in Punching Shear Failure of Slabs, ACI Structural Journal, Vol. 84, Jan.-Feb. 1987, pp.44-51.

3.2 Bennet, E.W. and Collings, B.C., High early strength concrete by means of very fine Portland cement, Inst. of Civil Engineers, Proceedings Vol. 43, pp.443-451, July, 1969.

3.3 British Standard Code of Practice for Special Circumstances. pp.7/1-7/2. 1985.

3.4 Carrasquillo, R.L., Nilson, A.H. and Slate, F.O., Properties of High Strength Concrete Subject to Short-Term Loads, ACI Journal, pp.171-178, MayJune, 1981.

3.5 CEB-FIP, Model Code for Concrete Structures, pp.348, April, 1978.

3.6 Elstner, R.C. anủ Hognestad, E, Shearing Strength of Reinforced Concrete Slabs, ACI Journal, Vol. 53, pp.29-58, July,1956.

3.7 Gardner, N.J., Early-age mechanical properties of Type I, Type III and Type I/flyash concretes with temperature, Dept. of Civil Engineering, Univ. of Ottawa, Canada.

3.8 Gardner, N.J., Study of the Strength and Durability of Type 30, Slag Cement and Flyash Concretes Cast at Arctic Marine Temperatures (phase II), Final Report of Contract 05SV.EN280-4-2787, Public Works Canada.

3.9 Gardner, N.J., Relationship of the Punching Shear Capacity of Reinforced Concrete Slabs with Concrete Strength, ACI Structural Journal, Jan.Feb., 1990, pp.66-71. 
3.10 Gardner, N.J. and Poon, S.M., Time and Temperature effects on tensile, bond and compressive strength, ACI Journal, Vol. 73, No.i. pp.405-409. 1976.

3.11 Grira, M., Punching Shear at Early Ages, M.A.Sc. Thesis, Dept. of Civil Engineering, University of Ottawa, Canada, Sept., 1990.

3.12 Kaar, P.H., Hanson, N.W. and Capell, H.T., Stress-Strain Characteristics of High-Strength Concrete, ACI SP-55, Detroit, pp.161-185, 1978.

3.13 Lew, H.S. and Reichard, T.W., Mechanical Properties of Concrete at Early Ages, ACI Journal, Vol.75, pp.533-543, Oct., 1978.

3.14 Moe, J., Shearing Strength of Reinforced Concrete Slabs and Footing under Concentrated Loads, Development Department Bulletin No. D47, Portland Cement Association, Skokie, Apr. 1961, 130 pp.

3.15 Mowrer, R.D. and Vanderbilt, M.D., Shear strength of Lightweight Aggregate Reinforced Concrete Flat Plates, ACI Journal, Vol.64, Nov. 1967, pp.722-729.

3.16 Neville, A.M., Properties of Concrete, Third Edition, Pitman Publish Inc. Page 544, 1981.

3.17 Pauw, A., Static Modulus of Elasticity of Concrete as Affected by Density, ACI Journal, pp.679-687, Dec., 1960.

3.18 Perenchio, W.F. and Klieger, P., Some physical properties of High-Strength Concrete, Research and Development Bulletin No. RD056.1t, PCA, Skokie, 1978.

3.19 Philleo, R.E., Comparison of results of three methods for determining Young's modulus of elasticity of concrete, ACI Journal, No.51, pp.461469, Jan., 1955. 
3.20 Price, W.H., Factors influencing concrete strength, ACI Journal, Vol. 47, pp.417-432, Feb., 1951.

3.21 Russell, H.G. and Corley, W.G., Time-Dependent Behavior of Columns in Water Tower Place, ACI SP-55, Detroit, pp.347-373, 1978.

3.22 Sau, P. A study on the casting and curing temperature on the mechanical properties of concrete, M.Eng. Thesis, Dept. of Civil Engineering, Univ. of Ottawa, Canada, 1984.

3.23 Stanton, W., Modulus of Elasticity of Concrete, Proceedings of ASTM, Vol. XIX, Part II, pp.510-606.

3.24 Walker, S. and Bloem, D.L., Effects of Aggregate size on properties of Concrete, ACI Journal, Vol. 57, No.3, pp.283-298, Sep., 1960.

4.1 ACI Committee 209, Prediction of Creep, Shrinkage and Temperature Effects in Concrete Structures, ACI SP-76, pp.193-300, 1982.

4.2 Bazant, Z.P. and Panula, L., Practical prediction of time-dependent deformations of concrete, Materials and Structures, RILEM, Paris, 11(65), pp.307-328; 11(66), pp.415-434; 12(69), pp.169-183, 1978.

4.3 Bazant, Z.P. and Panula, L., New model for prediction of creep and shrinkage, ACI SP-76, pp.7-23, 1982.

4.4 Bazant, Z.P., Wittmann, F.H., Kim, J.K. and Alow, F., Statistical extrapolation of shrinkiage data-part I: regression, ACI Materials Journal, No. 84(1), pp.20-34, 1987.

4.5 Brooks, J.J., Accuracy of estimating long-term strains in concrete, Magazine of Concrete Research, Vol. 36, No. 128, Sep., 1984, pp. 131-145. 
4.6 Brooks, J. J. and Neville, A. M., Predicting long-term creep and shrinkinge from short-term tests, Magazine of Concrete P.ssearch, Vol. 30, No. 103, June 1978, pp. 51-61.

4.7 Bryant, A. H., Creep and Shrinkage of a Bridge-Building Concrete, ACI Journal, No. 76, March 1979. pp. 387-403.

4.8 Bryant A.H. and Vadhanaviklit C., Creep, Shrinkage-Size, and Age at Loading Effects, ACI Materials Journal, pp. 117-123, March-April, 198T.

4.9 CEB-FIP Model Code for Concrete Structures, Paris, 1978.

4.10 CEB-FIP Model Code 1990, Bulletin D'Information, 1988.

4.11 Hansen, T.C. and Mattock, A.H., Influence of size and shape of member on shrinkage and creep of concrete, ACI Journal, No. 63, pp. 267-290, 1966.

4.12 Hummel, A., Wesche, K.H. and Brand, W., Wersuche uber Kriechen unbewehrten Betons. Deutscher Ausschuss fur Stahlbton, Heft 146, 1962.

4.13 Kasai, Y.M. and Yokoyama, K., Volume change of concrete at early ages, International Conference on Concrete at Early Ages, RILEM, Vol.1, pp.51-56, Paris, 1982.

4.14 Keeton, J. R., Study of Creep in Concrete, Technical Report R333-I, R333-II and R333-III, 1965, U. S. Naval Civil Engineering Laboratory, Port Hueneme, California.

4.15 L'Hermite, R.G. and Mamillan, M., Further results of shrinkage and creep tests, International Conference on Structures of Concrete, London, Cement and Concrete Association, pp.423-433, 1968.

4.16 Lorman, W.R., The Theory of Concrete Creep, ASTM Proc. 40, pp. 1082-1102, 1940. 
4.17 Mamillan, M., Evolution du fluage et des proprietes du beton. Annales de l'Institut Technique du Batimont et des Travau: Publics, No. 154, 1960 .

4.18 Mamillan, M. and L'Hermite, R. New and complementary results on research concerning shrinkage and creep in concrete and its structural effects, Cornell University, 1965.

4.19 Neville, A.M., Properties of Concrete, Third Edition, Pitman Publishing Inc., London, 1981.

4.20 Parrott, L., Effect of loading at early age upon creep and relaxation of concrete, RILEM Committee 42-CEA, Internal report UK5.

4.21 Pickett, G., Effect of gypsum content and other factors on shrinkage of concrete prisms, ACI Journal, No. 44, pp.149-175, Oct., 1947.

4.22 Powers, T.C., Causes and Control of Volume Change, J. Portl. Cem. Assoc. Research and Development Laboratories, Vol. 1, No.1, pp.29-39, Jan., 1959.

4.23 RILEM Committee 42-CEA, Properties of set concrete at early ages, Materials and Structures, pp.399-449, Nov.-Dec., 1981.

4.24 Shank, J.R., Plastic flow of concrete at high overload, ACI Journal, Feb., 1949, pp. 493-500.

4.25 Swayze, M.A., Early concrete volume changes and their control, ACI Journal, pp.425-440, April 1942.

4.26 Troxell, G.E., Raphale, J.M. and Vavis, R.E., Long time creep and shrinkage tests of plain and reinforced concrete, ASTM Proc. 58, pp. 1101-1120, 1958.

4.27 Wischers, G. and Dahms, J., Kriechen von Fruhbelastetem Beton mit hoher Anfangsfestigkeit. Beton 27, Heft 2 und 3, 1977. 
4.28 Ulitski, I.I., A method of computing creep and shrinkage deformation of concrete. Beton i Zhelezobeton, No. 4. 1962. pp. 174-180. 